\section{Check for updates}

Cite this: Mater. Adv., 2021, 2, 2231

Received 6th December 2020, Accepted 28th February 2021

DOI: $10.1039 / \mathrm{d} 0 \mathrm{ma00957a}$

rsc.li/materials-advances

\title{
Nanomaterials modulating stem cell behavior towards cardiovascular cell lineage
}

\author{
Hamidreza Arzaghi, (D) $\dagger^{\mathrm{ab}}$ Bahareh Rahimi, (D) $\dagger^{\mathrm{a}}$ Bashir Adel, (D) $\dagger^{\mathrm{c}}$ \\ Golbarg Rahimi, (D) ${ }^{d}$ Zahra Taherian, (D) ${ }^{c}$ Afsaneh L. Sanati (D) *e and \\ Amin Shiralizadeh Dezfuli (D)*bfg
}

\begin{abstract}
The cardiovascular system is one of the most complex and indispensable systems in the body and is responsible for the circulation of nutrition, oxygen, carbon dioxide, hormones to other parts of the body. Injuries and scar formation in various parts of the cardiovascular system could be overwhelming due to the limited regenerative ability of cardiomyocytes. Furthermore, surgeries for cardiovascular complications have major risks, and the shortage of organs is inevitable. However, cardiovascular tissue engineering is promising since it can promote cardiovascular regeneration. Although tissue engineering and regenerative medicine could offer solutions to overcoming these challenges, interactions between nanomaterials and stem cells are not fully understood. Therefore, controlling the behavior of stem cells is challenging due to the limited knowledge in this area. In this review, we discuss various nanomaterials that have recently been utilized in cardiovascular tissue engineering. We also highlight the effects of these nanomaterials on stem cell behavior, with specific emphasis on proliferation and differentiation. It is expected that a better understanding of the interactions of stem cells and nanomaterials would facilitate the design of nanomaterials for regenerative medicine and cardiovascular tissue engineering applications.
\end{abstract}

\section{Introduction}

Cardiovascular diseases (CVDs) are among the major health problems in the world, especially in developing countries. According to the World Health Organization, CVDs are the number one cause of death worldwide and it is estimated that 17.9 million people died in $2016 .{ }^{1}$ Myocardial infarction (MI) and coronary artery diseases are the primary causes of CVDsrelated death. ${ }^{2,3}$ Moreover, ischemia can cause necrosis and apoptosis, which can lead to scar formation and permanent

\footnotetext{
${ }^{a}$ Department of Medical Biotechnology, Faculty of Allied Medical Sciences, Iran University of Medical Sciences (IUMS), Tehran, Iran.

E-mail: hamidrezaarzaghy@gamil.com, bahareh_rahimi1373@yahoo.com

${ }^{b}$ Ronash Technology Pars Company (AMINBIC), Tehran, Iran

${ }^{c}$ Department of Biology, Faculty of Sciences, The University of Guilan, Rasht, Iran. E-mail: bashir.adel134@gmail.com, zahrataherian134@gmail.com

${ }^{d}$ Department of Cell and Molecular Biology and Microbiology, Faculty of Biological Science and Technology, University of Isfahan, Iran.

E-mail: golbarg.rahimi1994@gmail.com

${ }^{e}$ Institute of Systems and Robotics, University of Coimbra, 3030-194 Coimbra, Portugal. E-mail: Afsaneh.sanati@isr.uc.pt

${ }^{f}$ Radiation Biology Research Center, Iran University of Medical Sciences (IUMS), Tehran, Iran

${ }^{g}$ Young Researchers and Elite Club Shahr-e-Qods Branch, Islamic Azad University, Tehran 37515-374, Iran

$\dagger$ H. Arzaghi, B. Rahimi and B. Adel contributed equally to this work.
}

damage to heart structures, thereby reducing the contractile ability following heart failure in severe conditions. Furthermore, the regeneration ability of cardiomyocytes is extremely limited, and the only options for the treatment of CVDs are surgical methods such as heart transplant and reperfusion therapy. ${ }^{4-8}$

Stem cell transplantation has been utilized as a novel therapeutic method for the treatment of several diseases such as liver, ${ }^{9}$ kidney, ${ }^{10}$ brain, ${ }^{11}$ spinal cord,${ }^{12}$ and heart diseases. ${ }^{13}$ After transplantation, it is expected that stem cells differentiate to target cells in response to their microenvironment. In the past decade, stem cell therapy has been used for myocardial repair and heart regeneration. For instance, Bartunek et al. utilized the bone marrow-derived mesenchymal stem cells in the C-CURE clinical trial for a patient with heart failure, and they reported the safety and possibility of stem cell therapy in chronic heart failure. ${ }^{14}$ However, stem cell therapy has some limitations since the transplantation or injection of stem cells may result in low retention and poor survival of cells in the body. ${ }^{15-17}$ Moreover, in this method, there is no control over directing the fate of stem cells, which completely limits their therapeutic applications. Several stem cell behaviors such as proliferation, differentiation, migration, and cell adhesion can be controlled by manipulating intracellular signaling pathways utilizing different transcription and growth factors. This control over the fate of stem cells is an essential 
component for regenerative medicine and tissue engineering methods. $^{18}$

In the past decades, various nanomaterials have been utilized to design practical tools for therapeutic and diagnostic purposes in medicine. With the emergence of nanotechnology, the first use of nanomaterials was gene and drug delivery for modulating stem cell behavior by the encapsulation of drugs/genes in polymers and lipid-based nanomaterials. Several biomaterials have been synthesized with nanostructure featured to induce microenvironment cues, wherein stem cells can proliferate and differentiate to target cell lineage. ${ }^{19-22}$ Most researchers' interests are focused on designing new fabrication methods for therapeutic and imaging applications, however, the interactions between nanomaterials and stem cell behavior have not been investigated thoroughly. It has been shown that utilizing nanomaterials as scaffolds can change the differentiation and proliferation of stem

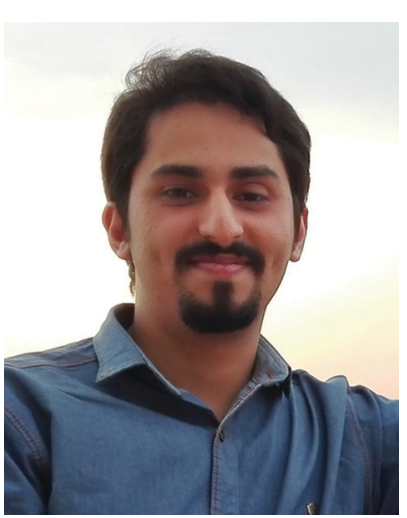

Hamidreza Arzaghi
Hamidreza Arzaghi received his MSc in Medical Biotechnology from Iran University of Medical Sciences (IUMS), Tehran, Iran in 2019 under the supervision of $\mathrm{Dr}$ Amin Shiralizade Dezfuli. He was selected as one of the best students in the national university entrance exam in Medical Biotechnology in the year 2016. He is currently working as a researcher at Ronash Technology Pars Company (AMINBIC), Tehran,

Iran. His research interests include the synthesis of nanoparticles/nanocomposites and their applications in soft tissue engineering and their effects on cellular behaviors.

cells, and also the aqueous suspension of nanoparticles can induce stem cell differentiation. ${ }^{23}$ This viewpoint can be utilized in the design and fabrication of nanomaterials for cardiac tissue engineering since acquiring regenerative medicine methods to replace the damaged cardiac tissues is promising in CVDs complications, especially in myocardial repair. ${ }^{24}$ For example, it has been shown that the conductive properties of carbon-based and metal-based nanomaterials can enhance the electrical signals passing through cardiomyocytes and promote both the proliferation and differentiation of stem cells. ${ }^{25}$ Therefore, we have provided a comprehensive review of nanomaterials utilized in cardiovascular tissue engineering, focusing on the effect of nanomaterials on cellular behaviors. It is expected that the increase in the knowledge of nanomaterials and stem cell interactions will be beneficial in the design and synthesis of novel therapeutic methods in tissue engineering and regenerative medicine.

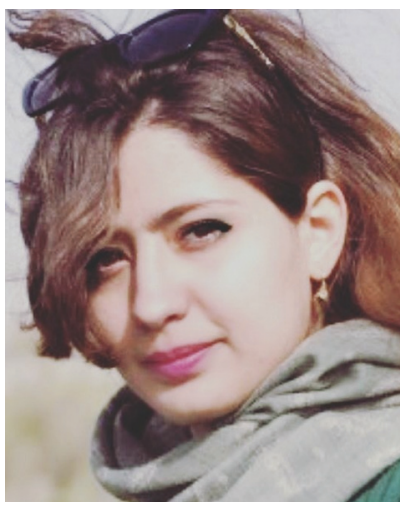

Bahareh Rahimi

Bahareh Rahimi received her BSc degree in Cellular and Molecular Biology (Genetics) at Isfahan University and her MSc degree in Medical Biotechnology at Iran University of Medical Sciences. She has been working at Pasteur Institute of Iran for about 2 years as a co-researcher. She is working on the design of new antimicrobial peptides against infectious bacteria under the supervision of Prof. Soroush Sardari. Bahareh's research interests are focused on stem cells and cell therapy, oxidative stress and antioxidants, protein network analysis, and proteomics. She is also interested in nanotechnology and has some research experience in nanoparticle applications in cancer therapy and tissue engineering.

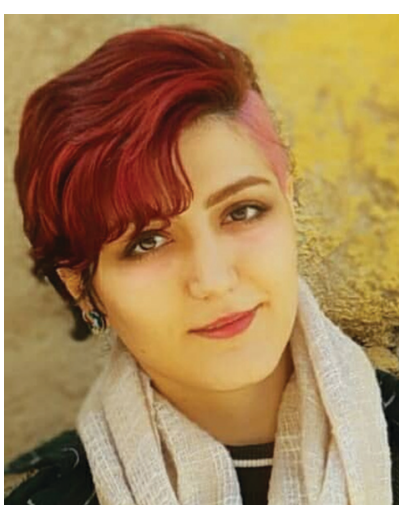

Golbarg Rahimi

Golbarg Rahimi received her BSc Bashir Adel received his MSc in Molecular Genetics under the supervision of Prof. Zivar Salehi. His research interests include biomedical engineering, biomaterials, tissue engineering, and regenerative medicine.

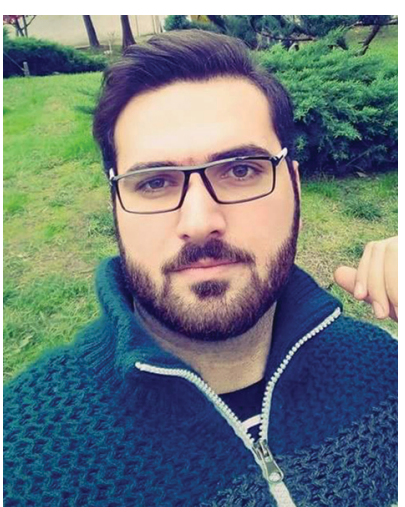

Bashir Adel

protein network data related to metabolic diseases and their related oxidative stress and inflammation pathways. degree in Genetics and MSc degree in Cellular and Molecular Biology from Isfahan University under the supervision of Prof. Kamran Ghaedi. She is a researcher at Royan Institute and her research interests are focused on diabetes mellitus, cardiovascular, and neurodegenerative disease, stem cell therapy, tissue engineering, and regenerative medicine. Golbarg is also interested in big gene and 


\section{Cardiovascular system overview}

The circulatory or cardiovascular system consists of the lymphatic system, heart, and blood vessels, which circulate blood, nutrition, oxygen, and carbon dioxide in the body, thereby stabilizing its conditions such as temperature, $\mathrm{pH}$, and homeostasis. ${ }^{26,27}$

The heart lies in the center of the cardiovascular system and pumps blood within the blood vessels to provide continuous flow throughout the body; it is located between the lungs in the middle mediastinum. The human heart consists of four chambers (two lower ventricles and two upper atria) and four one-way valves. This giant muscular organ consists of three layers in its wall (endocardium, myocardium, and epicardium), which are surrounded by the pericardium.

The endocardium is the most inner layer of the heart wall, which consists of a single squamous epithelium. This tissue is structurally similar to the endothelial cells that cover the internal structure of blood vessels. This layer not only controls the heart development in the embryo but also regulates the myocardium functions. Furthermore, it controls the

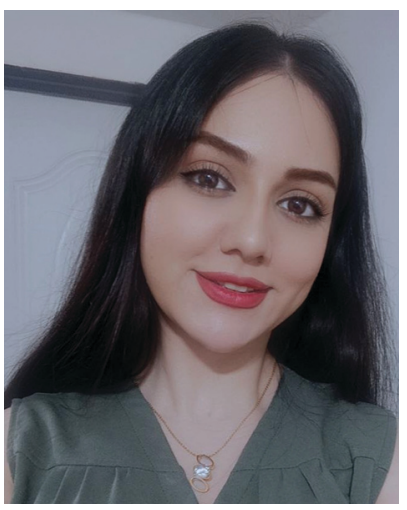

Zahra Taherian received her MSc degree in Molecular Genetics from the University of Guilan. Her research interests are focused on the application of biomaterials in tissue engineering and regenerative medicine.

Zahra Taherian

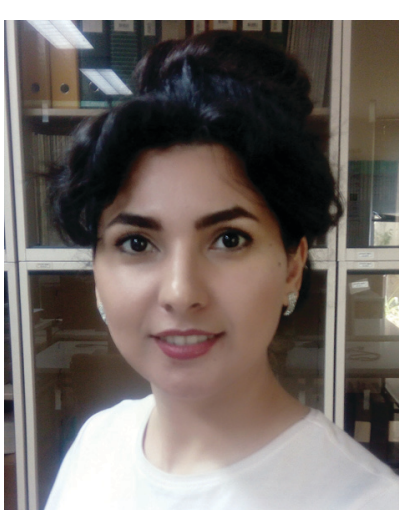

Afsaneh L. Sanati
Dr Afsaneh L. Sanati received her $P h D$ in Nanochemistry from the University of Tehran, Iran in 2019. She worked one year (2018-2019) as a visiting researcher at the University of Coimbra, Portugal and is currently working as a post-doc researcher at the Institute of Systems and Robotics (ISR), Coimbra, Portugal. The Electrochemical Society of Iran selected her as the best PhD student in Electrochemistry (2018). Her research interests include the synthesis of novel nanoparticles/ nanocomposites and their applications in flexible/stretchable energy storage devices, $\mathrm{Ag} / \mathrm{Zn}$ batteries and also modified electrodes for the analysis of biological, pharmaceutical and environmental compounds, and the investigation of the electrochemical behavior of electroactive materials.

contractility and electrophysiological environment of cardiomyocytes. Cardiomyocytes join with the intercalated discs and are coated mainly with collagen fibers as an extracellular matrix, which forms the cardiac muscles or myocardium. Cardiac muscle is an involuntary muscle similar to skeletal muscle with contraction ability due to the electrical stimulation of action potentials through the release of calcium from the sarcoplasmic reticulum. The action potentials are initiated by pacemaker cells in the sinoatrial node located in the right atria and depolarized neighboring contractile cells via gap junctions in the intercalated discs. These action potentials reach the other pacemaker cells in the atrioventricular node by the electrical conduction system of the heart. If the initiation of action potentials in SA nodes is compromised, the cells located in Purkinje fibers become responsible for the heart contractions. Cardiac fibroblasts are other cells located in the heart and they play a crucial role in creating the extracellular matrix of cardiomyocytes, whereby they can repair an injury by the secretion of collagen. Furthermore, cardiac fibroblasts can transform into the myofibroblast with a contracting ability during myocardial infarction (reduction in blood flow to the heart). ${ }^{28-33}$

Diseases that involve the myocardium are the most important clinical problems, which are the leading causes of death in developing countries. Coronary artery disease (CHD) or ischemic heart disease (IHD) is the most prevalent condition of the heart, which is the reduction of blood flow to the heart due to atherosclerosis. Consequently, the lack of oxygen leads to myocardial infarction and damage to the cardiomyocytes. Another condition that damages the cardiomyocytes is the inflammation of the myocardium (myocarditis or inflammatory cardiomyopathy) due to various circumstances such as viral or bacterial infections, autoimmune diseases, and alcohol and drug usage. .,34,35 $^{2}$

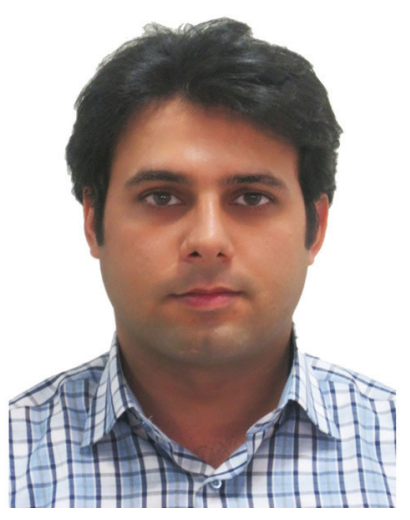

Amin Shiralizadeh Dezfuli
Dr Amin Shiralizadeh Dezfuli received his $P h D$ degree in Nanochemistry from the University of Tehran (UT, Iran) under the supervision of Prof. Mohammad Reza Ganjali in 2016. In the following years, he worked as a postdoctoral fellow at Iran University of Medical Sciences (IUMS, Iran). His research is focused on the application of nanomaterials in energy storage devices and biomaterials. 
The pericardium is the outermost layer of the heart, and it is made up of two layers: the fibrous pericardium and serous pericardium (epicardium). The pericardium consists of dense and loose connective tissue that protects the heart from any external damage or infections as well as lubricates the heart for better functioning during the heartbeat. The lubrication of the heart is carried out by serous fluid secreted by the pericardium, and it fills the pericardial cavity. ${ }^{36,37}$

Another component of the cardiovascular system is blood vessels that transport blood throughout the human body and are divided into five types: veins, arteries, venules, arterioles, and capillaries. In the blood circulatory system, arteries and arterioles transport oxygenated blood from the lungs to other parts of the body, but the veins and venules have reverse functions that transport deoxygenated blood from the body to the lungs. Trauma and mechanical damage to the blood vessels may lead to internal or external hemorrhaging, which can cause ischemia or myocardial infarction. In contrast, hypertension or an increase in blood pressure through the vessels may lead to stroke or heart failure. ${ }^{38,39}$ Valvular heart disease is another cardiovascular disease, which involves the dysfunction of one or more valves in the heart. Irrespective of the disease process, stenosis and insufficiency/regurgitation are the most common consequences of valvular heart disease. The former is the thickening of the valve, which can lead to narrowing the blood flow, and the latter is the capability of the heart valve to prevent the backflow of the blood. Valvular heart disease, similar to other cardiovascular diseases, can be life-threatening, and the treatments require the surgical repair or replacement of the valve. ${ }^{40,41}$

\section{Stem cells in cardiovascular tissue engineering}

Stem cells are unspecified cells that are capable of both selfrenewal and differentiation into a variety of specialized cell types under certain conditions. Mostly, stem cells are classified into three types, namely, embryonic stem cells (ESCs), induced pluripotent stem cells (iPSCs), and adult stem cells (ASCs). In this section, we review some of the important stem cells that have been utilized in cardiovascular tissue engineering.

\subsection{Embryonic stem cells (ESCs)}

Embryonic stem cells (ESCs) are pluripotent stem cells derived from the inner cell mass of blastocysts. Not only do ESCs have self-renewal ability but they are also capable of differentiating to all the cells in the body such as hepatocytes, chondrocytes, pancreatic cells, and cardiomyocytes. ${ }^{42}$ Several studies have reported the utilization of ESCs to improve the seizures associated with infarcted myocardium, blood pressure, and ventricular function in various animal models. For instance, Liu et al. utilized human embryonic stem cell-derived cardiomyocytes (hESC-CMs) transplantation as grafts for restoring the heart's function after myocardial infarction in macaque monkeys. They suggested that hESC-CMs grafts can re-muscularize substantial amounts of infarcted myocardium and reduce the scar size, thereby enhancing the overall cardiac function. Furthermore, they did not observe any teratoma formation, despite several reports on this possibility by employing pluripotent stem cells. ${ }^{43}$ In a related study, Romagnuolo et al. successfully tested the capacity and stability of hESC-CMs transplantation in the pig model as a next step in the preclinical development of hESC-CMs. ${ }^{44}$ Moreover, in the first human clinical trial, Menasché et al. confirmed that hESCs have good potential for transplantation in patients with severe ischemic left ventricular (LV) dysfunction, reliably giving rise to clinical-grade cardiovascular progenitors under defined conditions. To ensure the differentiation of hESCs into cardiovascular progenitors, they measured the co-expression of the transcription factor ISL1 (a marker for cardiac and vascular lineages) and stage-specific embryonic antigen-1 (SSEA-1; a marker for the loss of pluripotency). ${ }^{45,46}$ The cells-loaded fibrin patch was then transferred onto the epicardium of the infarcted area through a surgical procedure. As a result, with an increased systolic motion of the cell-treated segments, all patients were symptomatically improved and it showed that hESC-derived cardiovascular progenitors have short- and medium-term safety for cell therapy. ${ }^{47}$ However, the ethical concerns behind ESCs usage limit the application of these cells in tissue engineering and regenerative medicine, which can be solved by acquiring the IPSCs.

\subsection{Induced pluripotent stem cells (iPSCs)}

Following the repudiation of utilizing the ESCs cells in regenerative medicine by the Japanese Ministry of Health, Labour and Welfare in 2006, Yamanaka and Takahashi simultaneously introduced iPSCs from somatic cells. ${ }^{48,49}$ The characteristics of iPSCs are comparable to those of ESCs, such as pluripotency, embroid formation, and teratoma formation. The iPSCs' technology has been used as autologous cells to decrease immune rejection after transplantation and can overcome the ethical concern behind the ESCs, which created a novel path towards cell therapy and regenerative medicine. Similar to the ESCs' culture methods, IPSCs can differentiate into the cardiomyocytes through a variety of stimuli. Therefore, IPSCs are suitable for cardiovascular cell therapy and tissue engineering applications. For example, Nelson and co-workers utilized IPSCs delivery for treating myocardial infarction in mice. They reported that the transplanted IPSCs differentiate into the cardiomyocytes, smooth muscle cells and endothelial cells, and it significantly improved cardiac function. ${ }^{50}$ In another work by Maiullari and coworkers, They utilized a 3D-bioprinting approach to fabricate vascular cardiac tissues with Human Umbilical Vein Endothelial Cells (HUVECs) and induced pluripotent cell-derived cardiomyocytes (iPSC-CMs). The results suggest that these approaches can be considered for reconstructive therapy by the revascularization of ischemic and damaged organs ${ }^{32}$.

\subsection{Adult stem cells (ASCs)}

3.3.1. Cardiac progenitor cells (CPCs). Previously, it was considered that adult cardiac tissue does not have self-renewal ability and is incapable of regeneration. However, recent evidence has indicated the presence of a heterogeneous group of cells that are distributed throughout the heart. Endogenous 
cardiac stem cells or cardiac progenitor cells (CPCs) were identified in 2003 by the expression of the tyrosine kinase receptor and c-Kit in the adult mammalian heart. These cells have self-renewal ability and multi-potent characteristics, which can contribute to the restoration of adult cardiomyocytes and vascular cells after injury. ${ }^{51-53}$ Several studies have isolated the CPCs from different species and demonstrated that these multipotent cells can differentiate into cardiomyocytes, vascular smooth muscle cells, and endothelial cells. ${ }^{54-56}$ Therefore, CPCs can be utilized in stem cell therapy and tissue engineering. For example, Gaetani and coworkers constructed a cardiogenic scaffold by combining the human cardiac-derived cardiomyocyte progenitor cells, biomaterials, and 3D printing technology. ${ }^{57}$ Moreover, Streeter et al. designed polycaprolactone (PCL) nanofiber-based patches via the electrospinning method for the delivery of CPCs. ${ }^{58}$

3.3.2. Mesenchymal stem cells (MSCs). Mesenchymal stem cells (MSCs) are a group of adult stem cells that are widely used in tissue engineering and cell therapies due to their extraordinary potential for retaining the post-natal capacity of self-renewal and multi-lineage differentiation. MSCs have excellent properties such as limited immune response, secretion of a variety of antiinflammatory, and antifibrotic mediators, as well as high potential for the activation of resident precursors. ${ }^{59}$ Due to the spectacular differentiation potential, safety, and feasibility of mesenchymal stem cells, many investigations have proposed the MSCs as one of the most promising types of stem cells that can be used in cell therapy and tissue engineering. ${ }^{60-62}$ It has also been reported that MSCs can transdifferentiate into mesodermallyderived cell types, including cardiomyocytes. ${ }^{63}$ Recently, several studies were conducted utilizing MSCs as a source for cardiac regeneration. ${ }^{64}$ For instance, knowing that mechanical and electrical forces are among the important regulators of gene expression and cellular function in cardiac tissue, LluciàValldeperas and colleagues used cardiac adipose-derived hMSCs (cATMSCs) implantation within a fibrin patch for treating infarcted myocardium in a murine model. These findings indicate that electrical stimulation on cATMSCs improved synchronous contractions, tissue homogeneity, and immunomodulatory properties, which could be a promising therapeutic strategy for heart repair after myocardial infarction. ${ }^{65}$ In a related study, Chen et al. focused on improving the poor survivability and lower retention of implanted stem cells for cardiac infarction. By using chitosan/silk fibroin (CS/SF)-modified nanofibrous cardiac patch-loaded adipose tissue-derived mesenchymal stem cells (AD-MSCs), they showed that CS/SF-modified multilayers patches improved the left ventricular ejection fraction (LVEF), cell viability, cardiac function, and reduced adverse ventricular remodeling in the rat myocardial infarction model. ${ }^{66}$

\section{Nanomaterials controlling cellular behaviors}

To date, the effects of nanomaterials on stem cell behavior have been studied extensively. Nanomaterials can not only be utilized as nanoparticles that can easily cross the cell membrane and affect the intracellular signaling pathway, they can also be utilized as a three-dimensional substrate for culturing the stem cells. The interaction between nanomaterials and stem cells has not been entirely understood, but we know that the bulk properties or physicochemical parameters and surface properties of nanomaterials play a major role in controlling cellular behavior. However, the underlying mechanisms of various nanomaterials, through which they can promote or inhibit adhesion, migration, differentiation, or proliferation, need further investigation. Here, we briefly discuss the bulk (Fig. 1) and surface properties (Fig. 2) of nanomaterials and their effects on cellular behavior, which can be utilized in the treatment of cardiovascular diseases.

\subsection{Bulk properties}

4.1.1. Size and shape. Nanoparticles can activate certain signaling pathways since they can act as a mechanical stimulus for inducing or inhibiting a wide range of behaviors in stem cells. However, nanoparticles should have the appropriate size for internalization into the cells. It has been shown that the optimal size for the differentiation of stem cells is around 20 to $70 \mathrm{~nm} .{ }^{67}$ However, the toxicity of the nanoparticles is relative to their size. For example, it has been shown that the particles with a smaller size (less than $50 \mathrm{~nm}$ ) have shown more toxicity as compared to large particles. ${ }^{67,68}$ For example, in a study by Abdelhalim, GNPs with the size of 10 and $20 \mathrm{~nm}$ resulted in hemorrhaging and excess extravasation of red blood cells, which indicated heart muscle damage in rats. However, the rats treated with $50 \mathrm{~nm}$ GNPs showed normal heart muscle. ${ }^{69} \mathrm{It}$ has been suggested that the production of the higher ROS molecules is the main toxicity mechanism of smaller GNPS since the smaller particles have a relatively high surface-to-volume

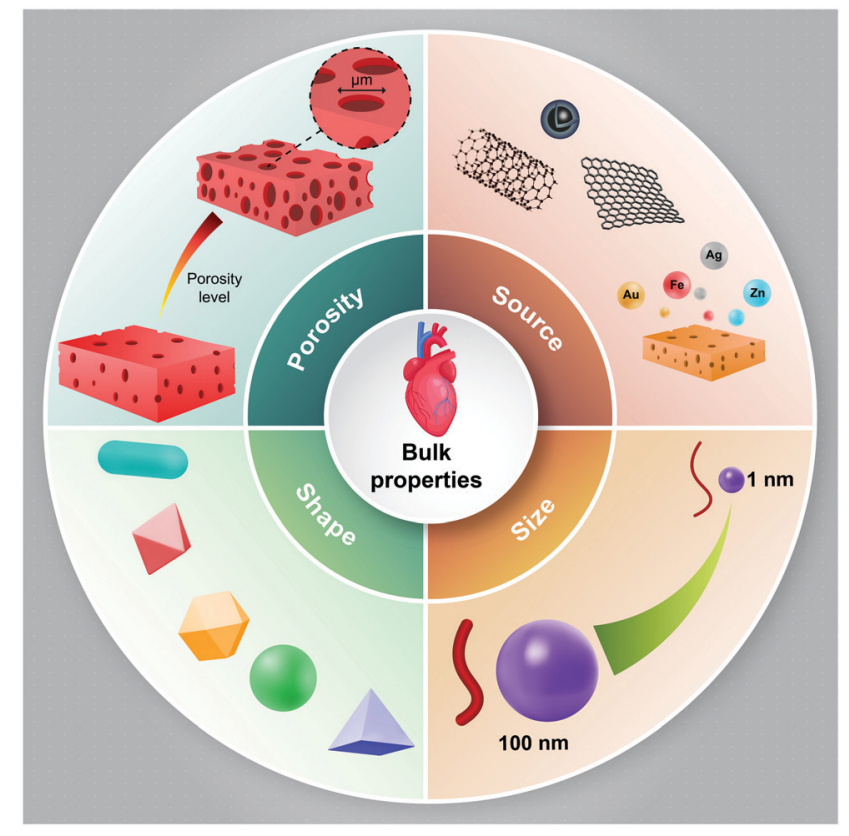

Fig. 1 Schematic representation of the bulk properties of nanomaterials, which may affect cellular behaviors towards cardiovascular cell lineage. 


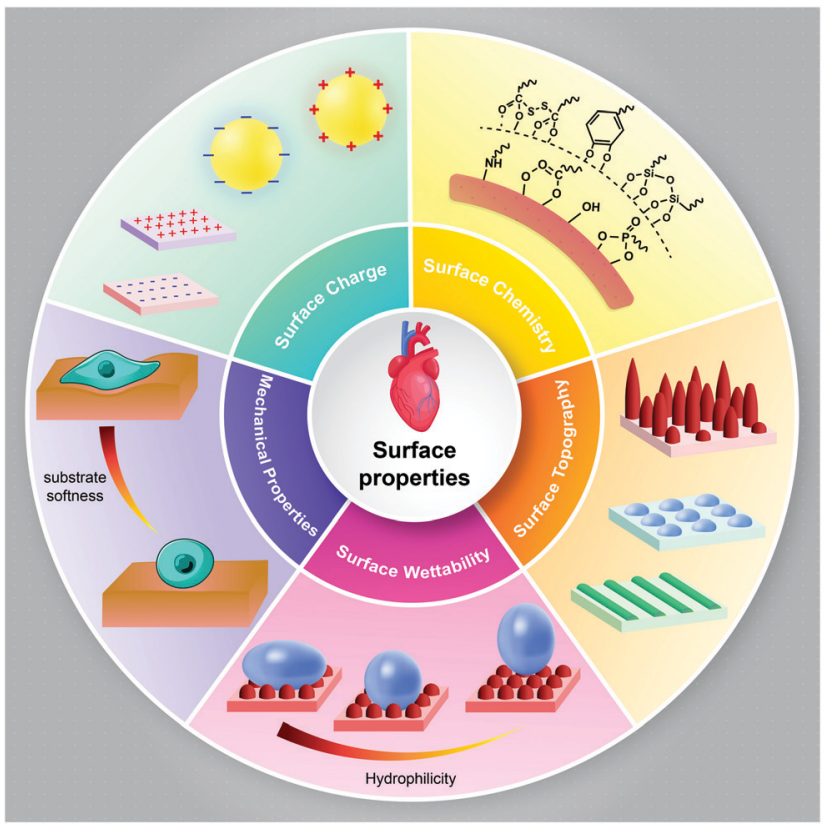

Fig. 2 Schematic representation of the surface properties of nanomaterials, which may modulate cellular behavior towards cardiovascular cell lineage.

ratio as compared to larger particles. Therefore, smaller particles tend to produce more ROS molecules and oxidative stress in heart muscles. ${ }^{69}$ Moreover, the shape of nanomaterials can control cellular behavior since the cellular uptake of nanoparticles is size and shape-dependent. It has been shown that the uptake of spherical nanoparticles is higher as compared to nanorods and other shapes when the size of the particles is lower than $100 \mathrm{~nm} .^{70,71}$

4.1.2. Nanomaterial source. The source of nanomaterials is another factor that should be taken into account since different kinds of materials have various effects on cellular biological response. Numerous scaffolds have been fabricated with different synthetic or natural materials. The advantage of utilizing natural materials such as hyaluronic acid, fibrinogen, collagen, and chitosan is the similarity of their components to the native ECM. ${ }^{72,73}$ The RGD sequence that can be found in scaffolds synthesized with natural materials facilitates the adhesion of cells to the surface of nanomaterials, providing a suitable environment for controlling the cell fate. In contrast, synthetic nanomaterials may require further modification. ${ }^{74}$ Moreover, the hydrophobicity and the low number of attachment sites in synthetic nanomaterials may result in weak cell adhesion and unfavorable cellular response. However, synthetic materials can be used to overcome weak mechanical properties and the lack of ideal chemical functional groups. ${ }^{75}$

4.1.3. Porosity. The porosity and pore size of scaffolds affect the cellular response and cellular behavior, which lead to determining the phenotype of the cells. It has been demonstrated that nanoporous scaffolds with pores smaller than $1 \mu \mathrm{m}$ can improve cell-surface interactions. However, cell-cell communication relies on the 1 to $3 \mu \mathrm{m}$ pore sizes. Furthermore, the optimum pore size for cell migration ranges from 3 to
$12 \mu \mathrm{m} .{ }^{76}$ However, a suitable pore size in the scaffold for the regeneration of different tissues is varied and depends on the source and the size of cells. For instance, it was shown that the higher ratio between cells and pore size increases cell migration and cell invasion. ${ }^{76}$ Turning to the cardiovascular system, it has been shown that a large pore size increase angiogenesis in porous PEG hydrogels. ${ }^{77}$ Culturing the vascular smooth muscle cells on L-PLA with a pore size of 38-150 $\mu \mathrm{m}$ showed cell proliferation and matrix deposition. ${ }^{78}$ Wang et al. showed the differentiation of iPSCs into smooth muscle cells on a PLLA scaffold with pore sizes of 60-150 $\mu \mathrm{m}$. Implanting this scaffold subcutaneously in nude mice showed the formation of vascular tissue. ${ }^{79}$

\subsection{Surface properties}

The nature of the surface of the nanomaterials and the bioactive agents and biomolecules that are utilized for functionalization can change the performance of nanomaterials in living tissue. ${ }^{80}$ Surface modification technology with bioactive agents and biomolecules can be employed as a proper tool for mimicking the tissue microenvironment. ${ }^{81}$ Whether nanomaterials are used as nanoparticles or 3D substrates for cardiac tissue engineering, understanding their surface properties and modifications techniques for changing the surface properties should be taken into account. The surface properties of nanomaterials such as surface charge, surface chemistry, surface topography, and surface wettability play major roles in cell adhesion, cell shape, cell proliferation, and differentiation. ${ }^{82}$ These properties can be manipulated in designing nanomaterials for cardiovascular tissue engineering.

4.2.1. Surface chemistry. The surface chemistry of nanomaterials is the main factor that affects the cell-matrix interactions. These interactions can change the behavior of certain cells, which can be utilized in designing new nanomaterials. Simpson and colleagues in 1994 demonstrated that the interactions between cardiomyocytes and collagen type I as a substrate determined the phenotype of the cells (rod-like cell shape) by controlling the signaling pathways, which affect the cardiac alpha or beta integrin chain. ${ }^{83}$ The surface chemistry of nanomaterials can be associated with other surface properties such as the wettability and surface charge affecting the cell adhesion, cell proliferation, and differentiation. ${ }^{82} \mathrm{~A}$ crucial key component that determines the surface properties of the nanomaterial is the chemical functional groups. The surface chemistry of a substrate can be modified by utilizing various surface modification techniques. These methods can be used to add new functional groups (acetylation, fluorination, silanization, etc.), or change the existing functional group (oxidation, reduction). For example, the modification of substrates with diethylenetriamine (DETA), which adds primary amines to the surface of a substrate, can enhance cell attachment, differentiation, and the long-term survival of rat embryonic cardiomyocytes. ${ }^{84}$ Moreover, nanomaterials can be functionalized with specific biological molecules if certain functional groups are present on the surface. For instance, Kang and coworkers immobilized fibronectin onto PCL nanofibers that were modified 
by initiating chemical vapor deposition (iCVD) of polymer films. These nanofibers increased umbilical-cord-blood-derived MSCs attachment, and improved cardiac function and angiogenesis in the rat myocardial infarction model. ${ }^{85}$

Modifying various substrates with nanomaterials is another strategy utilizing surface chemistry. For example, the mechanical and electrical properties of collagen can be increased by the surface coating of collagen hydrogels with CNTs. Yu et al. found that the incorporation of carboxyl-functionalized MWCNTs (30 $\pm 15 \mathrm{~nm}$ in diameter and 5-20 $\mu \mathrm{m}$ in length) with collagen type I hydrogel can improve the cardiac cell functions. ${ }^{86}$

4.2.2. Surface charge. Solid surfaces can become negatively and positively charged by changing the surface chemistry of nanomaterials with various chemical methods. It has been shown that the cell attachment on positively charged substrates is higher as compared to negatively and neutrally charged surfaces. $^{87,88}$ Moreover, It should be noted that the surface charge of nanoparticles is another factor that determines the uptake of nanoparticles, thereby affecting the biological response in the target cells. ${ }^{89}$ Asati and coworkers functionalized cerium oxide nanoparticles to produce neutral, negatively, and positively charged nanoparticles. They found that aminated cerium oxide nanoparticles, which have a positively charged surface, showed increased internalization and localization to cardiac myocytes. ${ }^{90}$ Furthermore, the surface charge can be used to form a complex structure with biomolecules such as DNA. For instance, Chang and colleagues synthesized AuNP loaded GMT (Gata4, Mef2c, and Tbx5) coated with PEI for the reprogramming of induced cardiomyocytes. They made a complex utilizing the electrostatic interactions between the positive and negative charges of PEI and DNA, respectively. Moreover, they found that the AuNPs/GMT/PEI complex like other cationic nanocarriers, has a high delivery efficacy. ${ }^{91}$

4.2.3. Surface wettability (hydrophilicity/hydrophobicity). The adhesive force between the solid surface and liquid, which causes the spreading of the liquid across the solid surface, is known as surface wettability. ${ }^{92}$ It has been shown that proteins are attracted to hydrophilic surfaces as compared to hydrophobic surfaces; consequently, cell attachment and proliferation are higher on hydrophilic surfaces. ${ }^{93}$ It should be noted that the surface wettability of nanomaterials can be adjusted by the manipulation of the surface chemistry and surface topography. ${ }^{94}$ For example, Wei and colleagues utilized plasma polymerization and oxygen plasma treatment to create a wide range of surfaces with wettability degrees ranging from $106^{\circ}$ to $0^{\circ}$ (hydrophobicity to hydrophilicity). They demonstrated that the rat fibroblast tends to spread on hydrophilic surfaces. Moreover, they showed that the fibronectin protein is attached to the hydrophilic surfaces to a higher degree as compared to albumin, which is absorbed on hydrophobic surfaces. ${ }^{95}$ Overall, cell spreading and cell attachment have a direct relationship with a positive cell surface and hydrophilicity, and a negative relationship with negative surface charge and hydrophobicity. ${ }^{96}$ However, a moderately wettable surface with a contact angle of $70-80^{\circ}$ is preferable for cell attachment. ${ }^{95-97}$ Mehdinavaz Aghdam et al. synthesized a PCL/PGA blend nanofibrous scaffold and they cultured CPC cells on the scaffold for the investigation of cell adhesion and proliferation. They used the PGA reinforcement to increase the mechanical properties of the scaffold. Moreover, increasing the PGA concentration enhanced the hydrophilicity of the scaffold. They demonstrated that the 65:35 PCL: PGA ratio showed the highest cell adhesion and proliferation. However, increasing PGA by more than 50\% substantially reduced cell proliferation and growth. ${ }^{98}$

4.2.4. Surface topography. Another aspect of surface properties, which is crucial for cardiac tissue engineering, is controlling cellular behavior through topographical features. One of the main challenges is to simulate the in vivo-like orientation and elongation of cardiomyocytes in tissue engineering strategies. We can see this three-dimensional syncytium formation of cells in adult cardiomyocytes, which enables the production of electrical signals. ${ }^{99}$ It has been shown that the topographical cues are the major determinant of cardiomyocyte orientations. $^{99}$ One of the most crucial aspects of surface topography is the surface roughness, which is calculated by measuring the protrusions and depressions of the surface. ${ }^{100} \mathrm{It}$ has been shown that rough and smooth surfaces can induce different cell responses. For example, an increase in surface roughness can increase the adsorption of key ECM proteins such as fibronectin and vitronectin. Fibronectin can enhance cell attachment and cell growth via chemoattractants of various cell types such as fibroblasts and endothelial cells, which are essentials in wound healing after myocardial infarction. ${ }^{101}$ Stout et al. utilized carbon nanofibers (CNF) for increasing the roughness of PLGA with different ratios (100:0, 75:25, $50: 50,25: 75$, and $0: 100 \mathrm{wt} \%$ CNF : PLGA). They observed that the increase of CNF into PLGA structures promoted cell attachment and the growth of cardiac muscle cells. They reported that the $50: 50$ ratio of PLGA and CNF with the $0.025 \mathrm{~g} \mathrm{~mL}^{-1}$ PLGA density showed the highest cardiomyocyte growth. ${ }^{102}$

Another aspect of surface topography is the surface pattern, which can be classified into isotropic and anisotropic patterns. A surface with no directional orientation is isotropic. However, surfaces with nanotopographical patterns, such as protrusions, pillars, circular, etc., are anisotropic. ${ }^{103}$ Several studies have investigated the effect of nanotopographical features on protein absorption and cell behaviors, such as growth and stem cell differentiation. ${ }^{104-107}$ It has been shown that these effects are the result of biochemical and biomechanical processes of adhesion and cytoskeletal conformation. Ngandu Mpoyi and coworkers designed a nanostructured polycarbonate surface in a square pattern with a diameter of $150 \mathrm{~nm}$, and $\approx 90 \mathrm{~nm}$ deep pits (NSQ50) to investigate the adsorption of proteins and cellular behaviors. They utilized the $\mathrm{C} 2 \mathrm{C} 12$ myoblasts to investigate the focal adhesion assembly and myogenic differentiation as compared to the flat control groups. They found that the fibronectin absorption caused an increase in globular clusters both on the inter-pit space and inside the nanopits, which increased the cell attachment to the surface. Moreover, C2C12 interacted with the edges of pits through filopodia and even entered the nanopits. Altogether, they concluded that the nanotopographical features can impact cellular behavior, such 
A

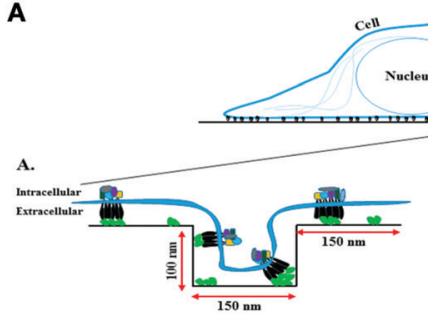

C

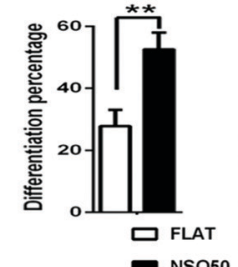

D

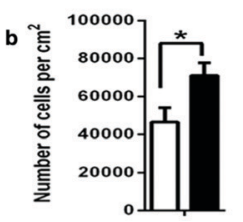

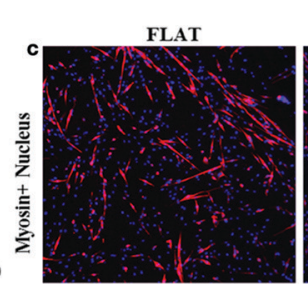

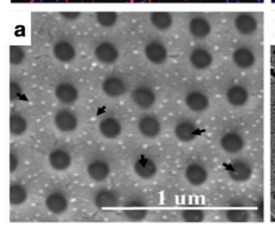

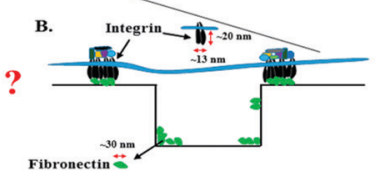
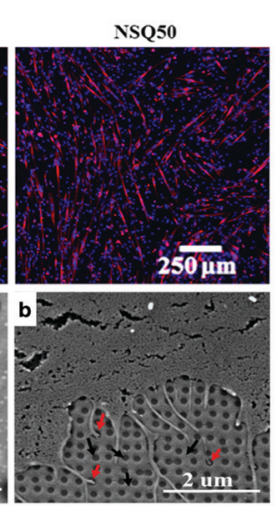

B
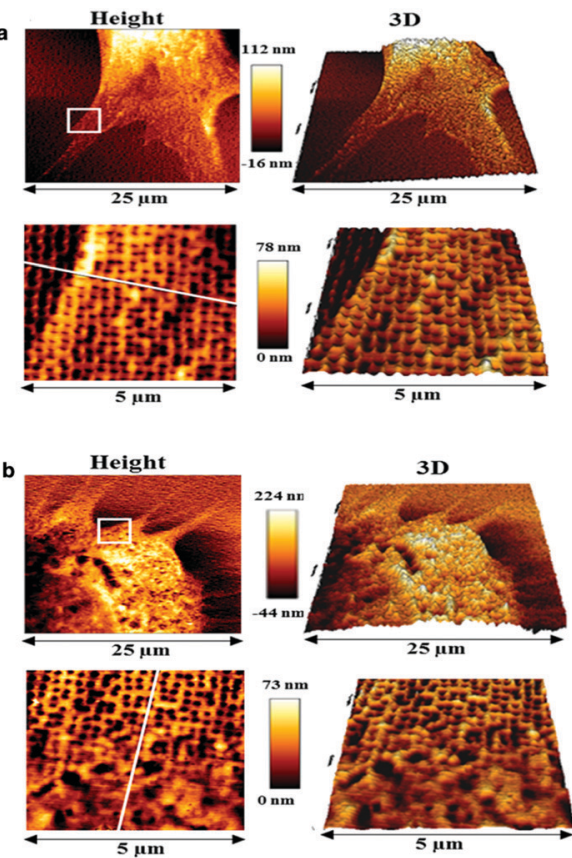

Fig. 3 (A) Schematic representation of the cell sensing the nanotopographical features on the surface of the biomaterial. (B) AFM image of C2C12 cells on (a) uncoated substrate (b) fibronectin-coated nanotopography. (C) The effects of surface topography on cell differentiation and proliferation of C2C12 cells. (a) Myogenic differentiation of C2C12 cell on flat and NSQ50 surfaces. (b) The cell density after 4 days of culture. (c) Immunofluorescence images of C2C12 cells (sarcomeric myosin (red), DAPI (blue)). (D) SEM images related to NSQ50 nanotopographies. (a) Fibronectin aggregation inside and outside of nanopits. (b) Cell adherence of $\mathrm{C} 2 \mathrm{C} 12$ on nanotopography coated with fibronectin. The red arrows show the cell filopodia entering the nanopits. ${ }^{106}$

as differentiation by changing the cell adhesion and cytoskeleton organization (Fig. 3). ${ }^{106} \mathrm{Au}$ and colleagues demonstrated that the effect of topographical features on cardiomyocyte orientations is significantly stronger as compared to the electrical stimulation..$^{99}$ Furthermore, it has been shown that cellular behaviors such as morphology, the velocity of action potential conduction, and cell-cell coupling protein interactions can be controlled by controlling the sizes of the nanogrooves. ${ }^{108}$

4.2.5. Mechanical properties. Controlling cellular behavior can be achieved by mimicking the tissue-specific niche properties by the modification of mechanical properties. These modifications adjust the cell-material interactions, which affect intracellular pathways regulating cellular behavior. ${ }^{109}$ Material stiffness is the resistance of materials to deformation when a force is applied, which means that the materials with high stiffness can resist deformation, but materials with low stiffness, deform easily. Every tissue displays a special stiffness value, which is determined by the composition of the ECM and cross-linking proteins. ${ }^{110}$ The interaction of stem cells with the matrix is crucial for the regulation of stem cell fate, such as in the early stages of differentiation. These cells mechanically interact with the ECM by cell adhesion molecules (CAMs) such as integrins, which help them to recognize the substrate stiffness. Consequently, these interactions convert to biochemical signals, which determine the cell behaviors and stem cell fate. ${ }^{109,111,112}$ Several studies revealed that mimicking the biomechanical properties of cardiac muscles is crucial in cardiac tissue engineering. First, the biomechanical cues may induce cardiac differentiation. Moreover, mechanical cues enable the tissue construct to be synchronized with the contraction of the heart, which induces mechanical transfer from the myocardial environment to the stem cells. ${ }^{113}$

In recent years, several biomaterials have been used to mimic the mechanical properties of the myocardium. The similarity between the mechanical properties of the heart and biomaterials is crucial. It has been demonstrated that Young's modulus for the heart is 10 to $20 \mathrm{kPa}$ in diastole and $200-300 \mathrm{kPa}$ at the end of systole. Therefore, a relatively low Young's modulus with high elasticity and tensile strength is optimal for cardiac tissue engineering; consequently, the materials with high stiffness are not desirable. ${ }^{114}$ For example, it has been shown that biodegradable polyesters, such as polylactide (PLA) and copolymers are not suitable for such applications since they lack suitable stiffness. ${ }^{115}$ The flexible and soft polymers with good elasticity, such as polyurethane, are good candidates for myocardial tissue engineering. For instance, Guan and coworkers used the electrospinning of poly(ester carbonate urethane)urea (PECUU) nanofibers and electrospraying MSCs to synthesize a myocardium-like tissue construct. They showed that the anisotropic mechanical properties with areal strains at $10 \mathrm{kPa}$, and strains at $10 \mathrm{kPa}$ were the same as the native myocardium. ${ }^{113}$ Moreover, Li et al. synthesized thermosensitive hydrogels based on $\mathrm{N}$-isopropylacrylamide, $\mathrm{N}$-acryloxysuccinimide, acrylic acid, and poly(trimethylene carbonate)-hydroxyethyl methacrylate with various mechanical properties $(16 \mathrm{kPa}$, $45 \mathrm{kPa}, 65 \mathrm{kPa}$ ). They observed that $76 \%$ hMSCs were encapsulated in the hydrogel with the higher modulus ( $65 \mathrm{kPa})$, and they 
expressed the essential proteins for the contraction of the heart, such as MYH6 and cTnI, which showed the successful differentiation of the MSCs into cardiomyocytes. ${ }^{116}$ This study proved that the modulation of the mechanical properties of the scaffold can induce greater differentiation of stem cells as compared to traditional techniques such as co-culturing the hMSCs with cardiomyocytes or using 5-azacytidine. Despite the compositions, several factors can contribute to the mechanical properties of biomaterials, which can be modulated to change the elasticity of the hydrogel. For example, Davenport Huyer, and colleagues synthesized poly(octamethylene maleate (anhydride) 1,2,4-butanetricarboxylate) (124 polymer) with a one-step polycondensation reaction, which showed ideal biodegradability, relatively low Young's modulus with excellent elasticity properties, high elongation, and tensile strength. The hydrogel properties were tunable by UV light exposure, monomer composition, and porosity content. They utilized an experimental design to find the best relationship between these properties. Afterward, the cell attachment ability of rat cardiomyocytes was investigated by live/dead staining, which showed an excellent cell-substrate and cell-cell attachment (Fig. 4). ${ }^{114}$

\section{The effects of nanomaterials on cellular behavior and their applications in cardiac tissue engineering}

\subsection{Metal-based nanomaterials}

5.1.1. Gold nanoparticles. Gold nanoparticles (AuNPs) are a colloidal suspension of gold particles in water with unique chemical, physical, thermal, optical, and biological properties. Gold nanoparticles have potential applications in various fields such as chemistry, physics, material science, biology, and medicine. AuNPs are widely used in drug delivery and regenerative medicine since they can be designed, produced, and modified utilizing different functional groups, which provide antibodies and ligands conjugation. ${ }^{117-119}$ Recent studies have demonstrated the impact of AuNPs on cell fate and cell behavior, as they can promote the differentiation of ESCs and MSCs into osteoblast and cardiomyocyte cells. It has been shown that different sizes of spherical AuNps significantly enhanced the differentiation of AD-MSCs into osteoblasts with no cytotoxic effect. ${ }^{120} \mathrm{Li}$ and coworkers used different sizes and shapes of AuNps (nanorods and nanostars) to investigate the shape and size of these nanoparticles on the osteogenic
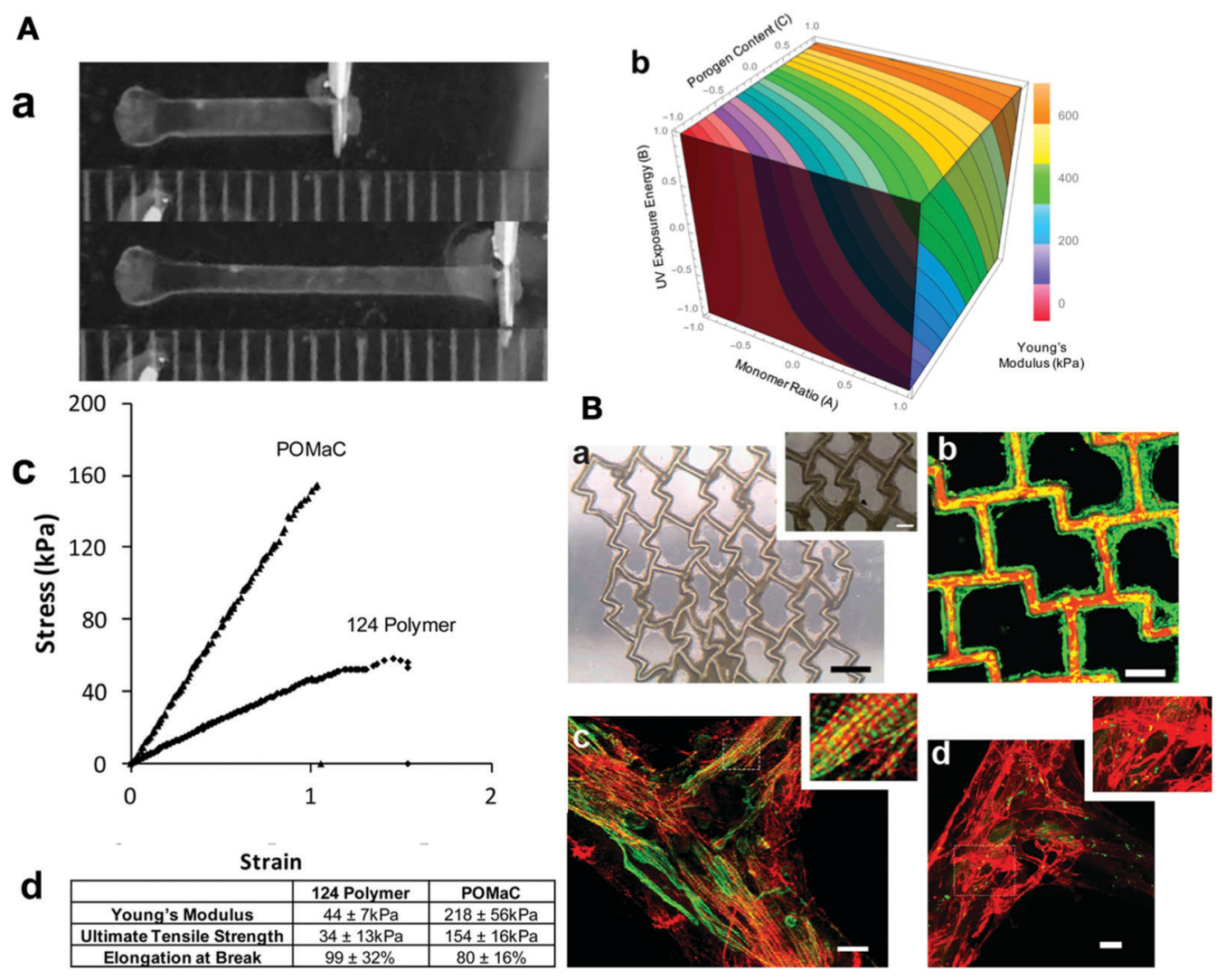

Fig. 4 (A) Mechanical properties of the 124 polymer construct. (a) Elastic properties of 124 polymer, suitable for cardiac tissue engineering (scale in mm). (b) Young's modulus to monomer ratio, UV exposure energy, and porogen content relationships. (c) Stress-strain curve, which demonstrated the elastic characterization of the 124 polymer. (d) Comparison of the elastomeric properties of polymer 124 and poly(octamethylene maleate (anhydride) citrate. (B) Culturing rat cardiac cells on the 124 polymer for 7 days. (a) Bright-field image with 250 and $100 \mu \mathrm{m}$ magnification. (b) Live (green)/dead (red) staining of rat cardiomyocytes. (c) Confocal microscopy of rat cardiac cells after staining with cardiac troponin-T (green) and F-actin (red), which demonstrated the formation of rat cardiomyocytes. (d) Representation of intercellular connections and organized cardiac tissue by Connexion 43 staining (green) at cellular junctions. ${ }^{114}$ Reproduced from ${ }^{114}$ with permission from the American Chemical Society, Copyright 2016. 
differentiation of hMSCs. They showed that the expression of osteogenic markers was increased by Au nanorods $(70 \mathrm{~nm})$ and $\mathrm{Au}$ nanospheres $(40$ and $70 \mathrm{~nm}) .{ }^{67}$ Such findings suggest that different shapes and sizes of AuNPs can significantly affect cellular behavior, which can be beneficial in tissue engineering applications. Ravichandran and coworkers, increased the cardiomyogenic differentiation of MSCs by the synergic effect of 5-azacytidine (5-aza) and AuNPs-loaded nanofibrous scaffolds. In this study, AuNps nanofibers were fabricated by a mixture of gold chloride (AuCl3), polyvinylalcohol (PVA) and bovine serum albumin. It showed that the pretreatment of MSCs with AuNpsloaded nanofibers increased the expression of cardiac-specific markers such as $\alpha$-actinin, $\mathrm{Cx} 43$, and troponin-T. ${ }^{121}$ It should be noted that the heart distribution of AuNPs is size-dependent. In a study by Zhang and colleges, using smaller sizes of AuNPs with less than $40 \mathrm{~nm}$ is recommended since the larger size of AuNPs may show cardiac toxicity. They suggested that the $5 \mathrm{~nm}$ AuNPs did not accumulate in the heart as compared to larger sizes, and it showed cardiac protective potential. ${ }^{122}$

Another important factor that plays a crucial role in cardiac tissue engineering and directing the fate of stem cells is the conductivity of AuNPs. Several studies showed that the various nanofibers can be decorated with AuNPs. For instance, decellularized scaffolds can be integrated with AuNPs, which is a novel electroconductive platform with high compatibility. Shevach and coworkers designed a hybrid scaffold with the fibrous decellularized omental matrices and they deposited different sizes of AuNPs ( 4 and $10 \mathrm{~nm}$ ) on this scaffold. This novel autologous scaffold, showed strong biocompatibility, electroconductivity, and enhanced mechanical properties. However, in in vivo conditions, the AuNPs may dissociate from the scaffold, but it showed excellent stability under in vitro conditions. The cardiac cells showed aligned and elongated morphologies with massive striation and organized connexin 43 electrical coupling proteins. The AuNPs in this hybrid scaffold reduced the proliferation, thereby maintaining the ratio of contracting to non-contracting cells (Fig. 5). ${ }^{123}$ Nevertheless, Baei et al. improved the conductivity of chitosan by the incorporation of gold NPs into the chitosan structure. This improvement showed the differentiation of MSCs into cardiac cells. Moreover, the rate of cardiac differentiation was higher as compared to the pristine scaffold. ${ }^{124}$

Besides conductivity, it has been shown that the integration of gold nanorods (AuNRs) with hydrogels can increase the stiffness of the scaffold, which enhances neonatal cardiomyocyte adhesion. Navaei and colleagues fabricated a gelatin methacrylate (GelMA)/AuNRs hybrid scaffold with various concentrations of AuNPs with an aspect ratio of 3.15 (16 $\pm 2 \mathrm{~nm}$ width and $53 \pm 4 \mathrm{~nm}$ length). They utilized different AuNRs concentrations $\left(0.5,1,1.5 \mathrm{mg} \mathrm{mL}^{-1}\right)$ in the scaffold, and the $1.5 \mathrm{mg} \mathrm{mL} \mathrm{m}^{-1}$ group demonstrated the best results in cell retention and cytoskeleton organization. It showed the cellmatrix interactions by enhancing the integrin 1 and cardiacspecific markers such as troponin I and sarcomeric $\alpha$-actinin. The conductive properties of this hybrid scaffold resulted in high cell-cell interactions and electrical signal propagation by increasing the Cx43 gap junctions expression level and synchronized calcium signaling in cardiomyocytes. ${ }^{125}$

In addition to the features that we discussed above, other properties of AuNPs can be used in designing new scaffolds for cardiac regeneration. Recently, a cardiac patch was developed by albumin electrospun fibers decorated with gold nanorods, which can absorb and convert light ( $808 \mathrm{~nm}$ near IR laser) into thermal energy. This thermal energy can change the molecular structure of the scaffold, which can help the integration of the patch to the wall of the heart. Scanning electron microscopy (SEM) images of the sliced heart confirmed a close interaction between the heart and the cardiac patch (Fig. 6). Cardiac cells showed excellent contractability and a high expression of $\mathrm{Cx} 43$ between cardiomyocytes, which resulted in the synchronous functioning of these cells. ${ }^{126}$

In another study by Sridhar and co-workers, a nanofibrous scaffold was constructed by AuNPs (16 nm in size) embedded in polycaprolactone (PCL), aloe vera (AV), vitamin B12, and silk fibroin (SF) scaffolds. They demonstrated that the chemical composition and the stiffness of the scaffold are responsible for the proliferation and differentiation of MSCs. The AuNPs and vitamins improved the surface area of the scaffold as well as enhanced the cellular properties such as sarcomeric structures. Nevertheless, the scaffold with the AuNPs significantly enhanced the initial cell proliferation on day 5 (Table 1). ${ }^{127}$

5.1.2. Silver nanoparticles. Silver nanoparticles (AgNPs) have potential applications in medicine, electronics, textiles, and cosmetics due to their superior antimicrobial properties. Different techniques can be used in AgNPs synthesis including laser ablation, gamma irradiation, electron irradiation, photochemical approach, and some biological mechanisms. ${ }^{138}$

Antiviral and antiseptic properties of AgNPs have been utilized for the production and development of biological instruments such as artificial cardiac pacemakers. Antimicrobial properties of AgNPs have been reported in tissue engineering and regenerative medicine studies, especially in wound healing. ${ }^{119}$ All the beneficial applications of AgNPs along with the manipulation of their size, shape, concentration, functionalization, and exposure time, generate significant developments for cardiovascular disease diagnosis and prognosis. ${ }^{139}$ The first cardiovascular usage of silver in the clinic was a silver-coated prosthetic silicone heart valve designed to reduce bacterial infection and the host inflammation response. ${ }^{140}$ In a study by $\mathrm{Fu}$ and co-workers, chitosan/heparin multilayer films were constructed, and not only showed an antibacterial effect on $E$. coli but also the incorporation of AgNPs into these multilayer films substantially improved its bactericidal properties. This study suggested that the nanosilver multilayer film could be useful on the surfaces of medical devices, especially in cardiovascular implants. ${ }^{141}$ In another study by Angelina et al., a pyrolytic carbon (PyC) biomaterial was constructed as an artificial heart valve and coated with a thin layer of AgNPs. The AgNPs gave the PyC excellent antibacterial properties and improve its haemocompatibility. ${ }^{142}$ However, there are substantial concerns about their effects on human health since AgNPs 


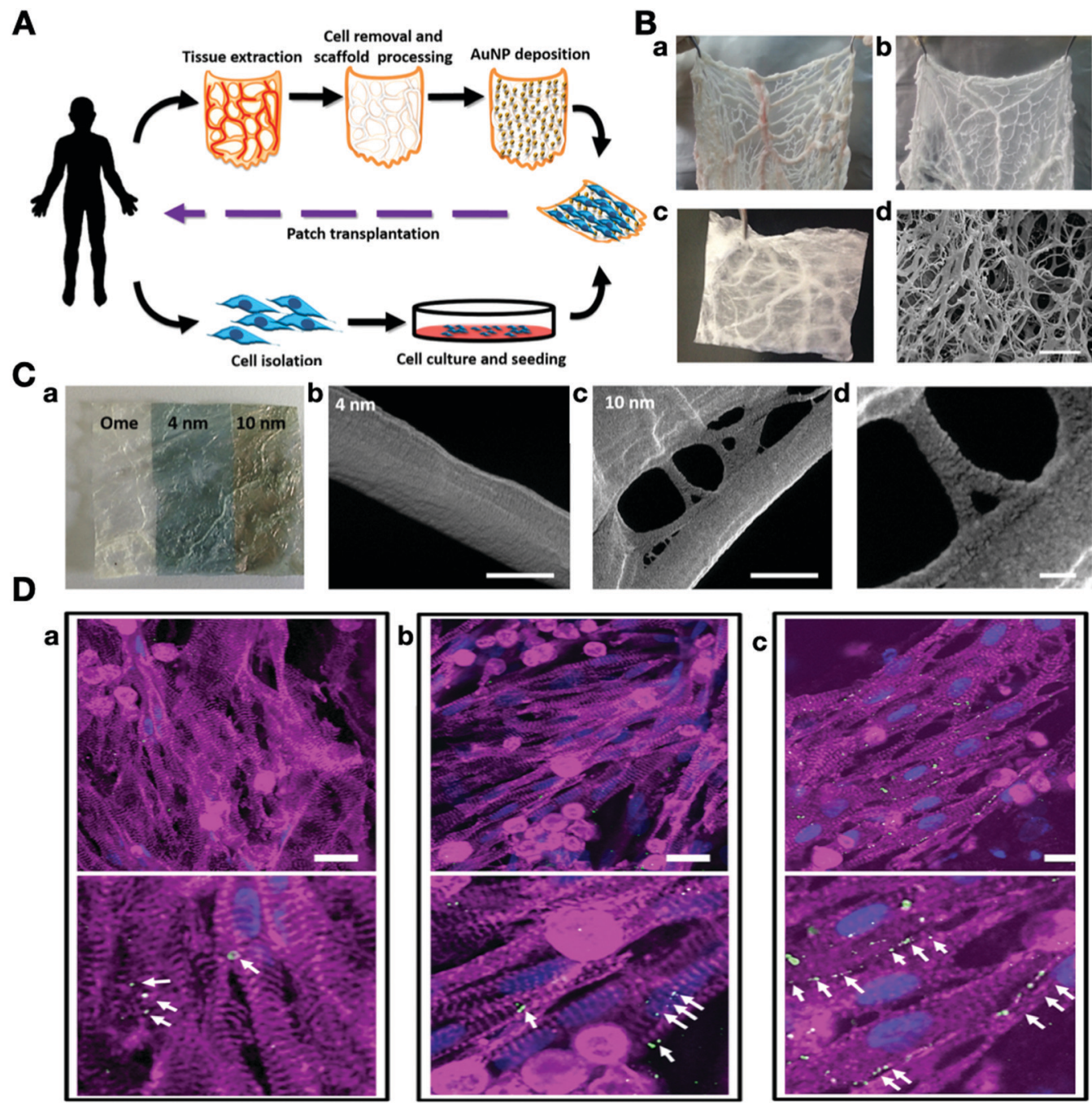

Fig. 5 (A) Schematic overview of the production of a 3D decellularized omental scaffold decorated with AuNPs as a personalized cardiac patch for cardiac tissue engineering. (B) Decellularization process of gold nanoparticle-decellularized matrix hybrids. (a) Native omentum tissue, (b) omentum tissue during the decellularization process, (c) after the complete decellularization process. (C-a) Decoration of the omentum decellularized scaffold with $4 \mathrm{~nm}$ and $10 \mathrm{~nm}$ AuNPs. (b-d) SEM images of the AuNPs-decellularized scaffold. (C) Immunostaining of the cardiac cell organization on day 5 (cardiac $\alpha$ sarcomeric actinin (pink), connexin 43 (green), and nuclei (blue)). (a) The pristine scaffold, (b) deposition of 4 nm AuNPs, (c) deposition of 10 nm AuNPs. ${ }^{123}$ Reproduced from ref. 123, published by American Chemical Society, Copyright 2014.

can be released into the environment and interact with physiological fluids. Oxidization of the elemental $\mathrm{Ag}(0)$ to $(\mathrm{Ag}+)$ and the subsequent binding of $\mathrm{Ag}+$ to protein ligands led to a toxic effect of AgNPs. ${ }^{143}$ It has been shown that extremely low concentrations of the ionic form of $\mathrm{Ag}$ such as silver chloride and silver nitrate can increase ventricular hypertrophy in cardiovascular systems, which is associated with high blood pressure, and the elevation of hemoglobin and hematocrit concentrations. ${ }^{144}$ Nevertheless, there is insufficient information about the impact of AgNPs on the cardiovascular system. Some studies suggest that these NPs produce reactive oxygen species (ROS), which can induce cardiotoxicity. ${ }^{145,146}$ In a recent study by Ferdous and co-workers, the cardiovascular mechanism of pulmonary exposure to two different citrates (CT) and polyvinylpyrrolidone (PVP) coated with AgNPs was evaluated. They reported that AgNPs exposure induced oxidative stress, which increased cardiac cell apoptosis and DNA damage. Besides, the time of thrombotic obstruction in cerebral microvessels and platelet aggregation increased after lung exposure to AgNPs. ${ }^{147}$ Moreover, Manuel and coworkers utilized a Langendorff heart (isolated perfused heart) preparation to demonstrate that the low concentrations of AgNPs ( 0.1 and $\left.1 \mu \mathrm{g} \mathrm{mL}{ }^{-1}\right)$ increased nitric oxide levels but the cardiac contractility or coronary vascular tone in normal Wistar rats were intact. However, high concentrations of AgNPs (10 and $100 \mu \mathrm{g} \mathrm{mL}^{-1}$ ) increased reactive oxygen species, which led to the induction of cardiac contractility and vasoconstriction. Furthermore, this reactive oxygen species generated by AgNPs caused the degradation of muscle or rhabdomyolysis. ${ }^{148}$

Silver nanoparticles are often utilized in tissue engineering, embedded in scaffolds that are subsequently cultured with MSCs. Moreover, AgNPs can induce a toxic effect in the 
A

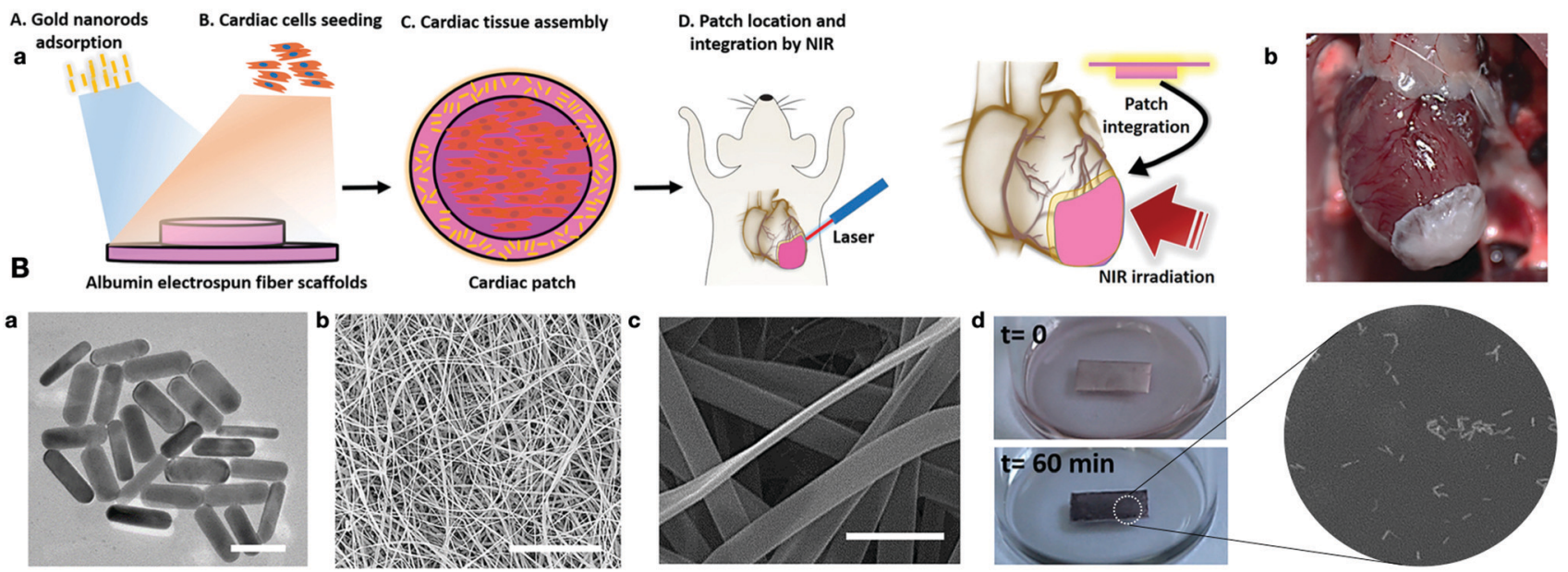

Fig. 6 (A-a) Schematic representation of a gold nanorods-based engineered cardiac patch for suture-free engraftment by near IR. (b) The cardiac patch after integration with a rat heart. (B-a) High-resolution TEM AuNPs. (b and c) SEM images of albumin electrospun nanofibers, (d and e) the adsorption of AuNPs on the albumin nanofibers. ${ }^{126}$

mesenchymal stem cells. Wei and co-workers revealed that after the uptake of AgNPs $(30 \mathrm{~nm})$ in hMSCs, apoptosis, necrosis, DNA damage, and reactive oxygen species increased and cell viability decreased (Table 2). ${ }^{149}$

5.1.3. Titanium dioxide. Titanium dioxide nanoparticles $\left(\mathrm{TiO}_{2}\right.$ NPs) are made in large quantities globally, which can be used in a variety of applications due to their anti-corrosive, high stability, and photocatalytic characteristics. Recently, a variety of techniques have been used to synthesize $\mathrm{TiO}_{2}$ NPs such as the sol-gel methods, reverse micelles, chemical vapor deposition, etc. ${ }^{152}$ These nanoparticles are being studied in the field of nanomedicine as a beneficial tool in advanced imaging and nanotherapeutics. ${ }^{153}$ Several studies have revealed that $\mathrm{TiO}_{2}$ NPs can be utilized in various biodegradable polymers as good filler materials since they can enhance cell attachment and proliferation. Moreover, unique physicochemical characteristics make $\mathrm{TiO}_{2}$ NPs suitable for controlling cellular behavior such as migration and differentiation of stem cells. ${ }^{154}$ In vivo studies showed the systemic distribution of $\mathrm{TiO}_{2}$ NPs to all tissues and organs in the body after the initial absorption. ${ }^{155}$ Due to the growing use of $\mathrm{TiO}_{2} \mathrm{NPs}$ in tissue engineering, the study of toxicity is crucial. For instance, Jawad and coworkers investigated the cellular toxicity of $\mathrm{TiO}_{2} \mathrm{NPs}$ on three different cardiac cell types including fibroblasts, adult rat ventricular cardiomyocytes, and human embryonic stem cellderived cardiomyocytes (hESC-CM). The Lowest test dose of $\mathrm{TiO}_{2} \mathrm{NPs}\left(10 \mathrm{mg} \mathrm{mL}^{-1}\right)$ showed a reduction in the beating rate of hESC-CM, but there was no significant impact on myocyte cell viability or the acute contractility of the myocytes observed in 24 hours. The cultivation of fibroblasts in $5-150 \mathrm{mg} \mathrm{mL}^{-1}$ $\mathrm{TiO}_{2}$ NPs stimulated cell death and decreased cell proliferation significantly in 4 days. However, There were no arrhythmias or discontinuation of the beating in three different cell types. ${ }^{156}$ It should be noted that the toxicity effect of $\mathrm{TiO}_{2} \mathrm{NPs}$ highly depends on various factors such as concentration and exposure time, which could affect cellular behavior by the activation or suppression of related cell signaling pathways. ${ }^{157}$ The inflammatory reaction generated by $\mathrm{TiO}_{2} \mathrm{NPs}$ is known to be one of the major causes of cardiovascular system dysfunction. In a recent study, Zhang et al. investigated the mechanism of cardiovascular toxicity induced by dermal exposure to $\mathrm{TiO}_{2}$ NPs. This study displayed that $\mathrm{TiO}_{2}$ NPs treatment highly elevated the reactive oxygen species and 8-hydroxy-2'deoxyguanosine. Besides, it increased the inflammatory biomarker rates, such as soluble intercellular adhesion molecule-1, immunoglobulin E, hypersensitive C-reactive protein, and interleukin-8. Furthermore, exposing human umbilical vein endothelial cells (HUVECs) to $\mathrm{TiO}_{2}$ NPs reduced cell viability and caused a rise in caspase- 3 levels, which induced cytotoxicity and cell apoptosis. ${ }^{158}$ In another study, Hong and coworkers revealed that the exposure of mice to $\mathrm{TiO}_{2}$ NPs for six months, damaged the heart muscle by disrupting the cytokine expression link to Th1 or Th2. ${ }^{159}$ Chen and colleges investigated the effect of $\mathrm{TiO}_{2} \mathrm{NPs}$ on the cardiovascular system after oral intake. After regular gastrointestinal administration of $\mathrm{TiO}_{2}$ NPs $\left(0,2,10,50 \mathrm{mg} \mathrm{kg}{ }^{-1}\right)$ for 30 and 90 days, they investigated the rate of heart injury by measuring the heart rate, biochemical parameters in the blood, cardiac histopathology, and blood pressure. $\mathrm{TiO}_{2}$ NPs exposure increased the inflammatory responses such as increased concentrations of interleukin 6, tumor necrosis factor $\alpha$, white blood cells count, and granulocytes. Even low concentrations of $\mathrm{TiO}_{2}$ NPs can cause harmful cardiovascular effects after 30 days or 90 days of oral exposure. ${ }^{157}$ However, $\mathrm{TiO}_{2}$ nanofilm showed good blood cells, endothelial cells, and smooth muscle cells compatibility in a work by Xiang and coworkers. ${ }^{160}$ Moreover, it has been shown that $\mathrm{TiO}_{2}$ nanotubes provide a favorable template for bone growth and differentiation but there is no evidence of favorable cell proliferation and differentiation in cardiovascular tissue reconstruction (Table 3). ${ }^{161}$ 
Table 1 A summary of gold nanomaterials, which impact cellular behavior, and their applications in cardiac tissue engineering

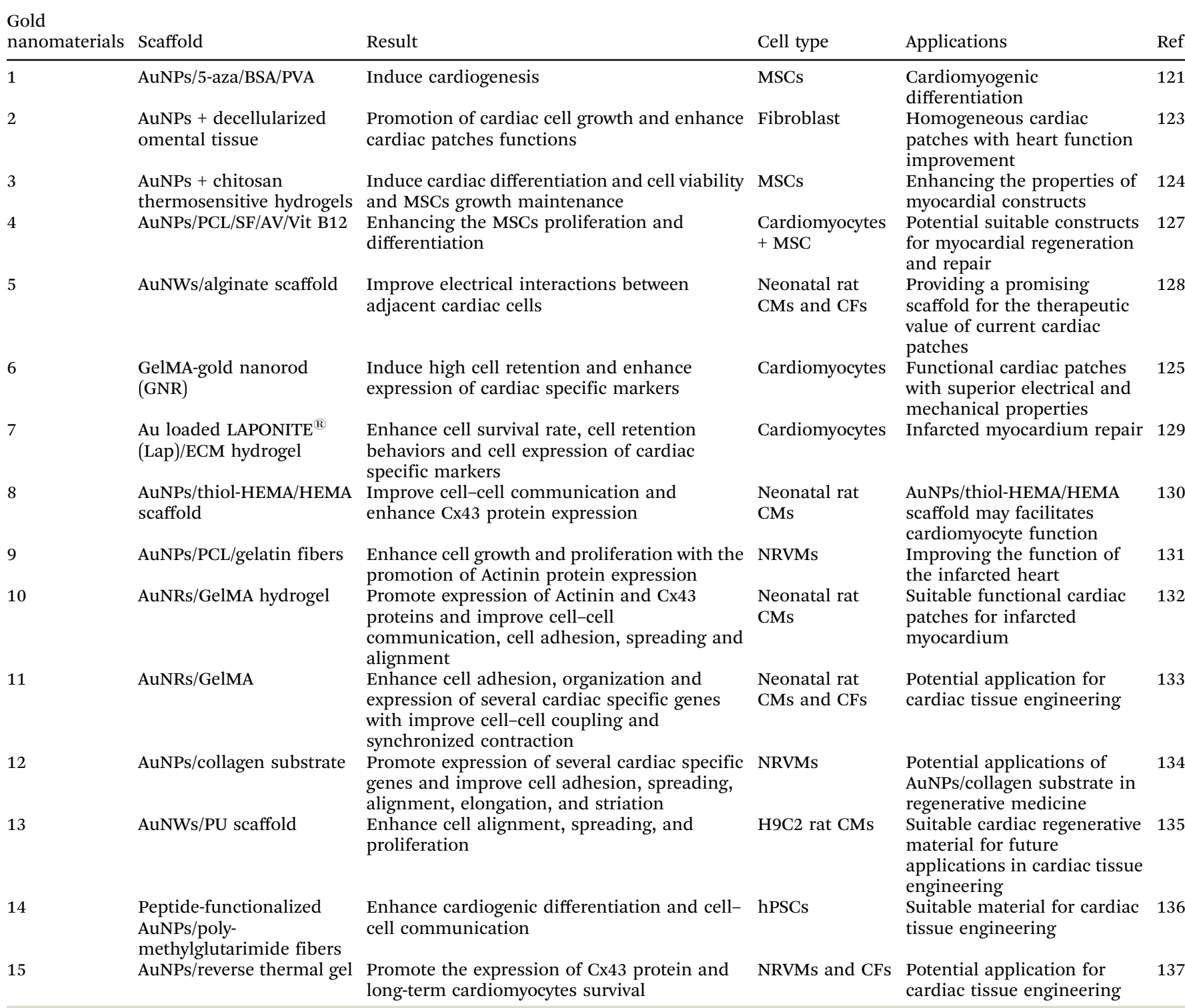

Table 2 Applications of silver nanomaterials in cardiac tissue engineering

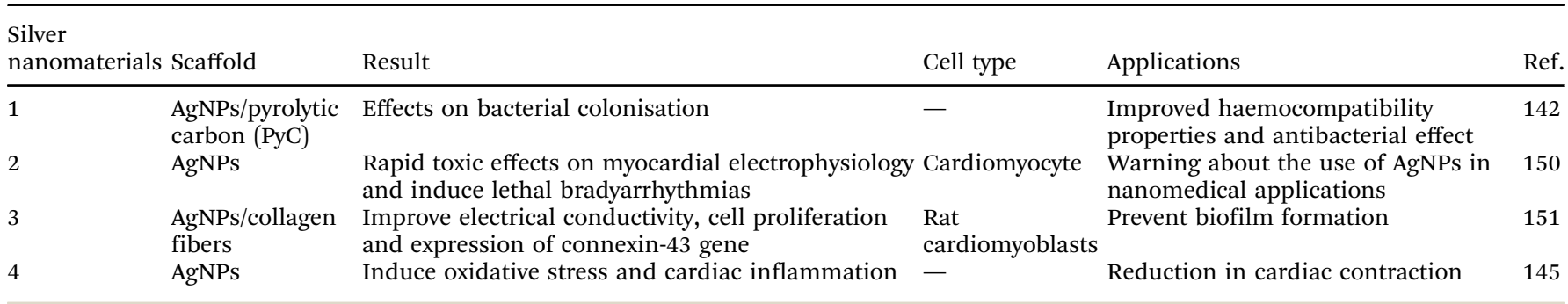

5.1.4. Magnetic nanoparticles. Magnetic nanoparticles (MNPs) are one of the important classes of nanomaterials, which have potential applications in nanomedicine. MNPs are synthesized using several methods such as thermal decomposition, microwave-assisted method, chemical vapor deposition, combustion, carbon arc, laser pyrolysis, etc. ${ }^{165}$ MNPs can be detected and controlled by magnetic fields, which opens up a wide range of possibilities for their clinical usage. MNPs have been utilized for a variety of clinical applications including the delivery of drugs and genes, magnetic imaging, 
Table 3 Titanium dioxide nanomaterials applied in cardiac tissue engineering

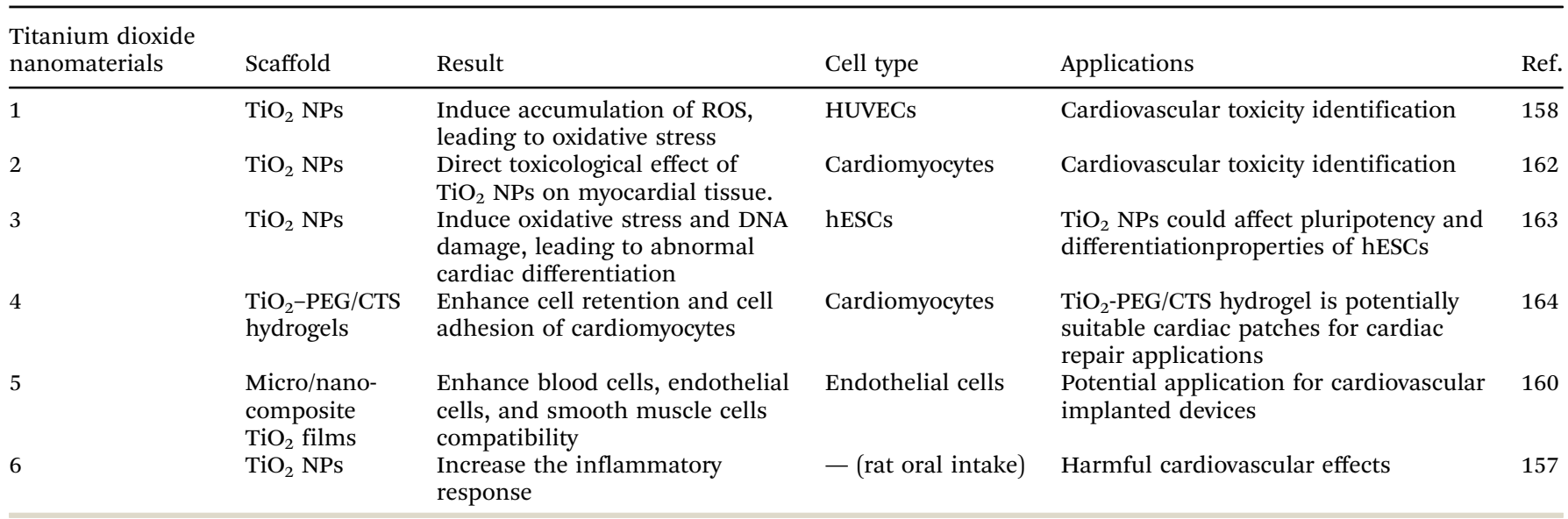

and hyperthermic treatment. ${ }^{166}$ Iron oxide magnetic nanoparticles (IONPs) have crucial diagnostic properties in clinical applications. The regulation of synthetic procedures, such as surface functionalization, size, and magnetization, is crucial for contributing to specific properties such as stability, physicochemical properties, and biological fate. ${ }^{167}$ Recently, several studies reported the tracking of stem cell fate by IONPS conjugated growth factors. ${ }^{168-170}$ Moreover, iron oxide NPS showed HRP and catalase-like activity that can reduce ROS due to their antioxidant properties. Furthermore, IONPs have been utilized in regenerative medicine and tissue engineering applications. ${ }^{171,172}$ Huang et al. showed the beneficial impression of Ferucarbotran nanoparticle labeling on human mesenchymal stem cell (hMSCs) proliferation. Superparamagnetic iron oxide (SPIO) nanoparticles have an intrinsic peroxidase-like activity that can decrease intracellular $\mathrm{H}_{2} \mathrm{O}_{2}$. After internalization into hMSCs, it increases the progression of the cell cycle regulation by the free iron released from lysosomal degradation. ${ }^{173}$ Moreover, IONPs are beneficial tools for cardiovascular protection. In a study by Xiong and co-workers, a rat coronary artery ligature model was used to evaluate the effect of 2,3dimercaptosuccinic acid-modified $\mathrm{Fe}_{2} \mathrm{O}_{3}$ NPs in cardiovascular disease. This study showed that IONPs, which can preserve the heart from ischemic injuries under in vitro and in vivo conditions without toxic effect, are a clinically good candidate for the treatment of cardiovascular disease. ${ }^{174}$ In a different study, Han and co-workers used IONPs to stimulate the cardiac mesenchymal stem cell differentiation. In this research, the H9c2 cardiomyocytes that were treated with IONPs were cocultured with MSCs. The internalization of IONPs in H9c2 increased the Cx43 expression, which is an important factor to trigger gap junctional signaling pathways and improve communications with hMSCs. The expression of cardiacspecific genes increased in hMSCs, which induced the cardiac differentiation; thereafter, H9c2 cells were separated from differentiated hMSCs, and they were utilized to treat the myocardial infarction by the reduction of the ventricle diameter and the systole and diastole time in a rat model. ${ }^{175}$ Recently, superparamagnetic IONPs were used for the labeling of MSCs for cardiac tissue regeneration. IONPs were PEGylated and then IONP-labeled MSCs were administered in a rat model with cardiac disease. The MRI was employed to track MSCs labeled with IONPs, and they utilized a magnetic field for the targeted delivery of IONPs to the heart. In the presence of the magnetic field, myocardial hypertrophy and heart function improved by utilizing SPION-labeled MSCs, but fibrosis formation was reduced. ${ }^{176}$ Moreover, IONPs can be used in the embedded scaffold structures for cardiovascular tissue engineering. For instance, Mou and co-workers treated the cardiomyocytes with different concentrations of 2,3-dimercaptosuccinic acid (DMSA)-modified IONPs. After the internalization of IONPs into the cells, IONPs showed peroxidase-like activity, which decreased ROS levels in the cardiomyocytes. DMSAIRONs peroxidase-similar activity imposed positive effects for enhancing the myocardial infarction remodeling (Fig. 7). ${ }^{177}$ Another study showed that the supplementation of DMSAcoated IONPs with cardiomyocytes led to the overexpression of Cx43 in the cells, which promoted gap junctions, desmosomes, and adherent junctions between the cardiomyocytes (Table 4$).{ }^{178}$

\subsection{Carbon-based nanomaterials}

5.2.1. CNTS. Carbon nanotubes (CNTs) are carbon allotropes with the $2 \mathrm{D}$ graphene sheet rolled into a cylinder to form 1D nanoscale structures, which were discovered in $1991 .^{181}$ Generally, CNTs can be classified into two types: single-walled carbon nanotubes (SWCNT) and multi-walled carbon nanotubes (MWCNT). Depending on the synthesis conditions, the diameter of SWCNTs is usually less than $1 \mathrm{~nm}$, while the diameter of MWCNTs is $1.4 \mathrm{~nm}$ to $100 \mathrm{~nm}$, due to the multiple one-atom-thick sheets of carbon. ${ }^{182,183}$ Carbon nanotubes have unique properties such as mechanical and thermal transfer features, tensile strength, and electrical conductivity, ${ }^{184,185}$ which make them excellent candidates for drug delivery, ${ }^{186}$ cancer therapy, ${ }^{187}$ immunostimulatory activity, ${ }^{188}$ biosensors, ${ }^{189}$ gene delivery ${ }^{190}$ regenerative medicine, and tissue engineering applications. ${ }^{191}$ Several methods have been utilized for synthesizing CNTs such as the electric arc discharge method, ${ }^{192}$ laser 
A

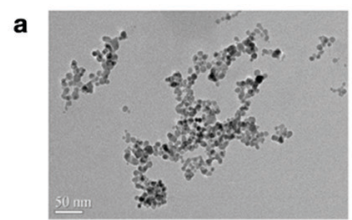

B
$\mathbf{a}$

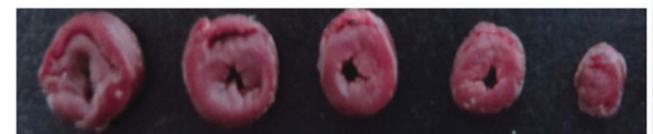

b

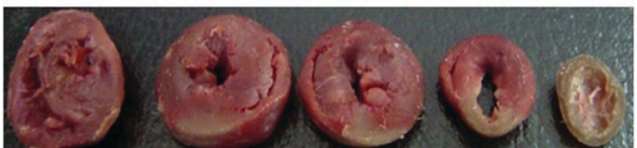

c
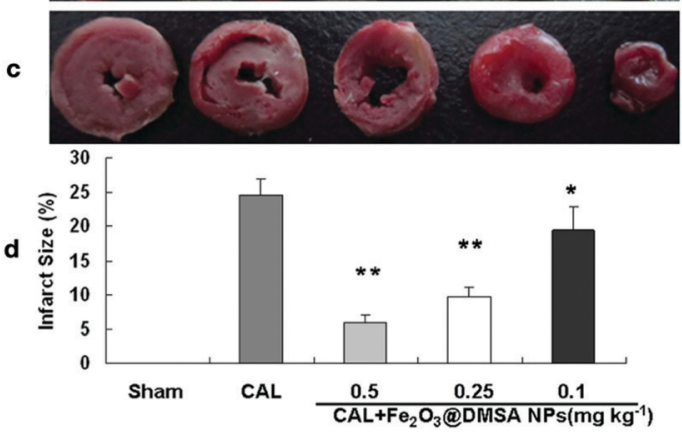

C a
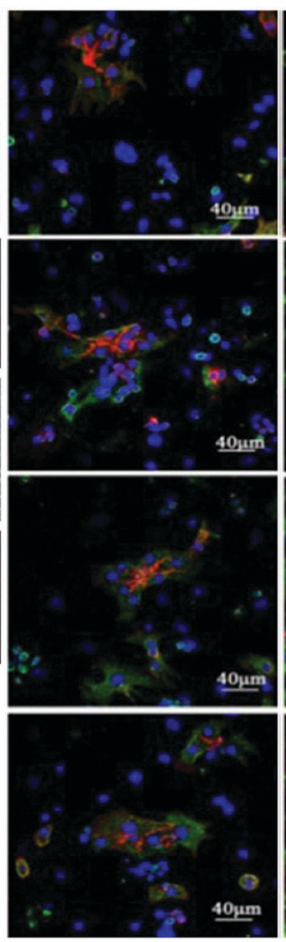

b

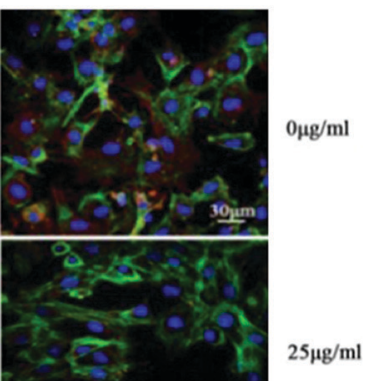

Fig. 7 (A-a) TEM image of $\mathrm{Fe}_{2} \mathrm{O}_{3} \mathrm{QDMSA}$ NPs $\left(9.8 \mathrm{~nm}\right.$ ). (b) TEM image of $\mathrm{Fe}_{2} \mathrm{O}_{3}$ @DMSA NPs $(35.2 \mathrm{~nm})$. (B) Heart sections stained with triphenyl

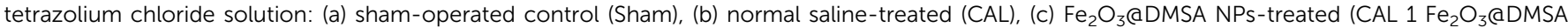
NPs). (d) Different sizes of the infarcted area in the heart sections in different groups. (C-a) The effects of different concentrations of iron oxide modified with 2,3-dimercaptosuccinic acid (DMSA-IRONs) on cardiomyocytes with double immunofluorescence staining ( $\alpha$-actinin (green) and connexin 43 (red) nucleus (blue)). (b) The effects of different concentrations of DMSA-IRONs on cardiomyocytes with double immunofluorescence staining (phalloidin (green) and N-cadherin (red) nucleus (blue)). ${ }^{174,177}$ Reproduced from ref. 174 with permission from John Wiley and Sons, Copyright 2015.

Table 4 Magnetic nanomaterials used applications in cardiac tissue engineering

\begin{tabular}{|c|c|c|c|c|c|}
\hline $\begin{array}{l}\text { Magnetic } \\
\text { nanomaterials }\end{array}$ & Scaffold & Result & Cell type & Applications & Ref. \\
\hline 1 & IONPs & $\begin{array}{l}\text { Increase expression of cardiac-specific genes in } \\
\text { hMSCs and cardiac differentiation }\end{array}$ & MSCs + cardiac cells & $\begin{array}{l}\text { Good candidate for the treatment } \\
\text { of cardiovascular disease without } \\
\text { toxic effect }\end{array}$ & 29 \\
\hline 2 & PEG-SPIONs & $\begin{array}{l}\text { SPION-labeled MSCs in the presence of magnetic } \\
\text { field might be able to improve cell homing of MSCs } \\
\text { in the site of injury }\end{array}$ & MSCs & $\begin{array}{l}\text { SPION-labeled MSCs could } \\
\text { contribute to improvement of } \\
\text { cardiac functions }\end{array}$ & 176 \\
\hline 3 & IONPs & $\begin{array}{l}\text { Enhance gap junctional communication between } \\
\text { MSC and the cardiomyblast via activation of } \\
\text { connexin- } 43\end{array}$ & hBM-MSCs & $\begin{array}{l}\text { Potential therapeutic effect of } \\
\text { IONP-cocultured MSCs }\end{array}$ & 175 \\
\hline 4 & IONPs & $\begin{array}{l}\text { Labeling hBM-MSCs with IONP retain cell viability, } \\
\text { proliferation rate and cardiogenic differentiation of } \\
\text { hBM-MSCs }\end{array}$ & hBM & $\begin{array}{l}\text { IONP-labeled hBM-MSCs is safe } \\
\text { and can be used in regenerative } \\
\text { medicine }\end{array}$ & 179 \\
\hline 5 & SF/SPION-casein & $\begin{array}{l}\text { Enhance the expression of cardiac functional genes } \\
\text { in ECCs and supports cardiac differentiation }\end{array}$ & $\begin{array}{l}\text { Mouse embryonic } \\
\text { cardiac cells (ECCs) }\end{array}$ & $\begin{array}{l}\text { Promising candidate for } \\
\text { functional cardiac tissue patches }\end{array}$ & 180 \\
\hline
\end{tabular}

ablation method, ${ }^{193}$ and chemical vapor deposition. ${ }^{194}$ The heart tissue is made up of collagen and elastin fibers that make a specific molecular network that provides unique electrical and mechanical properties for the heart. ${ }^{195}$ It has been demonstrated in recent years that tissue engineering scaffolds containing electrically conductive nanomaterials can mimic the myocardial ECM. ${ }^{196}$ Among all the conductive nanomaterials, CNTs have received special attention in recent years due to their unique electrical conductivity, topographical, and mechanical properties. ${ }^{197}$ Despite the above-mentioned spectacular properties of CNTs, the biocompatibility and direct utilization of these nanomaterials are controversial. Several studies suggest that the aggregation and agglomeration of CNTs could cause the toxicity and poor dispersibility of CNTs in polar solvents. ${ }^{198-200}$ To overcome these limitations and further improve the electrical and mechanical properties of these nanostructured materials, many studies have incorporated the CNTs into various polymeric scaffolds for cardiac tissue engineering. ${ }^{201,202}$ For 
instance, Dominguez et al. utilized a vapor phase polymerization (VPP) technique, which is widely used to deposit thin film layers of conductive polymers such as poly(3,4ethylenedioxythiophene) (PEDOT) or PPy onto non-conductive substrates to provide electrical conductivity. They utilized sugar grains as a porogen to manufacture 3D porous scaffolds composed of PEDOT and CNT. The results showed that the impedance of PEDOT/CNT $\left(\left|Z_{\text {PEDOT/CNT }}\right|=6 \mathrm{k} \Omega\right)$ scaffolds at 0.1 $\mathrm{Hz}$ was significantly lower than PDMS/CNT $\left(\left|Z_{\mathrm{PDMS} / \mathrm{CNT}}\right|=50\right.$ $\mathrm{k} \Omega$ ) and the naked electrode filled with PBS solution as the electrolyte $\left(\left|Z_{\mathrm{PBS}}\right|=90 \mathrm{k} \Omega\right)$. The result showed that PEDOT/CNT scaffolds are highly conductive with tunable electrical and mechanical properties, which can play a major role in electroactive cell growth. ${ }^{203}$ Another study by Martinelli et al. showed that CNTs can be utilized as scaffolds to encourage the growth of cardiomyocytes, the formation of the functional syncytium, and electrophysiological maturation. They developed an elastomeric scaffold made of MWCNTs integrated into polydimethylsiloxane (PDMS) containing micrometric cavities. They found that the 3D-PDMS + MWCNT can promote cell viability, proliferation, and functional maturation of cardiac myocytes. $^{204}$ In another study, Ahadian and colleagues described the incorporation of MWCNTs into polymer 124, which enhanced the electrical conductivity, swelling ability, and tissue maturity. This scaffold showed an improvement in the excitation threshold of materials with $0.5 \%$ CNT content $(3.6 \pm$ $\left.0.8 \mathrm{~V} \mathrm{~cm}^{-1}\right)$ as compared to materials with $0 \%\left(5.1 \pm 0.8 \mathrm{~V} \mathrm{~cm}^{-1}\right)$ and $0.1 \%\left(5.0 \pm 0.7 \mathrm{~V} \mathrm{~cm}^{-1}\right)$, suggesting greater tissue maturity. ${ }^{205}$ Furthermore, CNTs can be integrated into hydrogels, which can increase their biocompatibility and electrical activity. ${ }^{206}$ Hydrogel matrices have been widely developed for tissue engineering purposes. Various properties of hydrogels such as chemical, physical, and mechanical properties can be modified, which provide unique opportunities to enhance cell adhesion and cell viability for myocardium repair. ${ }^{207,208}$ For the first time, a study in 2014 proved that electroconvulsive therapies (ECTs) based on CNTs could improve heart function. A SWCNT $\left(1.5 \mathrm{mg} \mathrm{mL} \mathrm{mL}^{-1}\right) /$ gelatin hydrogel was constructed to provide a microenvironment that promotes cardiac contractility, the formation of a gap junction, the expression of electrochemically associated proteins in vitro, and enhanced cardiac function in vivo. ${ }^{201}$ Furthermore, several studies revealed that CNT incorporation in natural hydrogels like collagen with enhanced elastic modulus could support the growth of cardiomyocytes to increase the mechanical strength and electrical performance for cardiac tissue engineering. ${ }^{86}$ For example, Sun et al. demonstrated that the incorporation of SWCNTs embedded in small concentrations (1 $\mathrm{wt} \%$ ) within collagen hydrogels can promote cell adhesion, cell elongation, cell alignment, and the assembly of neonatal rat ventricular cardiomyocytes (NRVM). However, cell viability was significantly decreased with concentrations of CNTs up to $2 \mathrm{wt} \%$, suggesting that higher concentrations of CNTs incorporated within hydrogels showed cell toxicity. The CNT/collagen-hydrogel platform led to improved mechanical contraction potential and better functionality of cardiac constructs. ${ }^{206}$ Recent advances in tissue engineering by various methods for the fabrication of polymeric scaffolds have significantly improved our ability to mimic native cardiac tissue. Among them, electrospinning is well known for its capability of mimicking the fibrillary structure of the myocardial ECM to promote cardiomyogenesis and the tunability of the $3 \mathrm{D}$ architecture of the biodegradable scaffolds for the effective propagation of electric potential among the cardiomyocytes..$^{209,210}$ For example, GelMA-coated CNTs were incorporated into PGS/gelatin electrospun nanofibers to produce a CNT polymeric hybrid composite as a graft for cardiac tissue constructs. In another study, Shin and colleagues fabricated aligned CNT forest microelectrode arrays, which were embedded into flexible and biocompatible hydrogels. This construct showed excellent anisotropic electrical conductivity with control over the actuation behavior. After culturing the cardiomyocyte for 5-8 days, the cells showed homogeneous cell organization (homogenous Cx-43 distribution), with improved cell-cell interactions, and maturation (Fig. 8). ${ }^{211}$ Furthermore, Kharaziha et al. reported that the incorporation of 1.5\% CNTs within the PG nanofibrous scaffolds (aligned CNT-PG hybrid scaffold) significantly enhanced the fiber alignment and improved the electrical conductivity and mechanical properties of the scaffolds, which showed enhanced beating qualities (3.5-fold lower excitation threshold and 2.8-fold higher maximum capture rate) for the cultured cardiac tissue. ${ }^{212}$ In a related study, Liu et al. used the coaxial electrospinning technique to fabricate highly aligned and hybrid fibers $(D=2-3 \mu \mathrm{m})$ through the incubation of $3 \%$ MWCNTs (10-20 $\mathrm{nm}$ in diameter, 10-20 $\mu \mathrm{m}$ in length) in poly(ethylene glycol)-poly(D,L-lactide) copolymers (PELA) $\left(M_{\mathrm{w}}=\right.$ $\left.42.3 \mathrm{kDa}, M_{\mathrm{w}} / M_{\mathrm{n}}=1.23\right)$ to increase electrical conductivity and promote cell growth, cell viability, cell elongation and synchronous beating rates for cardiomyocytes (reached $75 \pm 8{\text { times } \text { min }^{-1} \text { ). }}^{213}$ Despite all the CNTs applications in the biomedical field, different studies have confirmed their various levels of toxicity. ${ }^{214-216}$ Besides the effect of concentration and shape dependency, SWCNTs can produce more cytotoxicity as compared to MWCNTs. $^{217,218}$ Moreover, several investigations have reported that high concentrations of CNTs could be toxic to cardiomyocytes. ${ }^{219,220}$ However, the main cause of these toxicities is mostly related to the structural, physical, and surface properties of CNTs. Therefore, surface modifications can significantly improve the biocompatibility of these nanomaterials. ${ }^{221,222}$ Furthermore, other techniques such as the use of certain enzymes, functionalization of the surface, and improving the biodegradability by incorporating with polymeric scaffolds or hydrogels can effectively eradicate or reduce the toxicity of CNTs (Table 5).$^{80}$

5.2.2. Graphene-based nanomaterials. Graphene-based nanomaterials (GBNs) have a two-dimensional carbon structure and were developed as a novel class of material with remarkable physicochemical properties and various applications. ${ }^{239,240}$ The GBNs include several graphene structures, such as graphene oxide (GO), reduced graphene oxide (RGO), graphene nanosheets, few-layered graphene (FLG), and ultra-thin graphite, which have different variations in surface properties, purity, size, and lateral dimensions. Various methods can be used for the preparation of GBNs depending on their applications, such as micromechanical cleavage, chemical vapor deposition, epitaxial 


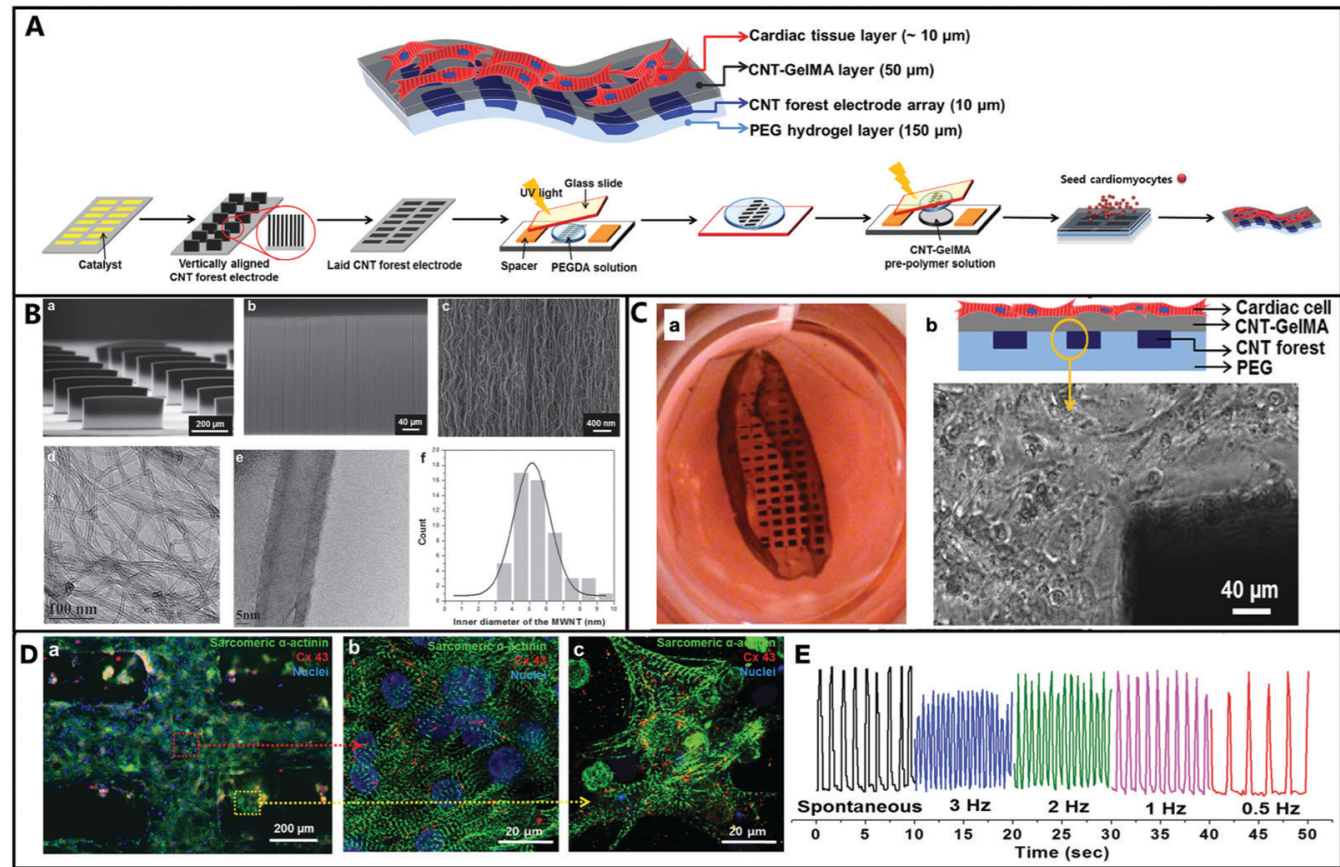

Fig. 8 (A) A Schematic illustration of the fabrication steps to generate vertically aligned CNT forest micro-electrode arrays in multilayer hydrogel sheets to engineer cardiac tissue-based 3D biohybrid actuators. (B) SEM images of (a) thin-film arrays with the uniform alignment of the CNT micro-electrode (460 $\mu \mathrm{m}$ width, $300 \mu \mathrm{m}$ height, $50 \mu \mathrm{m}$ thick, and $200 \mu \mathrm{m}$ space between each micro-electrode); (b) the magnified surface of the CNT forest microelectrode; (c) the 3D interconnected network of CNT with tortuous morphology. (B- $d$ and e) High-resolution transmission electron microscopy (HRTEM) was utilized to characterize the diameter distribution of CNTs inside the CNT forests. (B-f) The distribution of the inner diameter of the MWNTs in the CNT forests. (C-a) Freestanding 3D biohybrid actuator image with an average beating rate of 108 BPM on day 8. (C-b) A side-view schematic illustration of the multilayer hydrogel sheet saturated with aligned CNT microelectrodes and the phase contrast image of the boundary between the CNT forest electrodes boundary and the hydrogel layer. (D) Immune staining of cardiac cells on CNT-GelMA (sarcomeric $\alpha$-actinin (green), nuclei (blue), and Cx-43 (red)). (E) CNT forest electrode displacement in the multilayer hydrogel sheet under electrical stimulation. ${ }^{211}$ Reproduced from ref. 211 with permission from John Wiley and Sons, Copyright 2015.

growth on silicon carbide, electrochemical synthesis, total organic synthesis, and other methods. ${ }^{241}$ Graphene can be functionalized with various molecules since it has great surface chemical properties that enhance its variety of applications. ${ }^{242}$ GBNs are expected to exhibit specific interaction with biomolecules, cells, and tissues based on their number of layers, chemical functionality, dimensions, hydrophilicity, etc. The high surface area of graphene facilitates its cellular interactions. ${ }^{243}$ The specific properties of GBNs, such as high conductivity, flexibility, and adaption to smooth/rough surfaces make them ideal for the structural strengthening of tissue-based materials, and they can enhance the differentiation, proliferation, and adhesion of stem cells. For instance, functional groups of a scaffold, such as carboxyl, hydroxyl, and amine groups are crucial to regulating cell function. ${ }^{244}$

Graphene oxide is one of the most popular GBNs, and it can be easily modified due to the functional groups in its structure such as hydroxyl, carboxyl, and epoxy groups. GO can be easily converted by thermal and chemical reduction into RGO, which makes GO a successful precursor for the production of G-based composites. GO, RGO and other GBN composites can be chemically manipulated for interaction with different biological molecules such as proteins and peptides. Furthermore, GBNs have high antimicrobial activity, which promotes their function in tissue engineering by reducing infections. ${ }^{245,246}$ Besides, the hybridization of GO and RGO with other nanoparticles such as AgNPs, ${ }^{247,248} \mathrm{TiO}_{2} \mathrm{NPs}^{249}$ and, $\mathrm{Fe}_{3} \mathrm{O}_{4} \mathrm{NPs}^{250}$ can increase their antibacterial activity. All these specific features of GBNs make them a popular tool in tissue engineering. ${ }^{251,252}$

Nayak and co-workers showed the effect of graphene synthesized by chemical vapor deposition (CVD) on the enhancement of GBNs ability for the differentiation of human mesenchymal stem cells. They reported that the large-scale surface characteristics induced by the ripples in the CVD graphene play a vital role in cell adhesion and differentiation. Graphene's capacity to withstand lateral stress was thought to provide adequate local cytoskeletal resistance for differentiation of the bone stem cells. ${ }^{251}$ GBNs have shown great potential to regulate in vitro and in vivo cardiac differentiation by improving the electrical and mechanical conductivity of scaffolds and providing appropriate morphological indications. In a study by Lee et al., the vitronectin (VN)-coated graphene effect on the cardiomyogenesis of human embryonic stem cells (hESCs) was evaluated. They cultured hESCs on three different substrates including VNcoated graphene (graphene group), VN-coated glass (glass group), and glass coated with Matrigel (Matrigel group). The cultivation of hESCs on VN-graphene stimulated the expression of genes, which led to the gradual differentiation into the mesodermal and 


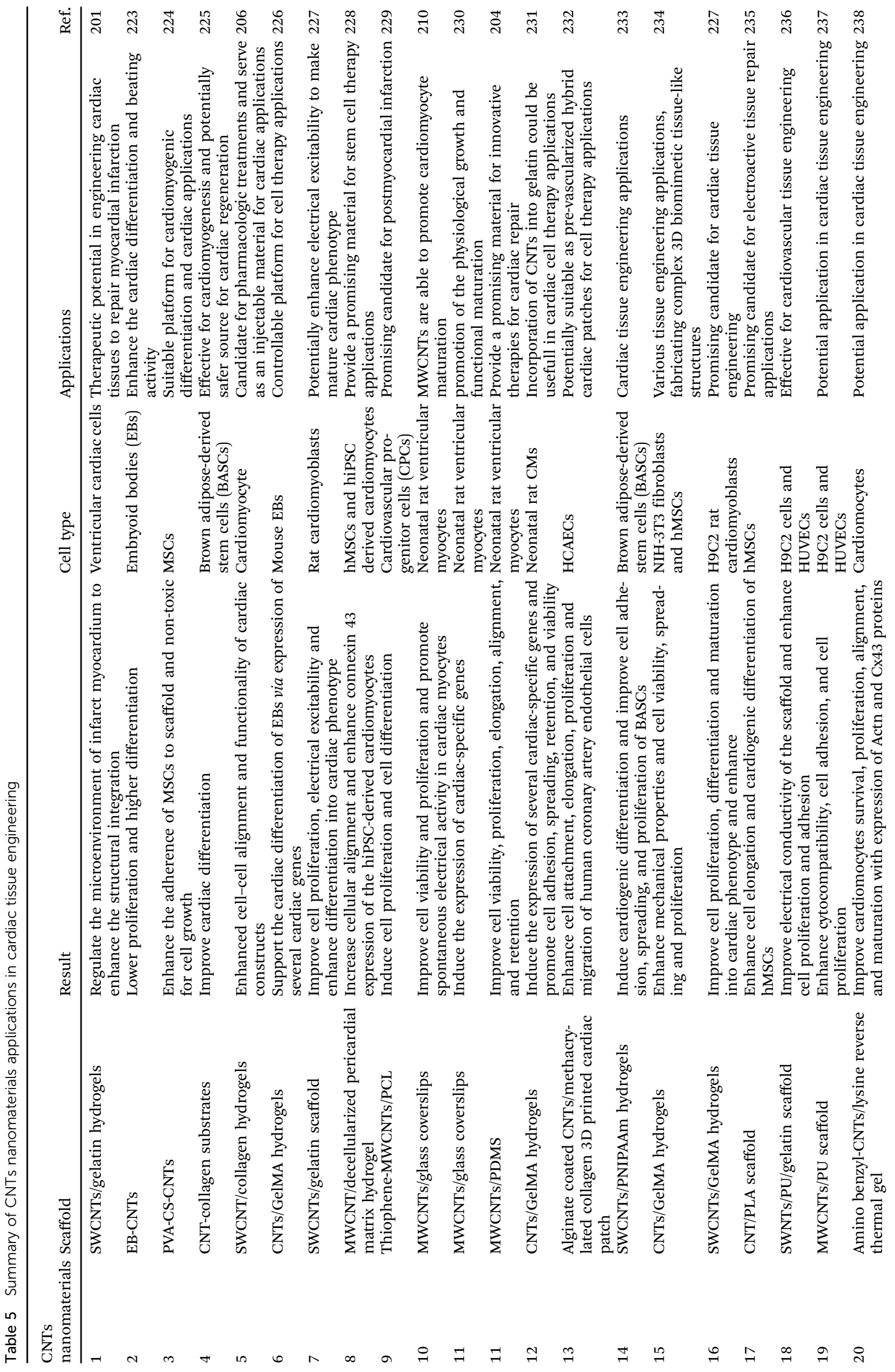


endodermal lineage. Ultimately, graphene improved the cardiomyogenic differentiation of stem cells because of its roughness and upregulation of the ERK signaling pathway. As a result, graphene can provide a new approach to stem cell therapy for ischemic heart disease by improving the cardiomyogenic differentiation of hESCs. ${ }^{253}$ In another study by Ahadian and coworkers, graphene was integrated into the structure of mouse embryoid bodies (EBs), which significantly improved the cardiac differentiation of EBs. ${ }^{254}$ Park et al. reported that MSCs coupled with GO showed excellent cell survival in vivo for cardiac repair since the GO preserved the cells against reactive oxygen species. They developed the GO flakes to protect the implanted MSCs from ROS-mediated death, thereby improving the therapeutic efficacy of the MSCs. ${ }^{255}$ In another study, RGO flakes with the thickness of 1-2 $\mathrm{nm}$ and the size range of $2-5 \mu \mathrm{m}$ were inserted into hMSC spheroids, which led to an increase in cardiac specificbiomarkers. The high electrical conductivity of RGO and hybridization of RGO with hMSCs spheroids enhanced heart repair and its function as compared to RGO alone or hMSCs alone. One of the best advantages of this hybrid method is the efficient delivery of cells to damaged tissue, and multiple pharmaceutical molecules can be loaded onto the graphene for sustainable drug release (Fig. 9). ${ }^{256}$ GBNs can combine with different scaffolds and enhance their electrical conductivity and mechanical properties. In a recent study, Norahan et al. showed different biological and antibacterial effects of RGO coating on collagen scaffolds for cardiac patch applications. They showed that rGO significantly improved the mechanical properties and the electroactivity of the collagen scaffolds $\left(1100 \pm 31 \mathrm{kPa}, 4 \times 10^{-4} \pm 1.20 \mathrm{~S} \mathrm{~m}^{-1}\right)$. Electroactive RG-collagen scaffolds enhanced the expression of

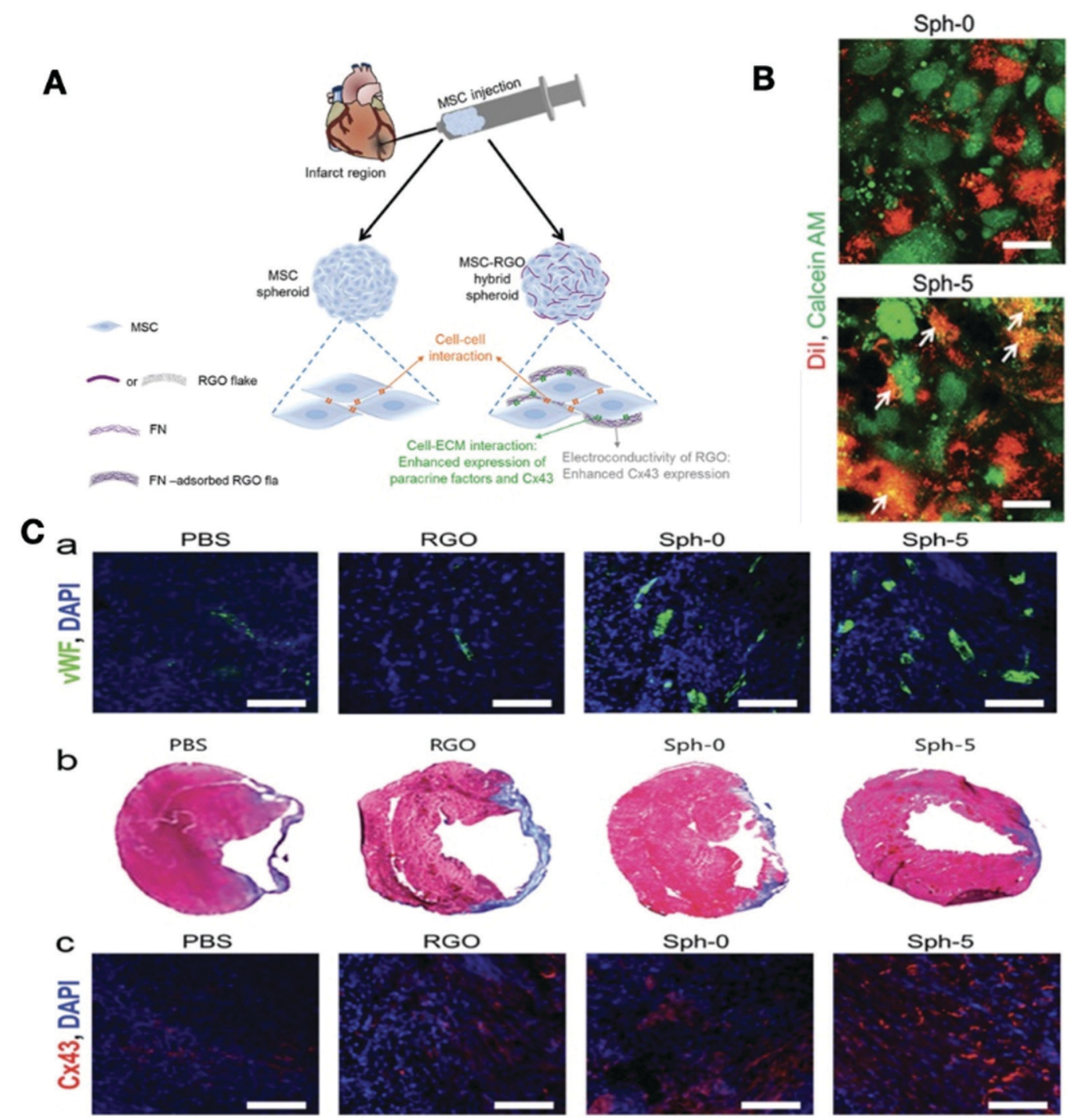

Fig. 9 (A) Schematic illustration of RGO flake and MSC spheroids for the treatment of myocardial infarction. (B) The effect of implanting MSC-RGO hybrid spheroids on cardiac function and regeneration (a) capillary density in the peri-infarct border zone assessed by immunostaining (b) Masson's trichrome staining for the indication of cardiac fibrosis (blue). (c) Expression of $\mathrm{Cx} 43$ (red) in the infarct zone by immunohistochemical staining. (C) Characterization of gap junctions in MSC-RGO hybrid spheroids with calcein-AM (green) and Dil (red) staining (the yellow colors show the transfer from green to red). ${ }^{256}$ Reproduced from ref. 256 with permission from John Wiley and Sons, Copyright 2015. 
Table 6 Graphene-based nanomaterials applied in cardiac tissue engineering

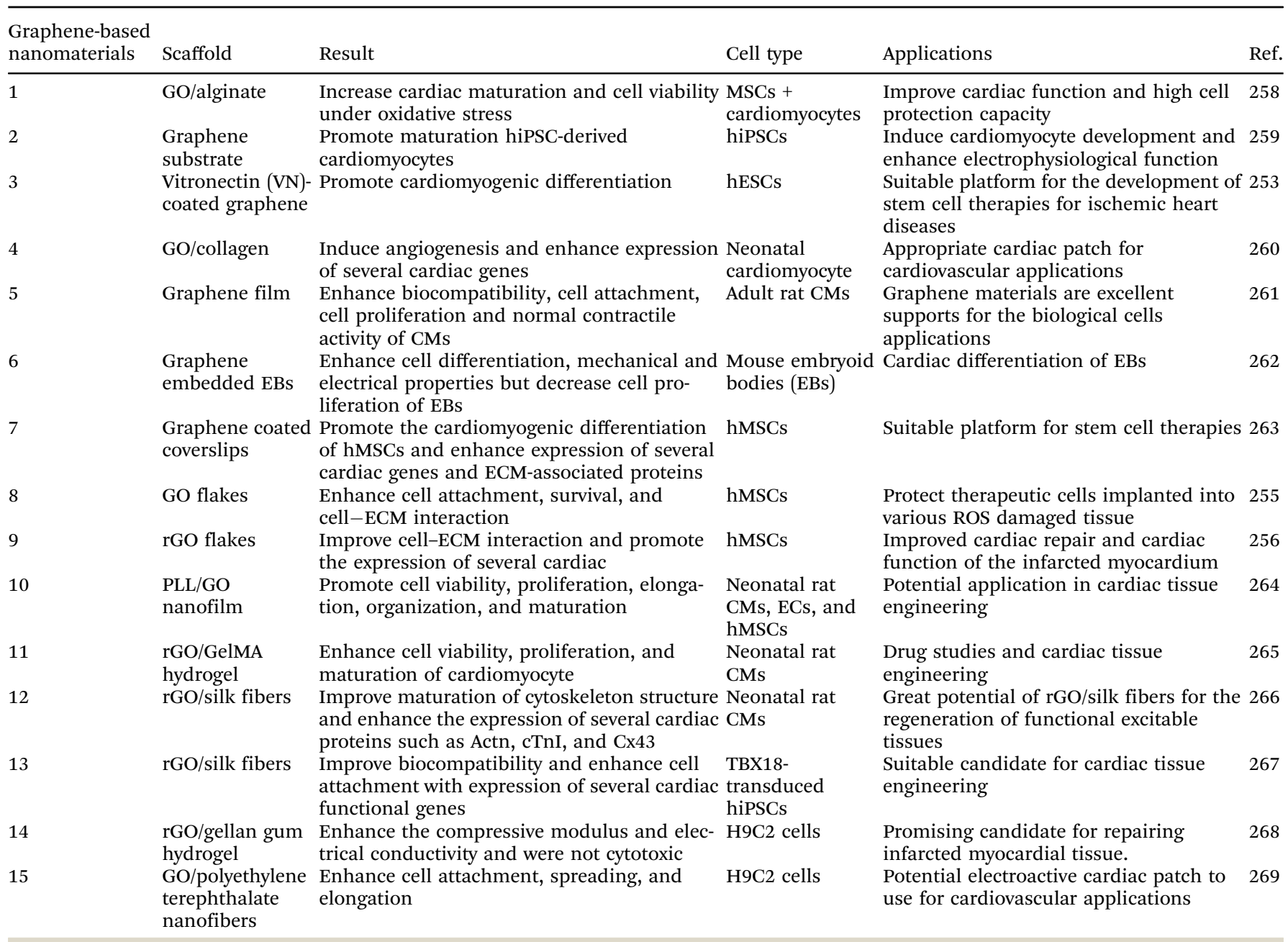

cardiac-specific genes such as $\mathrm{Cx} 43$, troponin- $\mathrm{T}$ and, actinin-4 as compared to the collagen scaffold counterpart. Also, the coating of collagen scaffolds with RGO increased the antibacterial activity against $E$. coli, $S$. aureus, and $S$. pyogenes, which could reduce the chance of infection (Table 6). ${ }^{257}$

\subsection{Polymeric nanomaterials}

One of the main aspects of tissue engineering is controlling the behavior of stem cells, which can be achieved by traditional ways such as utilizing growth factors and cell signaling molecules. However, such methods are inadequate, due to the erratic distribution, short half-life, limited tissue penetration, and enzymatic degradation of growth factors. These limitations can be overcome by the incorporation of growth and signaling factors with polymeric nanomaterials (natural or synthetic) as a vehicle for the delivery of growth factors. These factors can either load into or adsorb to the surface of various polymeric nanomaterials structures such as polymeric nanoparticles (sphere or capsules) and hydrogels. ${ }^{270,271}$ Other polymeric structures are conductive polymers such as polypyrrole and polyaniline that can be synthesized as a scaffold for cardiac tissue engineering, thereby, improving the migration, proliferation, and differentiation of cardiac cells. $^{197}$ Gelmi and coworkers investigated the culture of human iPSCs in PLGA fibers with a layer of polypyrrole (PPy). The PLGA fibers-coated PPy increased the cell viability and expression of specific cardiac markers (Actinin, Myh6, Nkx2.5, GATA4, c-kit) without any cytotoxic effects. This study showed the first application of PPy as an appropriate supportive conductive material and a dynamic mechanical stimulating fiber scaffold for hiPSCs. ${ }^{272}$ Also, some studies incorporated polyaniline into different polymers and hydrogels to produce electrically conductive scaffolds for cardiac tissue engineering. Polyaniline is one of the commonly observed conductive polymers, offering simple synthesis, controllable electrical properties, and environmental stability. ${ }^{273-275}$ Combining polyaniline with various biological materials can improve its biocompatibility. For example, Moura and co-workers functionalized polyaniline with polyglycerol dendrimers with high hydrophilicity and showed this combination increased the capacity of the scaffold to support cardiac cell adhesion and proliferation. ${ }^{276}$ In a recent study by Roshanbinfar et al., the effect of electrospun fiber mats with different conductive materials such as polyaniline, collagen, and hyaluronic acid 
A

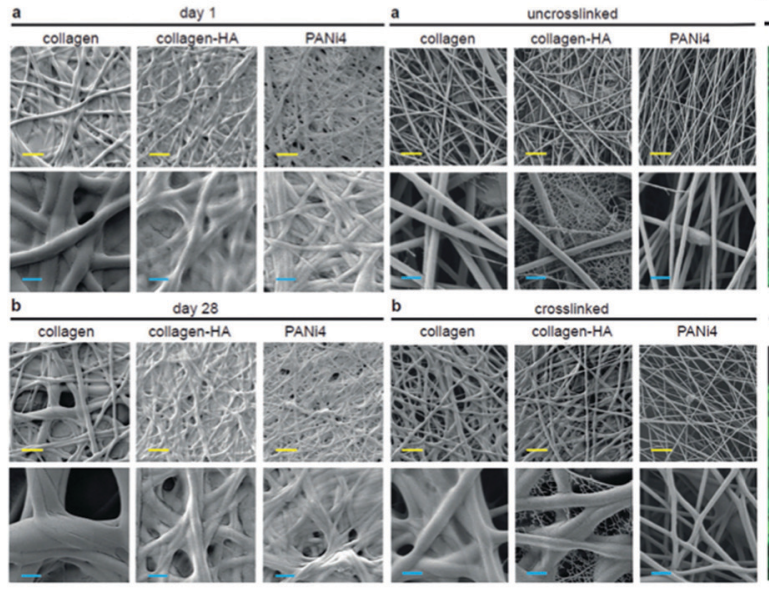

C
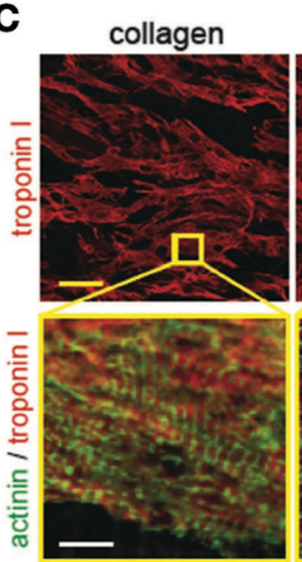

collagen-HA
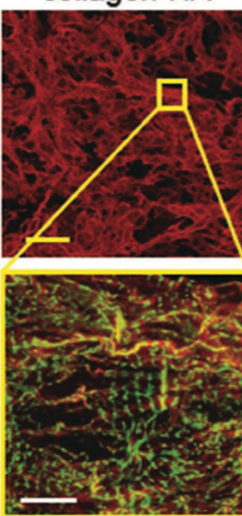

B

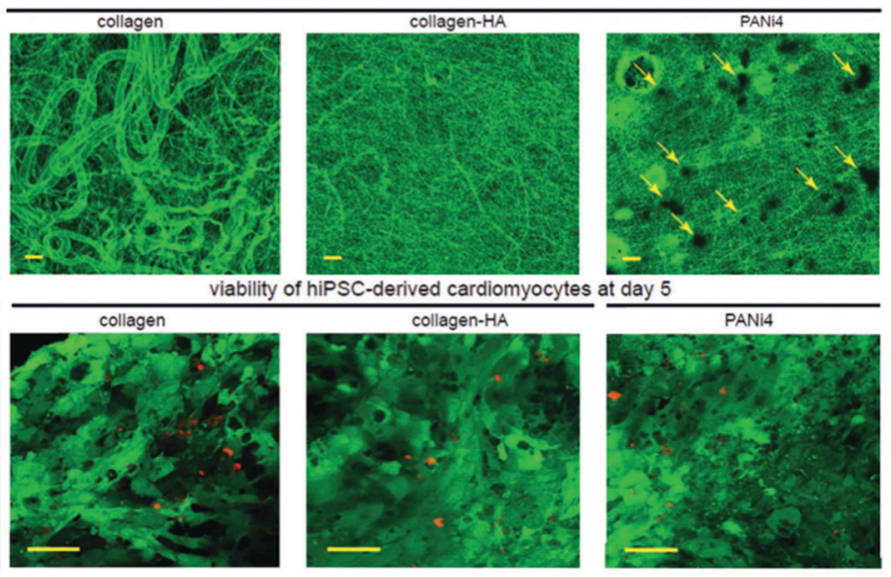

D

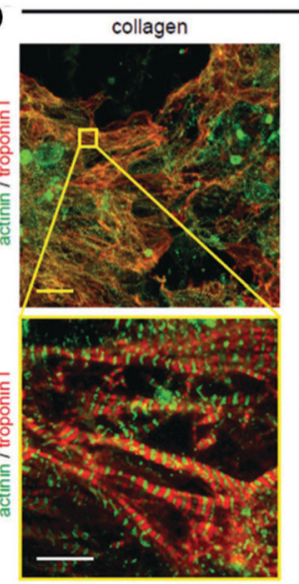

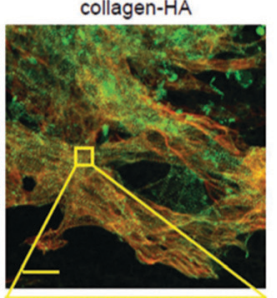

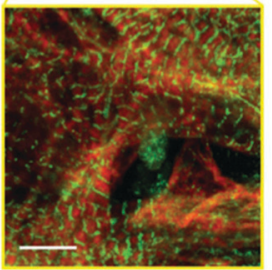

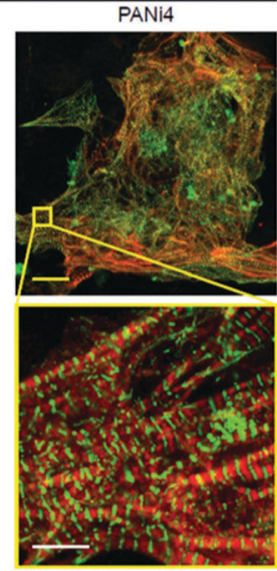

Fig. 10 (A) Morphological properties of various electrospun scaffolds. (B) Microstructure of various fiber mats with confocal microscopy (the yellow arrow shows the presence of polyaniline in the scaffold). (C) Expression of the cardiomyocyte-specific markers (troponin I, sarcomeric- $\alpha$-actinin) for neonatal cardiomyocytes cultured at day 5. (D) Confocal image of cardiomyocyte-specific markers (troponin I, sarcomeric- $\alpha$-actinin) for hiPSC-derived cardiomyocytes cultured on electrospun fiber mats at day 5. ${ }^{279}$ Reproduced from ref. 279 with permission from John Wiley and Sons, Copyright 2015.

on cardiomyocyte attachment and contraction was investigated. They tested various concentrations of polyaniline in the nanofibrous composite and showed that fiber mats containing $1.34 \%$ polyaniline had the most desirable properties, with a longer contraction time, lower beating rates, and greater contractile amplitude (Fig. 10). ${ }^{277}$ The unique feature of piezoelectric scaffolds such as polypyrrole and polyaniline in generating electric charges with little mechanical forces make them attractive in cardiac tissue engineering applications. Hitscherich and co-workers utilized a piezoelectric scaffold made

Table 7 Examples of polymeric nanomaterials applied in cardiac tissue engineering

\section{Polymeric}

nanomaterials Scaffold fibers scaffold scaffolds
Result

Collagen-HA-PANi Improve electrical conductivity and mechanical properties as the native myocardium

PLGA + simvastatin Induce proliferation and migration activities AdSCs conjugated nano- $\quad$ of hAdSCs particles (SimNPs) PANI/PCL patch

Promote the cardiomyogenic differentiation hMSCs of hMSCs

PGS/aniline trimer Enhance cell proliferation, alignment, and $\mathrm{H} 9 \mathrm{C} 2$ cells elongation of $\mathrm{H} 9 \mathrm{C} 2$ cells

Silk/PPy composite Increase cell viability cellular organization and sarcomere development PU-AP/PCL scaffold

Enhance cell prolife
several cardiac gene

\section{Cell type Applications}

Ref.

Cardiomyocytes Suitable substrates for cardiac tissue $\quad 277$ engineering

Induce endogenous cardiac regeneration 280 and improve cardiac function in myocardial infarction

PANI/PCL patch potentially enhance the 281 regeneration of damaged myocardium

Suitable polymeric films for cardiac tissue 282 repair and regeneration

Appropriate substrate for cardiovascular 283 applications

PU-AP/PCL scaffold is useful for tissue hPSC-derived cardiac cells

engineering and regenerative purposes 
from electrospun polyvinylidene fluoride-trifluoroethylene (PVDF-TrFE) and evaluated its effect on mouse embryonic stem cell-derived cardiomyocytes (mES-CM). They cultured mES-CM on PVDF-TrFE and showed that the expression of cardiac genes increased in the mES-CM, and these cells contracted automatically with an exhibition of well-organized sarcomeres. This study illustrated the efficacy of PVDF-TrFE scaffolds as a suitable material for the production of engineered cardiovascular tissues using stem cells (Table 7). ${ }^{278}$

\section{Conclusion and future perspective}

Cardiovascular diseases that involve the heart and blood vessels have been the number one cause of death worldwide in the past few years. ${ }^{285}$ The rapid development of nanotechnology has provided various nanomaterials with diverse features. The combination of nanomaterials and stem cell research offers new approaches for the treatment of various cardiovascular diseases since the regeneration ability of cardiovascular tissues is quite limited as compared to other organs. However, various bulk and surface properties of nanomaterials can affect stem cell behavior by modulating underlying intracellular pathways. Understanding these features and their effects on cellular behavior opens up new and effective ways to take control of stem cell fate, which is crucial in designing new nanomaterials suitable for cardiac tissue engineering. The surface properties of nanomaterials can control stem cell attachment; e.g., hydrophilic surfaces enhance cell adherence and cell spreading on the surface of nanomaterials. Moreover, the surface topology is the determinant of cell arrangement and cell alignment on the surface of nanomaterials. After cell attachment, migration, proliferation, and differentiation are the next steps for directing stem cells towards cardiac cell lineage. For example, it has been shown that large pore sizes in biomaterials increase angiogenesis, cell migration, and proliferation. ${ }^{78}$ Furthermore, various properties of nanomaterials can induce the differentiation of stem cells into cardiac cells. Li et al. showed that controlling the mechanical properties is enough to induce MSCs differentiation into cardiomyocytes by designing a hydrogel with Young's modulus of $65 \mathrm{kPa} .{ }^{116}$ Nevertheless, before using nanomaterials in clinical applications, several factors should be considered thoroughly. For example, the toxicity of the nanomaterials should be investigated in depth since some nanomaterials can be quite toxic. Generally, metallic nanoparticles are more toxic as compared to other nanoparticles, and soluble nanoparticles showed more toxicity as compared to the particles that bind to a substrate. The functionalization of a substrate with metallic nanoparticles could be an efficient method for cardiovascular tissue engineering. On the one hand, the functionalization of a substrate can decrease the toxicity related to metallic nanoparticles and on the other hand, the electrical conductivity of such particles can efficiently benefit the differentiation and alignment of stem cells. Furthermore, electroconductive nanomaterials can not only mimic the myocardial ECM, they can also support the electromechanical integration of cardiomyocytes. ${ }^{197}$ In addition to metallic nanoparticles, graphene-based nanomaterials and intrinsically conductive polymers (polypyrroles, polythiophenes, poly (3,4-ethylenedioxythiophene), polyanilines, etc.) can be used in cardiovascular tissue engineering. Undoubtedly, the biocompatibility of carbon-based nanomaterials and the mechanical properties of conductive polymers should be thoroughly investigated. Numerous challenges have to be overcome to utilize nanomaterials to address CVDs treatment obstacles in clinics.

\section{Conflicts of interest}

The authors declare no conflict of interest.

\section{References}

1 R. Garcia and J. Burkle, New and Future Parenteral Therapies for the Management of Lipid Disorders, Arch. Med. Res., 2018, 49(8), 538-547.

2 A. D. Lopez, C. D. Mathers, M. Ezzati, D. T. Jamison and C. J. L. Murray, Global and regional burden of disease and risk factors, 2001: systematic analysis of population health data, Lancet, 2006, 367(9524), 1747-1757.

3 R. Beaglehole and R. Bonita, Global public health: a scorecard, Lancet, 2008, 372(9654), 1988-1996.

4 P. Lamendola, A. M. Di, L. Barone, C. Pisanello, G. A. Lanza and F. Crea, Mechanisms of myocardial cell protection from ischemia/reperfusion injury and potential clinical implications, Giornale Italiano Di Cardiologia (2006), 2009, 10(1), 28-36.

5 M. A. Laflamme and C. E. Murry, Heart regeneration, Nature, 2011, 473(7347), 326-335.

6 R. M. Mentzer, Myocardial protection in heart surgery, J. Cardiovasc. Pharmacol. Ther., 2011, 16(3-4), 290-297.

7 K. P. Rentrop and F. Feit, Reperfusion therapy for acute myocardial infarction: Concepts and controversies from inception to acceptance, Am. Heart J., 2015, 170(5), 971-980.

8 G. Vunjak-Novakovic, K. O. Lui, N. Tandon and K. R. Chien, Bioengineering Heart Muscle: A Paradigm for Regenerative Medicine, Annu. Rev. Biomed. Eng., 2011, 13(1), 245-267.

9 L. Ordovás, Y. Park and C. M. Verfaillie, Stem cells and liver engineering, Biotechnol. Adv., 2013, 31(7), 1094-1107.

$10 \mathrm{~S}$. Yokote and T. Yokoo, Stem cells in kidney regeneration, Curr. Med. Chem., 2012, 19(35), 6009-6017.

11 A. Tsukamoto, N. Uchida, A. Capela, T. Gorba and S. Huhn, Clinical translation of human neural stem cells, Stem Cell Res. Ther., 2013, 4(4), 1-13.

12 A. J. Mothe and C. H. Tator, Review of transplantation of neural stem/progenitor cells for spinal cord injury, Int. J. Dev. Neurosci., 2013, 31(7), 701-713.

13 B. Assmus, V. Schachinger, C. Teupe, M. Britten, R. Lehmann and N. Döbert, et al., Transplantation of 
progenitor cells and regeneration enhancement in acute myocardial infarction (TOPCARE-AMI), Circulation, 2002, 106(24), 3009-3017.

14 J. Bartunek, A. Behfar, D. Dolatabadi, M. Vanderheyden, M. Ostojic and J. Dens, et al., Cardiopoietic stem cell therapy in heart failure: the C-CURE (Cardiopoietic stem Cell therapy in heart failURE) multicenter randomized trial with lineage-specified biologics, J. Am. Coll. Cardiol., 2013, 61(23), 2329-2338.

15 A. Al Kindi, Y. Ge, D. Shum-Tim and R. C. Chiu, Cellular cardiomyoplasty: routes of cell delivery and retention, Front. Biosci., 2008, 13, 2421-2434.

16 C. Templin, R. Zweigerdt, K. Schwanke, R. Olmer, J.-R. Ghadri and M. Y. Emmert, et al., Transplantation and tracking of human-induced pluripotent stem cells in a pig model of myocardial infarction: assessment of cell survival, engraftment, and distribution by hybrid single photon emission computed tomography/computed tomography of sodium iodide symporter transgene expression, Circulation, 2012, 126(4), 430-439.

17 A. E. Mayfield, E. L. Tilokee, N. Latham, B. McNeill, B.-K. Lam and M. Ruel, et al., The effect of encapsulation of cardiac stem cells within matrix-enriched hydrogel capsules on cell survival, post-ischemic cell retention and cardiac function, Biomaterials, 2014, 35(1), 133-142.

18 M.-C. Hofmann, Stem cells and nanomaterials, Nanomaterial, 2014, 255-275.

19 P. Chandra and S. J. Lee, Synthetic Extracellular Microenvironment for Modulating Stem Cell Behaviors: Supplementary Issue: Stem Cell Biology, Biomarker Insights, 2015, 10, BMI.S20057.

20 F. Poustchi, H. Amani, Z. Ahmadian, S. V. Niknezhad, S. Mehrabi and H. A. Santos, et al., Combination Therapy of Killing Diseases by Injectable Hydrogels: From Concept to Medical Applications. Advanced Healthcare, Materials, 2020, 2001571.

21 S. Pacelli, P. Paolicelli, S. Petralito, S. Subham, D. Gilmore and G. Varani, et al., Investigating the role of polydopamine to modulate stem cell adhesion and proliferation on gellan gum-based hydrogels, ACS Appl. Bio Mater., 2020, 3(2), 945-951.

22 H. Amani, M.-A. Shahbazi, C. D’Amico, F. Fontana, S. Abbaszadeh and H. A. Santos, Microneedles for painless transdermal immunotherapeutic applications, J. Controlled Release, 2021, 330, 185-217.

23 H. Arzaghi, B. Adel, H. Jafari, S. Askarian-Amiri, A. S. Dezfuli and A. Akbarzadeh, et al., Nanomaterial integration into the scaffolding materials for nerve tissue engineering: a review, Rev. Neurosci., 2020, 1, DOI: 10.1515/ revneuro-2020-0008.

24 B. Fujita and W.-H. Zimmermann, Myocardial tissue engineering for regenerative applications, Curr. Cardiol. Rep., 2017, 19(9), 78.

25 Y. Yao, W. Liao, R. Yu, Y. Du, T. Zhang and Q. Peng, Potentials of combining nanomaterials and stem cell therapy in myocardial repair, Nanomedicine, 2018, 13(13), 1623-1638.
26 C. S. Wirkner and S. Richter, Circulatory system and respiration, Nat. Hist. Crustacea, 2013, 1, 376-412.

27 S. Whittemore, The circulatory system, Infobase Publishing, 2014.

28 B. Sakmann, A. Noma and W. Trautwein, Acetylcholine activation of single muscarinic $\mathrm{K}+$ channels in isolated pacemaker cells of the mammalian heart, Nature, 1983, 303(5914), 250-253.

29 Y. Yaniv, A. Ganesan, D. Yang, B. D. Ziman, A. E. Lyashkov and A. Levchenko, et al., Real-time relationship between PKA biochemical signal network dynamics and increased action potential firing rate in heart pacemaker cells: Kinetics of PKA activation in heart pacemaker cells, J. Mol. Cell. Cardiol., 2015, 86, 168-178.

30 S. Burkhard, V. Van Eif, L. Garric, V. M. Christoffels and J. Bakkers, On the evolution of the cardiac pacemaker, J. Cardiovasc. Dev. Dis., 2017, 4(2), 4.

31 M.-T. Piccoli, K. Gupta Shashi, J. Viereck, A. Foinquinos, S. Samolovac and L. Kramer Freya, et al., Inhibition of the Cardiac Fibroblast-Enriched lncRNA Meg3 Prevents Cardiac Fibrosis and Diastolic Dysfunction, Circ. Res., 2017, 121(5), 575-583.

32 F. Maiullari, M. Costantini, M. Milan, V. Pace, M. Chirivì and S. Maiullari, et al., A multi-cellular 3D bioprinting approach for vascularized heart tissue engineering based on HUVECs and iPSC-derived cardiomyocytes, Sci. Rep., 2018, 8(1), 13532.

33 W. Liang, P. Han, E. H. Kim, J. Mak, R. Zhang and A. G. Torrente, et al., Canonical Wnt signaling promotes pacemaker cell specification of cardiac mesodermal cells derived from mouse and human embryonic stem cells, Stem Cells, 2019, 38(3), 352-368, DOI: 10.1002/stem.3106.

34 F. Al Badarin, A. Aljizeeri, F. Almasoudi and M. H. AlMallah, Assessment of myocardial blood flow and coronary flow reserve with positron emission tomography in ischemic heart disease: current state and future directions, Heart Failure Rev., 2017, 22(4), 441-453.

35 K. Ashtari, H. Nazari, H. Ko, P. Tebon, M. Akhshik and M. Akbari, et al., Electrically conductive nanomaterials for cardiac tissue engineering, Adv. Drug Delivery Rev., 2019, 144, 162-179.

36 B. D. Hoit, Pathophysiology of the Pericardium, Prog. Cardiovasc. Dis., 2017, 59(4), 341-348.

37 S. Z. Chong and V. Angeli, Cavity Macrophages Get to the Heart of the Issue, Immunity, 2019, 51(1), 7-9.

38 A. Plein, A. Fantin, L. Denti, J. W. Pollard and C. Ruhrberg, Erythro-myeloid progenitors contribute endothelial cells to blood vessels, Nature, 2018, 562(7726), 223-228.

39 Y. Sheng and L. Zhu, The crosstalk between autonomic nervous system and blood vessels, Int. J. Physiol. Pathophysiol. Pharmacol., 2018, 10(1), 17-28.

40 K. Maganti, V. H. Rigolin, M. E. Sarano and R. O. Bonow, Valvular Heart Disease: Diagnosis and Management, Mayo Clin. Proc., 2010, 85(5), 483-500.

41 B. Iung and A. Vahanian, Epidemiology of valvular heart disease in the adult, Nat. Rev. Cardiol., 2011, 8(3), 162-172. 
42 R. S. Mahla, Stem cells applications in regenerative medicine and disease therapeutics, Int. J. Cell Biol., 2016, 2016, 1-24, DOI: 10.1155/2016/6940283.

43 Y.-W. Liu, B. Chen, X. Yang, J. A. Fugate, F. A. Kalucki and A. Futakuchi-Tsuchida, et al., Human embryonic stem cellderived cardiomyocytes restore function in infarcted hearts of non-human primates, Nat. Biotechnol., 2018, 36(7), 597-605.

44 R. Romagnuolo, H. Masoudpour, A. Porta-Sánchez, B. Qiang, J. Barry and A. Laskary, et al., Human embryonic stem cell-derived cardiomyocytes regenerate the infarcted pig heart but induce ventricular tachyarrhythmias, Stem Cell Rep., 2019, 12(5), 967-981.

45 A. Moretti, L. Caron, A. Nakano, J. T. Lam, A. Bernshausen and Y. Chen, et al., Multipotent embryonic isl1+ progenitor cells lead to cardiac, smooth muscle, and endothelial cell diversification, Cell, 2006, 127(6), 1151-1165.

46 C. L. Mummery, J. Zhang, E. S. Ng, D. A. Elliott, A. G. Elefanty and T. J. Kamp, Differentiation of human embryonic stem cells and induced pluripotent stem cells to cardiomyocytes: a methods overview, Circ. Res., 2012, 111(3), 344-358.

47 P. Menasché, V. Vanneaux, A. Hagège, A. Bel, B. Cholley and A. Parouchev, et al., Transplantation of human embryonic stem cell-derived cardiovascular progenitors for severe ischemic left ventricular dysfunction, J. Am. Coll. Cardiol., 2018, 71(4), 429-438.

$48 \mathrm{~K}$. Takahashi and S. Yamanaka, Induction of pluripotent stem cells from mouse embryonic and adult fibroblast cultures by defined factors, Cell, 2006, 126(4), 663-676.

49 N. Nagoshi and H. Okano, iPSC-derived neural precursor cells: potential for cell transplantation therapy in spinal cord injury, Cell. Mol. Life Sci., 2018, 75(6), 989-1000.

50 C. Perez-Terzic, Y. Ikeda and A. Terzic, Repair of Acute Myocardial Infarction by Human Stemness Factors Induced Pluripotent, Stem Cells, 2009, 120(5), 408-416, DOI: $10.1161 /$ CIRCULATIONAHA.109.865154.

51 P. C. H. Hsieh, V. F. M. Segers, M. E. Davis, C. MacGillivray, J. Gannon and J. D. Molkentin, et al., Evidence from a genetic fate-mapping study that stem cells refresh adult mammalian cardiomyocytes after injury, Nat. Med., 2007, 13(8), 970-974.

52 O. Bergmann, R. D. Bhardwaj, S. Bernard, S. Zdunek, F. Barnabé-Heider and S. Walsh, et al., Evidence for cardiomyocyte renewal in humans, Science, 2009, 324(5923), 98-102.

53 S. E. Senyo, M. L. Steinhauser, C. L. Pizzimenti, V. K. Yang, L. Cai and M. Wang, et al., Mammalian heart renewal by preexisting cardiomyocytes, Nature, 2013, 493(7432), 433-436.

54 K.-L. Laugwitz, A. Moretti, J. Lam, P. Gruber, Y. Chen and S. Woodard, et al., Postnatal isl1+ cardioblasts enter fully differentiated cardiomyocyte lineages, Nature, 2005, 433(7026), 647-653.

55 C. Bearzi, M. Rota, T. Hosoda, J. Tillmanns, A. Nascimbene and A. De Angelis, et al., Human cardiac stem cells, Proc. Natl. Acad. Sci. U. S. A., 2007, 104(35), 14068-14073.
56 J. J. H. Chong, V. Chandrakanthan, M. Xaymardan, N. S. Asli, J. Li and I. Ahmed, et al., Adult cardiacresident MSC-like stem cells with a proepicardial origin, Cell Stem Cell, 2011, 9(6), 527-540.

57 R. Gaetani, P. A. Doevendans, C. H. G. Metz, J. Alblas, E. Messina and A. Giacomello, et al., Cardiac tissue engineering using tissue printing technology and human cardiac progenitor cells, Biomaterials, 2012, 33(6), 1782-1790.

58 B. W. Streeter, J. Xue, Y. Xia and M. E. Davis, Electrospun Nanofiber-Based Patches for the Delivery of Cardiac Progenitor Cells, ACS Appl. Mater. Interfaces, 2019, 11(20), 18242-18253.

59 S. Golpanian, A. Wolf, K. E. Hatzistergos and J. M. Hare, Rebuilding the damaged heart: mesenchymal stem cells, cell-based therapy, and engineered heart tissue, Physiol. Rev., 2016, 96(3), 1127-1168.

60 V. Karantalis, D. L. DiFede, G. Gerstenblith, S. Pham, J. Symes and J. P. Zambrano, et al., Autologous mesenchymal stem cells produce concordant improvements in regional function, tissue perfusion, and fibrotic burden when administered to patients undergoing coronary artery bypass grafting: the Prospective Randomized Study of Mesenchymal Stem Cell Therapy in Patients Undergoing Cardiac Surgery (PROMETHEUS) trial, Circ. Res., 2014, 114(8), 1302-1310.

61 A. W. Heldman, D. L. DiFede, J. E. Fishman, J. P. Zambrano, B. H. Trachtenberg and V. Karantalis, et al., Transendocardial mesenchymal stem cells and mononuclear bone marrow cells for ischemic cardiomyopathy: the TAC-HFT randomized trial, JAMA, 2014, 311(1), $62-73$.

62 A. Caplan, Why are MSCs therapeutic? New data: new insight, J. Pathol., 2009, $217(2), 318-324$.

63 X. Guo, Y. Bai, L. Zhang, B. Zhang, N. Zagidullin and K. Carvalho, et al., Cardiomyocyte differentiation of mesenchymal stem cells from bone marrow: new regulators and its implications, Stem Cell Res. Ther., 2018, 9(1), 44.

64 M. Swaminathan, M. Stafford-Smith, G. M. Chertow, D. G. Warnock, V. Paragamian and R. M. Brenner, et al., Allogeneic mesenchymal stem cells for treatment of AKI after cardiac surgery, J. Am. Soc. Nephrol., 2018, 29(1), 260-267.

65 A. Llucià-Valldeperas, C. Soler-Botija, C. Gálvez-Montón, S. Roura, C. Prat-Vidal and I. Perea-Gil, et al., Electromechanical conditioning of adult progenitor cells improves recovery of cardiac function after myocardial infarction, Stem Cells Transl. Med., 2017, 6(3), 970-981.

66 J. Chen, Y. Zhan, Y. Wang, D. Han, B. Tao and Z. Luo, et al., Chitosan/silk fibroin modified nanofibrous patches with mesenchymal stem cells prevent heart remodeling postmyocardial infarction in rats, Acta Biomater., 2018, 80, 154-168.

67 J. Li, J. Zhang, X. Wang, N. Kawazoe and G. Chen, Gold nanoparticle size and shape influence on osteogenesis of mesenchymal stem cells, Nanoscale, 2016, 8(15), 7992-8007. 
68 L. Lv, Y. Liu, P. Zhang, X. Zhang, J. Liu and T. Chen, et al., The nanoscale geometry of $\mathrm{TiO} 2$ nanotubes influences the osteogenic differentiation of human adipose-derived stem cells by modulating H3K4 trimethylation, Biomaterials, 2015, 39, 193-205.

69 M. A. K. Abdelhalim, Exposure to gold nanoparticles produces cardiac tissue damage that depends on the size and duration of exposure, Lipids Health Dis., 2011, 10(1), 205.

70 P. Rivera-Gil, D. Jimenez De Aberasturi, V. Wulf, B. Pelaz, P. Del Pino and Y. Zhao, et al., The challenge to relate the physicochemical properties of colloidal nanoparticles to their cytotoxicity, Acc. Chem. Res., 2013, 46(3), 743-749.

71 T. Albanesea and C. Chanw, The effect of nanoparticle size, shape, and surface chemistry on biological systems, Annu. Rev. Biomed. Eng., 2012, 14, 1.

72 F. Zamboni, S. Vieira, R. L. Reis, J. M. Oliveira and M. N. Collins, The potential of hyaluronic acid in immunoprotection and immunomodulation: chemistry, processing and function, Prog. Mater. Sci., 2018, 97, 97-122.

73 R. Sridhar, R. Lakshminarayanan, K. Madhaiyan, V. A. Barathi, K. H. C. Lim and S. Ramakrishna, Electrosprayed nanoparticles and electrospun nanofibers based on natural materials: applications in tissue regeneration, drug delivery and pharmaceuticals, Chem. Soc. Rev., 2015, 44(3), 790-814.

74 K. Schacht, J. Vogt and T. Scheibel, Foams made of engineered recombinant spider silk proteins as 3D scaffolds for cell growth, ACS Biomater. Sci. Eng., 2016, 2(4), 517-525.

75 M. S. Hossain, F. Mohamed and M. A. M. Shafri, Poly (trimethylene carbonate-co-caprolactone): An emerging drug delivery nanosystem in pharmaceutics, Biomater. Biomech. Bioeng., 2020, 5(1), 65-86.

76 I. Bružauskaitè, D. Bironaitè, E. Bagdonas and E. Bernotienè, Scaffolds and cells for tissue regeneration: different scaffold pore sizes-different cell effects, Cytotechnology, 2016, 68(3), 355-369.

77 A. Artel, H. Mehdizadeh, Y.-C. Chiu, E. M. Brey and A. Cinar, An agent-based model for the investigation of neovascularization within porous scaffolds, Tissue Eng., Part A, 2011, 17(17-18), 2133-2141.

78 J. Zeltinger, J. K. Sherwood, D. A. Graham, R. Müeller and L. G. Griffith, Effect of pore size and void fraction on cellular adhesion, proliferation, and matrix deposition, Tissue Eng., 2001, 7(5), 557-572.

79 Y. Wang, J. Hu, J. Jiao, Z. Liu, Z. Zhou and C. Zhao, et al., Engineering vascular tissue with functional smooth muscle cells derived from human iPS cells and nanofibrous scaffolds, Biomaterials, 2014, 35(32), 8960-8969.

80 H. Amani, H. Arzaghi, M. Bayandori, A. S. Dezfuli, H. Pazoki-Toroudi and A. Shafiee, et al., Controlling Cell Behavior through the Design of Biomaterial Surfaces: A Focus on Surface Modification Techniques, Adv. Mater. Interfaces, 2019, 1900572.

81 S. Ahn, C. O. Chantre, A. R. Gannon, J. U. Lind, P. H. Campbell and T. Grevesse, et al., Soy protein/cellulose nanofiber scaffolds mimicking skin extracellular matrix for enhanced wound healing, Adv. Healthcare Mater., 2018, 7(9), 1701175.

82 T.-T. Yu, F.-Z. Cui, Q.-Y. Meng, J. Wang, D.-C. Wu and $\mathrm{J}$. Zhang, et al., Influence of surface chemistry on adhesion and osteo/odontogenic differentiation of dental pulp stem cells, ACS Biomater. Sci. Eng., 2017, 3(6), 1119-1128.

83 D. Simpson, L. Terracio, M. Terracio, R. L. Price, D. C. Turner and T. K. Borg, Modulation of cardiac myocyte phenotype in vitro by the composition and orientation of the extracellular matrix, J. Cell. Physiol., 1994, 161, 89-105.

84 M. Das, P. Molnar, C. Gregory, L. Riedel, A. Jamshidi and J. J. Hickman, Long-term culture of embryonic rat cardiomyocytes on an organosilane surface in a serum-free medium, Biomaterials, 2004, 25(25), 5643-5647.

85 B.-J. Kang, H. Kim, S. K. Lee, J. Kim, Y. Shen and S. Jung, et al., Umbilical-cord-blood-derived mesenchymal stem cells seeded onto fibronectin-immobilized polycaprolactone nanofiber improve cardiac function, Acta Biomater., 2014, 10(7), 3007-3017.

$86 \mathrm{H}$. Yu, H. Zhao, C. Huang and Y. Du, Mechanically and electrically enhanced CNT-collagen hydrogels as potential scaffolds for engineered cardiac constructs, ACS Biomater. Sci. Eng., 2017, 3(11), 3017-3021.

87 P. S. Castro, M. Bertotti, A. F. Naves, L. H. Catalani, D. R. Cornejo and G. D. Bloisi, et al., Hybrid magnetic scaffolds: The role of scaffolds charge on the cell proliferation and Ca2+ ions permeation, Colloids Surf., B, 2017, 156, 388-396.

88 M. Park, D. Lee, S. Shin and J. Hyun, Effect of negatively charged cellulose nanofibers on the dispersion of hydroxyapatite nanoparticles for scaffolds in bone tissue engineering, Colloids Surf., B, 2015, 130, 222-228.

89 D. Jing and B. Bhushan, Quantification of surface charge density and its effect on boundary slip, Langmuir, 2013, 29(23), 6953-6963.

90 A. Asati, S. Santra, C. Kaittanis and J. M. Perez, Surfacecharge-dependent cell localization and cytotoxicity of cerium oxide nanoparticles, ACS Nano, 2010, 4(9), 5321-5331.

91 Y. Chang, E. Lee, J. Kim, Y.-W. Kwon, Y. Kwon and J. Kim, Efficient in vivo direct conversion of fibroblasts into cardiomyocytes using a nanoparticle-based gene carrier, Biomaterials, 2019, 192, 500-509.

92 Y. Lai, F. Pan, C. Xu, H. Fuchs and L. Chi, In situ surfacemodification-induced superhydrophobic patterns with reversible wettability and adhesion, Adv. Mater., 2013, 25(12), 1682-1686.

93 Y. Arima and H. Iwata, Effect of wettability and surface functional groups on protein adsorption and cell adhesion using well-defined mixed self-assembled monolayers, Biomaterials, 2007, 28(20), 3074-3082.

94 E. Ueda and P. A. Levkin, Emerging applications of superhydrophilic-superhydrophobic micropatterns, Adv. Mater., 2013, 25(9), 1234-1247.

95 J. Wei, M. Yoshinari, S. Takemoto, M. Hattori, E. Kawada and B. Liu, et al., Adhesion of mouse fibroblasts on 
hexamethyldisiloxane surfaces with wide range of wettability, J. Biomed. Mater. Res., Part B, 2007, 81(1), 66-75.

96 S. Guo, X. Zhu, M. Li, L. Shi, J. L. T. Ong and D. Jańczewski, et al., Parallel Control over Surface Charge and Wettability Using Polyelectrolyte Architecture: Effect on Protein Adsorption and Cell Adhesion, ACS Appl. Mater. Interfaces, 2016, 8(44), 30552-30563.

97 N. J. Vickers, Animal communication: when i'm calling you, will you answer too?, Curr. Biol., 2017, 27(14), R713-R715.

98 R. M. Aghdam, S. Shakhesi, S. Najarian, M. M. Mohammadi, S. H. Ahmadi Tafti and H. Mirzadeh, Fabrication of a nanofibrous scaffold for the in vitro culture of cardiac progenitor cells for myocardial regeneration, Int. J. Polym. Mater. Polym. Biomater., 2014, 63(5), 229-239.

99 H. T. H. Au, I. Cheng, M. F. Chowdhury and M. Radisic, Interactive effects of surface topography and pulsatile electrical field stimulation on orientation and elongation of fibroblasts and cardiomyocytes, Biomaterials, 2007, 28(29), 4277-4293.

100 C. Xu, F. Yang, S. Wang and S. Ramakrishna, In vitro study of human vascular endothelial cell function on materials with various surface roughness, J. Biomed. Mater. Res., Part A, 2004, 71(1), 154-161.

101 F. Grinnell, Fibronectin and wound healing, J. Cell. Biochem., 1984, 26(2), 107-116.

102 D. A. Stout, J. Yoo, A. N. Santiago-Miranda and T. J. Webster, Mechanisms of greater cardiomyocyte functions on conductive nanoengineered composites for cardiovascular application, Int. J. Nanomed., 2012, 7, 5653.

103 X. Yao, R. Peng and J. Ding, Cell-material interactions revealed via material techniques of surface patterning, $A d v$. Mater., 2013, 25(37), 5257-5286.

104 M. Biggs, R. Richards, N. Gadegaard, C. Wilkinson and M. Dalby, The effects of nanoscale pits on primary human osteoblast adhesion formation and cellular spreading, J. Mater. Sci.: Mater. Med., 2007, 18(2), 399-404.

105 L. Ji, V. L. LaPointe, N. D. Evans and M. M. Stevens, Changes in embryonic stem cell colony morphology and early differentiation markers driven by colloidal crystal topographical cues, Eur. Cell Mater., 2012, 23, 135-146.

106 E. Ngandu Mpoyi, M. Cantini, P. M. Reynolds, N. Gadegaard, M. J. Dalby and M. Salmerón-Sánchez, Protein adsorption as a key mediator in the nanotopographical control of cell behavior, ACS Nano, 2016, 10(7), 6638-6647.

107 M. Dalby, N. T. R. Gadegaard, A. Andar, M. O. Riehle, P. Herzyk, C. D. W. Wilkinson and R. O. C. Oreffo, Nat. Mater., 2007, 6, 997.

108 D.-H. Kim, E. A. Lipke, P. Kim, R. Cheong, S. Thompson and M. Delannoy, et al., Nanoscale cues regulate the structure and function of macroscopic cardiac tissue constructs, Proc. Natl. Acad. Sci. U. S. A., 2010, 107(2), 565-570.

109 S. B. Han, J. K. Kim, G. Lee and D. H. Kim, Mechanical Properties of Materials for Stem Cell Differentiation. Advanced, BioSystems, 2020, 4(11), 2000247.
110 A. M. Handorf, Y. Zhou, M. A. Halanski and W.-J. Li, Tissue stiffness dictates development, homeostasis, and disease progression, Organogenesis, 2015, 11(1), 1-15.

111 S. Tatsumi, K. Ishii, N. Amizuka, M. Li, T. Kobayashi and K. Kohno, et al., Targeted ablation of osteocytes induces osteoporosis with defective mechanotransduction, Cell Metab., 2007, 5(6), 464-475.

112 T. Yeung, P. Georges, L. Flanagan, B. Marg, M. Ortiz, M. Funaki and P. Janmey, et al., Effects of substrate stiffness on cell morphology, cytoskeletal structure, and adhesion, Cell Motil. Cytoskeleton, 2005, 60, 24-34.

113 J. Guan, F. Wang, Z. Li, J. Chen, X. Guo and J. Liao, et al., The stimulation of the cardiac differentiation of mesenchymal stem cells in tissue constructs that mimic myocardium structure and biomechanics, Biomaterials, 2011, 32(24), 5568-5580.

114 L. Davenport Huyer, B. Zhang, A. Korolj, M. Montgomery, S. Drecun and G. Conant, et al., Highly elastic and moldable polyester biomaterial for cardiac tissue engineering applications, ACS Biomater. Sci. Eng., 2016, 2(5), 780-788.

115 B. Wang, A. Borazjani, M. Tahai, A. L. de Jongh Curry, D. T. Simionescu and J. Guan, et al., Fabrication of cardiac patch with decellularized porcine myocardial scaffold and bone marrow mononuclear cells, J. Biomed. Mater. Res., Part A, 2010, 94(4), 1100-1110.

116 Z. Li, X. Guo, A. F. Palmer, H. Das and J. Guan, Highefficiency matrix modulus-induced cardiac differentiation of human mesenchymal stem cells inside a thermosensitive hydrogel, Acta Biomater., 2012, 8(10), 3586-3595.

117 M. H. Jazayeri, H. Amani, A. A. Pourfatollah, H. PazokiToroudi and B. Sedighimoghaddam, Various methods of gold nanoparticles (GNPs) conjugation to antibodies, Sens. Bio-Sens. Res., 2016, 9, 17-22.

118 H. Amani, E. Mostafavi, M. R. Alebouyeh, H. Arzaghi, A. Akbarzadeh and H. Pazoki-Toroudi, et al., Would colloidal gold nanocarriers present an effective diagnosis or treatment for ischemic stroke?, Int. J. Nanomed., 2019, 14, 8013.

119 M. Fathi-Achachelouei, H. Knopf-Marques, C. E. Riberio de Silva, J. G. D. Barthès, E. Bat and A. Tezcaner, et al., Use of nanoparticles in tissue engineering and regenerative medicine, Front. Bioeng. Biotechnol., 2019, 7, 113.

120 W.-K. Ko, D. N. Heo, H.-J. Moon, S. J. Lee, M. S. Bae and J. B. Lee, et al., The effect of gold nanoparticle size on osteogenic differentiation of adipose-derived stem cells, J. Colloid Interface Sci., 2015, 438, 68-76.

121 R. Ravichandran, R. Sridhar, J. R. Venugopal, S. Sundarrajan, S. Mukherjee and S. Ramakrishna, Gold nanoparticle loaded hybrid nanofibers for cardiogenic differentiation of stem cells for infarcted myocardium regeneration, Macromol. Biosci., 2014, 14(4), 515-525.

122 J. Zhang, Y. Xue, Y. Ni, F. Ning, L. Shang and A. Ma, Size dependent effects of Gold Nanoparticles in ISO-induced Hyperthyroid Rats, Sci. Rep., 2018, 8(1), 1-13.

123 M. Shevach, S. Fleischer, A. Shapira and T. Dvir, Gold Nanoparticle-Decellularized Matrix Hybrids for Cardiac Tissue Engineering, Nano Lett., 2014, 14(10), 5792-5796. 
124 P. Baei, S. Jalili-Firoozinezhad, S. Rajabi-Zeleti, M. Tafazzoli-Shadpour, H. Baharvand and N. Aghdami, Electrically conductive gold nanoparticle-chitosan thermosensitive hydrogels for cardiac tissue engineering, Mater. Sci. Eng., C, 2016, 63, 131-141.

125 A. Navaei, H. Saini, W. Christenson, R. T. Sullivan, R. Ros and M. Nikkhah, Gold nanorod-incorporated gelatin-based conductive hydrogels for engineering cardiac tissue constructs, Acta Biomater., 2016, 41, 133-146.

126 M. Malki, S. Fleischer, A. Shapira and T. Dvir, Gold nanorod-based engineered cardiac patch for suture-free engraftment by near IR, Nano Lett., 2018, 18(7), 4069-4073.

127 S. Sridhar, J. R. Venugopal, R. Sridhar and S. Ramakrishna, Cardiogenic differentiation of mesenchymal stem cells with gold nanoparticle loaded functionalized nanofibers, Colloids Surf., B, 2015, 134, 346-354.

128 T. Dvir, B. P. Timko, M. D. Brigham, S. R. Naik, S. S. Karajanagi and O. Levy, et al., Nanowired threedimensional cardiac patches, Nat. Nanotechnol., 2011, 6(11), 720-725.

129 Y. Zhang, W. Fan, K. Wang, H. Wei, R. Zhang and Y. Wu, Novel preparation of $\mathrm{Au}$ nanoparticles loaded Laponite nanoparticles/ECM injectable hydrogel on cardiac differentiation of resident cardiac stem cells to cardiomyocytes, J. Photochem. Photobiol., B, 2019, 192, 49-54.

130 J.-O. You, M. Rafat, G. J. C. Ye and D. T. Auguste, Nanoengineering the Heart: Conductive Scaffolds Enhance Connexin 43 Expression, Nano Lett., 2011, 11(9), 3643-3648.

131 M. Shevach, B. M. Maoz, R. Feiner, A. Shapira and T. Dvir, Nanoengineering gold particle composite fibers for cardiac tissue engineering, J. Mater. Chem. B, 2013, 1(39), 5210-5217.

132 A. Navaei, N. Moore, R. T. Sullivan, D. Truong, R. Q. Migrino and M. Nikkhah, Electrically conductive hydrogel-based micro-topographies for the development of organized cardiac tissues, RSC Adv., 2017, 7(6), 3302-3312.

133 K. Zhu, S. R. Shin, T. van Kempen, Y.-C. Li, V. Ponraj and A. Nasajpour, et al., Gold Nanocomposite Bioink for Printing 3D Cardiac Constructs, Adv. Funct. Mater., 2017, 27(12), 1605352.

134 Y. Li, X. Shi, L. Tian, H. Sun, Y. Wu and X. Li, et al., AuNPCollagen Matrix with Localized Stiffness for Cardiac-Tissue Engineering: Enhancing the Assembly of Intercalated Discs by $\beta 1$-Integrin-Mediated Signaling, Adv. Mater., 2016, 28(46), 10230-10235.

135 Y. Ganji, Q. Li, E. S. Quabius, M. Böttner, C. SelhuberUnkel and M. Kasra, Cardiomyocyte behavior on biodegradable polyurethane/gold nanocomposite scaffolds under electrical stimulation, Mater. Sci. Eng., C, 2016, 59, 10-18.

136 D. Jung, I. Minami, S. Patel, J. Lee, B. Jiang and Q. Yuan, et al., Incorporation of functionalized gold nanoparticles into nanofibers for enhanced attachment and differentiation of mammalian cells, J. Nanobiotechnol., 2012, 10(1), 23.
137 B. Peña, M. Maldonado, A. J. Bonham, B. A. Aguado, A. Dominguez-Alfaro and M. Laughter, et al., Gold Nanoparticle-Functionalized Reverse Thermal Gel for Tissue Engineering Applications, ACS Appl. Mater. Interfaces, 2019, 11(20), 18671-18680.

138 S. Iravani, H. Korbekandi, S. V. Mirmohammadi and B. Zolfaghari, Synthesis of silver nanoparticles: chemical, physical and biological methods, Res. Pharm. Sci., 2014, $9(6), 385$.

139 C. Gonzalez, H. Rosas-Hernandez, M. A. Ramirez-Lee, S. Salazar-García and S. F. Ali, Role of silver nanoparticles (AgNPs) on the cardiovascular system, Arch. Toxicol., 2016, 90(3), 493-511.

140 L. Ge, Q. Li, M. Wang, J. Ouyang, X. Li and M. M. Xing, Nanosilver particles in medical applications: synthesis, performance, and toxicity, Int. J. Nanomed., 2014, 9, 2399.

141 J. Fu, J. Ji, D. Fan and J. Shen, Construction of antibacterial multilayer films containing nanosilver via layer-by-layer assembly of heparin and chitosan-silver ions complex, J. Biomed. Mater. Res., Part A, 2006, 79(3), 665-674.

142 J. T. T. Angelina, S. Ganesan, T. Panicker, R. Narayani, M. Paul Korath and K. Jagadeesan, Pulsed laser deposition of silver nanoparticles on prosthetic heart valve material to prevent bacterial infection, Mater. Technol., 2017, 32(3), 148-155.

143 R. Behra, L. Sigg, M. J. Clift, F. Herzog, M. Minghetti and B. Johnston, et al., Bioavailability of silver nanoparticles and ions: from a chemical and biochemical perspective, J. R. Soc., Interface, 2013, 10(87), 20130396.

144 L. Espinosa-Cristobal, G. Martinez-Castanon, J. LoyolaRodriguez, N. Patino-Marin, J. Reyes-Macias and J. Vargas-Morales, et al., Toxicity, distribution, and accumulation of silver nanoparticles in Wistar rats, J. Nanopart. Res., 2013, 15(6), 1702.

145 H. B. Bostan, R. Rezaee, M. G. Valokala, K. Tsarouhas, K. Golokhvast and A. M. Tsatsakis, et al., Cardiotoxicity of nano-particles, Life Sci., 2016, 165, 91-99.

146 X. Yu, F. Hong and Y. Q. Zhang, Bio-effect of nanoparticles in the cardiovascular system, J. Biomed. Mater. Res., Part A, 2016, 104(11), 2881-2897.

147 Z. Ferdous, S. Al-Salam, Y. E. Greish, B. H. Ali and A. Nemmar, Pulmonary exposure to silver nanoparticles impairs cardiovascular homeostasis: Effects of coating, dose and time, Toxicol. Appl. Pharmacol., 2019, 367, 36-50.

148 A. R.-L. Manuel, P. P. Martinez-Cuevas, H. RosasHernandez, C. Oros-Ovalle, M. Bravo-Sanchez and G. A. Martinez-Castañon, et al., Evaluation of vascular tone and cardiac contractility in response to silver nanoparticles, using Langendorff rat heart preparation, Nanomedicine, 2017, 13(4), 1507-1518.

149 W. He, X. Liu, A. Kienzle, W. E. Müller and Q. Feng, In vitro uptake of silver nanoparticles and their toxicity in human mesenchymal stem cells derived from bone marrow, J. Nanosci. Nanotechnol., 2016, 16(1), 219-228.

150 C.-X. Lin, S.-Y. Yang, J.-L. Gu, J. Meng, H.-Y. Xu and J.-M. Cao, The acute toxic effects of silver nanoparticles 
on myocardial transmembrane potential, I Na and I K1 channels and heart rhythm in mice, Nanotoxicology, 2017, 11(6), 827-837.

151 S. Allison, M. Ahumada, C. Andronic, B. McNeill, F. Variola and M. Griffith, et al., Electroconductive nanoengineered biomimetic hybrid fibers for cardiac tissue engineering, J. Mater. Chem. B, 2017, 5(13), 2402-2406.

152 P. Nyamukamba, O. Okoh, H. Mungondori, R. Taziwa and S. Zinya, Synthetic methods for titanium dioxide nanoparticles: a review, Titanium Dioxide-Material for a Sustainable Environment, ed. D. Yang, 2018, pp. 151-175.

153 H. Shi, R. Magaye, V. Castranova and J. Zhao, Titanium dioxide nanoparticles: a review of current toxicological data, Part. Fibre Toxicol., 2013, 10(1), 15.

154 J. Park, S. Bauer, K. von der Mark and P. Schmuki, Nanosize and vitality: $\mathrm{TiO} 2$ nanotube diameter directs cell fate, Nano Lett., 2007, 7(6), 1686-1691.

155 F. Hong, X. Yu, N. Wu and Y.-Q. Zhang, Progress of in vivo studies on the systemic toxicities induced by titanium dioxide nanoparticles, Toxicol. Res., 2017, 6(2), 115-133.

156 H. Jawad, A. R. Boccaccini, N. N. Ali and S. E. Harding, Assessment of cellular toxicity of TiO2 nanoparticles for cardiac tissue engineering applications, Nanotoxicology, 2011, 5(3), 372-380.

157 Z. Chen, Y. Wang, L. Zhuo, S. Chen, L. Zhao and X. Luan, et al., Effect of titanium dioxide nanoparticles on the cardiovascular system after oral administration, Toxicol. Lett., 2015, 239(2), 123-130.

158 Q. Zhang, Z. Liu, J. Du, W. Qin, M. Lu and H. Cui, et al., Dermal exposure to nano-TiO2 induced cardiovascular toxicity through oxidative stress, inflammation and apoptosis, J. Toxicol. Sci., 2019, 44(1), 35-45.

159 F. Hong, L. Wang, X. Yu, Y. Zhou, J. Hong and L. Sheng, Toxicological effect of TiO 2 nanoparticle-induced myocarditis in mice, Nanoscale Res. Lett., 2015, 10(1), 1-11.

160 L-j Xiang, J-a Li, Z-k He, J-j Wu, P. Yang and N. Huang, Design and construction of $\mathrm{TiO} 2$ nanotubes in microarray using two-step anodic oxidation for application of cardiovascular implanted devices. Micro \&, Nano Lett., 2015, 10(6), 287-291.

161 K. C. Popat, L. Leoni, C. A. Grimes and T. A. Desai, Influence of engineered titania nanotubular surfaces on bone cells, Biomaterials, 2007, 28(21), 3188-3197.

162 M. Savi, S. Rossi, L. Bocchi, L. Gennaccaro, F. Cacciani and A. Perotti, et al., Titanium dioxide nanoparticles promote arrhythmias via a direct interaction with rat cardiac tissue. Particle and Fibre, Toxicology, 2014, 11(1), 63.

163 L. Pan, Y. M. Lee, T. K. Lim, Q. Lin and X. Xu, Quantitative proteomics study reveals changes in the molecular landscape of human embryonic stem cells with impaired stem cell differentiation upon exposure to titanium dioxide nanoparticles, Small, 2018, 14(23), 1800190.

164 N. Liu, J. Chen, J. Zhuang and P. Zhu, Fabrication of engineered nanoparticles on biological macromolecular (PEGylated chitosan) composite for bio-active hydrogel system in cardiac repair applications, Int. J. Biol. Macromol., 2018, 117, 553-558.

165 S. Majidi, F. Zeinali Sehrig, S. M. Farkhani, M. Soleymani Goloujeh and A. Akbarzadeh, Current methods for synthesis of magnetic nanoparticles, Artif. Cells, Nanomed., Biotechnol., 2016, 44(2), 722-734.

166 K. Wu, D. Su, J. Liu, R. Saha and J.-P. Wang, Magnetic nanoparticles in nanomedicine: a review of recent advances, Nanotechnology, 2019, 30(50), 502003.

167 L. Mohammed, H. G. Gomaa, D. Ragab and J. Zhu, Magnetic nanoparticles for environmental and biomedical applications: A review, Particuology, 2017, 30, 1-14.

168 W. Willmann and R. Dringen, Monitoring of the cytoskeleton-dependent intracellular trafficking of fluorescent iron oxide nanoparticles by nanoparticle pulse-chase experiments in C6 glioma cells, Neurochem. Res., 2018, 43(11), 2055-2071.

169 M. Giannaccini, M. P. Calatayud, A. Poggetti, S. Corbianco, M. Novelli and M. Paoli, et al., Magnetic nanoparticles for efficient delivery of growth factors: stimulation of peripheral nerve regeneration, Adv. Healthcare Mater., 2017, 6(7), 1601429.

170 M. Marcus, H. Skaat, N. Alon, S. Margel and O. Shefi, NGFconjugated iron oxide nanoparticles promote differentiation and outgrowth of PC12 cells, Nanoscale, 2015, 7(3), 1058-1066.

171 M. M. Jansman and L. Hosta-Rigau, Cerium-and ironoxide-based nanozymes in tissue engineering and regenerative medicine, Catalysts, 2019, 9(8), 691.

172 M. Panahi, B. Rahimi, G. Rahimi, T. Yew Low, N. Saraygord-Afshari and E. Alizadeh, Cytoprotective effects of antioxidant supplementation on mesenchymal stem cell therapy, J. Cell. Physiol., 2020, 235(10), 6462-6495, DOI: 10.1002/jcp.29660.

173 D.-M. Huang, J.-K. Hsiao, Y.-C. Chen, L.-Y. Chien, M. Yao and Y.-K. Chen, et al., The promotion of human mesenchymal stem cell proliferation by superparamagnetic iron oxide nanoparticles, Biomaterials, 2009, 30(22), 3645-3651.

174 F. Xiong, H. Wang, Y. Feng, Y. Li, X. Hua and X. Pang, et al., Cardioprotective activity of iron oxide nanoparticles, Sci. Rep., 2015, 5(1), 1-8.

175 J. Han, B. Kim, J.-Y. Shin, S. Ryu, M. Noh and J. Woo, et al., Iron oxide nanoparticle-mediated development of cellular gap junction crosstalk to improve mesenchymal stem cells' therapeutic efficacy for myocardial infarction, ACS Nano, 2015, 9(3), 2805-2819.

176 M. Naseroleslami, N. Aboutaleb and K. Parivar, The effects of superparamagnetic iron oxide nanoparticles-labeled mesenchymal stem cells in the presence of a magnetic field on attenuation of injury after heart failure, Drug Delivery Transl. Res., 2018, 8(5), 1214-1225.

177 Y. Mou, J. Zhou, F. Xiong, H. Li, H. Sun and Y. Han, et al., Effects of 2,3-dimercaptosuccinic acid modified Fe $2 \mathrm{O} 3$ nanoparticles on microstructure and biological activity of cardiomyocytes, RSC Adv., 2015, 5(25), 19493-19501. 
178 Y. Mou, S. Lv, F. Xiong, Y. Han, Y. Zhao and J. Li, et al., Effects of different doses of 2,3-dimercaptosuccinic acidmodified $\mathrm{Fe} 2 \mathrm{O} 3$ nanoparticles on intercalated discs in engineered cardiac tissues, J. Biomed. Mater. Res., Part B, 2018, 106(1), 121-130.

179 S. Mohanty, K. G. Jain, S. B. Nandy, A. Kakkar, M. Kumar and A. K. Dinda, et al., Iron oxide labeling does not affect differentiation potential of human bone marrow mesenchymal stem cells exhibited by their differentiation into cardiac and neuronal cells, Mol. Cell. Biochem., 2018, 448(1), 17-26.

180 H. Nazari, A. Heirani-Tabasi, M. Hajiabbas, M. Salimi Bani, M. Nazari and V. Pirhajati Mahabadi, et al., Incorporation of SPION-casein core-shells into silk-fibroin nanofibers for cardiac tissue engineering, J. Cell. Biochem., 2020, 121(4), 2981-2993.

181 C. Santhosh, V. Velmurugan, G. Jacob, S. K. Jeong, A. N. Grace and A. Bhatnagar, Role of nanomaterials in water treatment applications: a review, Chem. Eng. J., 2016, 306, 1116-1137.

$182 \mathrm{X}$. Jia and F. Wei, Advances in production and applications of carbon nanotubes. Single-Walled Carbon Nanotubes, Springer, 2019, pp. 299-333.

183 M. F. De Volder, S. H. Tawfick, R. H. Baughman and A. J. Hart, Carbon nanotubes: present and future commercial applications, Science, 2013, 339(6119), 535-539.

184 M. Prato, Controlled nanotube reactions, Nature, 2010, 465(7295), 172-173.

185 S. Ahadian, R. Obregón, J. Ramón-Azcón, G. Salazar, H. Shiku and M. Ramalingam, et al., Carbon nanotubes and graphene-based nanomaterials for stem cell differentiation and tissue regeneration, J. Nanosci. Nanotechnol., 2016, 16(9), 8862-8880.

186 G. A. Hughes, Nanostructure-mediated drug delivery, Nanomedicine in Cancer, Pan Stanford, 2017, pp. 47-72.

187 S. Gai, G. Yang, P. Yang, F. He, J. Lin and D. Jin, et al., Recent advances in functional nanomaterials for lighttriggered cancer therapy, Nano Today, 2018, 19, 146-187.

188 H. Wang and D. J. Mooney, Biomaterial-assisted targeted modulation of immune cells in cancer treatment, Nat. Mater., 2018, 17(9), 761-772.

189 S. Gupta, C. Murthy and C. R. Prabha, Recent advances in carbon nanotube based electrochemical biosensors, Int. J. Biol. Macromol., 2018, 108, 687-703.

190 S. Taghavi, A. H. Nia, K. Abnous and M. Ramezani, Polyethylenimine-functionalized carbon nanotubes tagged with AS1411 aptamer for combination gene and drug delivery into human gastric cancer cells, Int. J. Pharm., 2017, 516(1-2), 301-312.

191 S. Shrestha, B. K. Shrestha, J. I. Kim, S. W. Ko, C. H. Park and C. S. Kim, Electrodeless coating polypyrrole on chitosan grafted polyurethane with functionalized multiwall carbon nanotubes electrospun scaffold for nerve tissue engineering, Carbon, 2018, 136, 430-443.

192 Y. Zhang, J. Zhao, Y. Fang, Y. Liu and X. Zhao, Preparation of long linear carbon chain inside multi-walled carbon nanotubes by cooling enhanced hydrogen arc discharge method, Nanoscale, 2018, 10(37), 17824-17833.

193 L. Mocan, I. Ilie, F. A. Tabaran, C. Iancu, O. Mosteanu and T. Pop, et al., Selective laser ablation of methicillinresistant staphylococcus aureus with IgG functionalized multi-walled carbon nanotubes, J. Biomed. Nanotechnol., 2016, 12(4), 781-788.

194 Y. Xu, Y. Ma, Y. Liu, S. Feng, D. He and P. Haghi-Ashtiani, et al., Evolution of nanoparticles in the gas phase during the floating chemical vapor deposition synthesis of carbon nanotubes, J. Phys. Chem. C, 2018, 122(11), 6437-6446.

195 T. Dvir, B. P. Timko, D. S. Kohane and R. Langer, Nanotechnological strategies for engineering complex tissues, Nat. Nanotechnol., 2011, 6(1), 13.

196 N. Ashammakhi, S. Ahadian, C. Xu, H. Montazerian, H. Ko and R. Nasiri, et al., Bioinks and bioprinting technologies to make heterogeneous and biomimetic tissue constructs, Mater. Today Bio, 2019, 100008.

197 K. Ashtari, H. Nazari, H. Ko, P. Tebon, M. Akhshik and M. Akbari, et al., Electrically conductive nanomaterials for cardiac tissue engineering, Adv. Drug Delivery Rev., 2019, 144, 162-179.

198 Z. Li, T. Hulderman, R. Salmen, R. Chapman, S. S. Leonard and S.-H. Young, et al., Cardiovascular effects of pulmonary exposure to single-wall carbon nanotubes, Environ. Health Perspect., 2007, 115(3), 377-382.

199 B. Bagheri, M. Abdouss and A. Shoushtari, New procedure for preparation of highly stable and well separated carbon nanotubes in an aqueous modified polyacrylonitrile, Materialwiss. Werkstofftech., 2010, 41(4), 234-240.

200 R. N. Urankar, R. M. Lust, E. Mann, P. Katwa, X. Wang and R. Podila, et al., Expansion of cardiac ischemia/reperfusion injury after instillation of three forms of multi-walled carbon nanotubes, Part. Fibre Toxicol., 2012, 9(1), 38.

201 J. Zhou, J. Chen, H. Sun, X. Qiu, Y. Mou and Z. Liu, et al., Engineering the heart: evaluation of conductive nanomaterials for improving implant integration and cardiac function, Sci. Rep., 2014, 4, 3733.

202 R. K. Kankala, K. Zhu, X.-N. Sun, C.-G. Liu, S.-B. Wang and A.-Z. Chen, Cardiac tissue engineering on the nanoscale, ACS Biomater. Sci. Eng., 2018, 4(3), 800-818.

203 A. Dominguez-Alfaro, N. Alegret, B. Arnaiz, J. M. GonzalezDominguez, A. Martin Pacheco and U. Cossío, et al., Tailored Methodology based on Vapor Phase Polymerization to Manufacture PEDOT/CNT Scaffolds for Tissue Engineering, ACS Biomater. Sci. Eng., 2019, 6(2), 1269-1278, DOI: 10.1021/acsbiomaterials.9b01316.

204 V. Martinelli, S. Bosi, B. Peña, G. Baj, C. S. Long and O. Sbaizero, et al., 3D carbon-nanotube-based composites for cardiac tissue engineering, ACS Appl. Bio Mater., 2018, 1(5), 1530-1537.

205 S. Ahadian, L. D. Huyer, M. Estili, B. Yee, N. Smith and $\mathrm{Z}$. Xu, et al., Moldable elastomeric polyester-carbon nanotube scaffolds for cardiac tissue engineering, Acta Biomater., 2017, 52, 81-91.

206 H. Sun, J. Zhou, Z. Huang, L. Qu, N. Lin and C. Liang, et al., Carbon nanotube-incorporated collagen hydrogels 
improve cell alignment and the performance of cardiac constructs, Int. J. Nanomed., 2017, 12, 3109.

207 G. Camci-Unal, N. Annabi, M. R. Dokmeci, R. Liao and A. Khademhosseini, Hydrogels for cardiac tissue engineering, NPG Asia Mater., 2014, 6(5), e99.

208 Y. Wu, L. Wang, B. Guo and P. X. Ma, Interwoven aligned conductive nanofiber yarn/hydrogel composite scaffolds for engineered 3D cardiac anisotropy, ACS Nano, 2017, 11(6), 5646-5659.

209 M. Kitsara, O. Agbulut, D. Kontziampasis, Y. Chen and P. Menasché, Fibers for hearts: a critical review on electrospinning for cardiac tissue engineering, Acta Biomater., 2017, 48, 20-40.

210 V. Martinelli, G. Cellot, F. M. Toma, C. S. Long, J. H. Caldwell and L. Zentilin, et al., Carbon nanotubes promote growth and spontaneous electrical activity in cultured cardiac myocytes, Nano Lett., 2012, 12(4), 1831-1838.

211 S. R. Shin, C. Shin, A. Memic, S. Shadmehr, M. Miscuglio and H. Y. Jung, et al., Aligned carbon nanotube-based flexible gel substrates for engineering biohybrid tissue actuators, Adv. Funct. Mater., 2015, 25(28), 4486-4495.

212 M. Kharaziha, S. R. Shin, M. Nikkhah, S. N. Topkaya, N. Masoumi and N. Annabi, et al., Tough and flexible CNT-polymeric hybrid scaffolds for engineering cardiac constructs, Biomaterials, 2014, 35(26), 7346-7354.

213 Y. Liu, J. Lu, G. Xu, J. Wei, Z. Zhang and X. Li, Tuning the conductivity and inner structure of electrospun fibers to promote cardiomyocyte elongation and synchronous beating, Mater. Sci. Eng., C, 2016, 69, 865-874.

214 J. Muller, F. Huaux, N. Moreau, P. Misson, J.-F. Heilier and M. Delos, et al., Respiratory toxicity of multi-wall carbon nanotubes, Toxicol. Appl. Pharmacol., 2005, 207(3), 221-231.

215 S. Lanone, P. Andujar, A. Kermanizadeh and J. Boczkowski, Determinants of carbon nanotube toxicity, Adv. Drug Delivery Rev., 2013, 65(15), 2063-2069.

216 T. Chen, H. Nie, X. Gao, J. Yang, J. Pu and Z. Chen, et al., Epithelial-mesenchymal transition involved in pulmonary fibrosis induced by multi-walled carbon nanotubes via TGF-beta/Smad signaling pathway, Toxicol. Lett., 2014, 226(2), 150-162.

217 Y. Zhang, S. F. Ali, E. Dervishi, Y. Xu, Z. Li and D. Casciano, et al., Cytotoxicity effects of graphene and single-wall carbon nanotubes in neural phaeochromocytoma-derived PC12 cells, ACS Nano, 2010, 4(6), 3181-3186.

218 L. Wang, S. Luanpitpong, V. Castranova, W. Tse, Y. Lu and V. Pongrakhananon, et al., Carbon nanotubes induce malignant transformation and tumorigenesis of human lung epithelial cells, Nano Lett., 2011, 11(7), 2796-2803.

219 M. Helfenstein, M. Miragoli, S. Rohr, L. Müller, P. Wick and M. Mohr, et al., Effects of combustion-derived ultrafine particles and manufactured nanoparticles on heart cells in vitro, Toxicology, 2008, 253(1-3), 70-78.

220 M. A. Correa-Duarte, N. Wagner, J. Rojas-Chapana, C. Morsczeck, M. Thie and M. Giersig, Fabrication and biocompatibility of carbon nanotube-based 3D networks as scaffolds for cell seeding and growth, Nano Lett., 2004, 4(11), 2233-2236.

221 S. W. Kim, T. Kim, Y. S. Kim, H. S. Choi, H. J. Lim and S. J. Yang, et al., Surface modifications for the effective dispersion of carbon nanotubes in solvents and polymers, Carbon, 2012, 50(1), 3-33.

222 A. Moorthi, Y.-C. Tyan and T.-W. Chung, Surface-modified polymers for cardiac tissue engineering, Biomater. Sci., 2017, 5(10), 1976-1987.

223 S. Ahadian, S. Yamada, M. Estili, X. Liang, R. B. Sadeghian and K. Nakajima, et al., Carbon nanotubes embedded in embryoid bodies direct cardiac differentiation, Biomed. Microdevices, 2017, 19(3), 57.

224 S. Mombini, J. Mohammadnejad, B. Bakhshandeh, A. Narmani, J. Nourmohammadi and S. Vahdat, et al., Chitosan-PVA-CNT nanofibers as electrically conductive scaffolds for cardiovascular tissue engineering, Int. J. Biol. Macromol., 2019, 140, 278-287.

225 H. Sun, Y. Mou, Y. Li, X. Li, Z. Chen and K. Duval, et al., Carbon nanotube-based substrates promote cardiogenesis in brown adipose-derived stem cells via $\beta 1$-integrindependent TGF- $\beta 1$ signaling pathway, Int. J. Nanomed., 2016, 11, 4381.

226 S. Ahadian, S. Yamada, J. Ramón-Azcón, M. Estili, X. Liang and K. Nakajima, et al., Hybrid hydrogel-aligned carbon nanotube scaffolds to enhance cardiac differentiation of embryoid bodies, Acta Biomater., 2016, 31, 134-143.

227 M. Cabiati, F. Vozzi, F. Gemma, F. Montemurro, C. De Maria and G. Vozzi, et al., Cardiac tissue regeneration: A preliminary study on carbon-based nanotubes gelatin scaffold, J. Biomed. Mater. Res., Part B, 2018, 106(8), 2750-2762.

228 K. Roshanbinfar, Z. Mohammadi, A. S.-M. Mesgar, M. M. Dehghan, O. P. Oommen and J. Hilborn, et al., Carbon nanotube doped pericardial matrix derived electroconductive biohybrid hydrogel for cardiac tissue engineering, Biomater. Sci., 2019, 7(9), 3906-3917.

229 A. M. Wickham, M. M. Islam, D. Mondal, J. Phopase, V. Sadhu and É. Tamás, et al., Polycaprolactonethiophene-conjugated carbon nanotube meshes as scaffolds for cardiac progenitor cells, J. Biomed. Mater. Res., Part B, 2014, 102(7), 1553-1561.

230 V. Martinelli, G. Cellot, F. M. Toma, C. S. Long, J. H. Caldwell and L. Zentilin, et al., Carbon Nanotubes Instruct Physiological Growth and Functionally Mature Syncytia: Nongenetic Engineering of Cardiac Myocytes, ACS Nano, 2013, 7(7), 5746-5756.

231 S. R. Shin, S. M. Jung, M. Zalabany, K. Kim, P. Zorlutuna and S. B. Kim, et al., Carbon-nanotube-embedded hydrogel sheets for engineering cardiac constructs and bioactuators, ACS Nano, 2013, 7(3), 2369-2380.

232 M. Izadifar, D. Chapman, P. Babyn, X. Chen and M. E. Kelly, UV-assisted 3D bioprinting of nanoreinforced hybrid cardiac patch for myocardial tissue engineering, Tissue Eng., Part C, 2018, 24(2), 74-88. 
233 X. Li, J. Zhou, Z. Liu, J. Chen, S. Lü and H. Sun, et al., A PNIPAAm-based thermosensitive hydrogel containing SWCNTs for stem cell transplantation in myocardial repair, Biomaterials, 2014, 35(22), 5679-5688.

234 S. R. Shin, H. Bae, J. M. Cha, J. Y. Mun, Y.-C. Chen and H. Tekin, et al., Carbon nanotube reinforced hybrid microgels as scaffold materials for cell encapsulation, ACS Nano, 2012, 6(1), 362-372.

235 E. Mooney, J. N. Mackle, D. J.-P. Blond, E. O’Cearbhaill, G. Shaw and W. J. Blau, et al., The electrical stimulation of carbon nanotubes to provide a cardiomimetic cue to MSCs, Biomaterials, 2012, 33(26), 6132-6139.

236 F. Tondnevis, H. Keshvari and J. A. Mohandesi, Fabrication, characterization, and in vitro evaluation of electrospun polyurethane-gelatin-carbon nanotube scaffolds for cardiovascular tissue engineering applications, J. Biomed. Mater. Res., Part B, 2020, 108(5), 2276-2293.

237 N. Shokraei, S. Asadpour, S. Shokraei, M. Nasrollahzadeh Sabet, R. Faridi-Majidi and H. Ghanbari, Development of electrically conductive hybrid nanofibers based on CNT-polyurethane nanocomposite for cardiac tissue engineering, Microsc. Res. Tech., 2019, 82(8), 1316-1325.

238 B. Peña, S. Bosi, B. A. Aguado, D. Borin, N. L. Farnsworth and E. Dobrinskikh, et al., Injectable carbon nanotubefunctionalized reverse thermal gel promotes cardiomyocytes survival and maturation, ACS Appl. Mater. Interfaces, 2017, 9(37), 31645-31656.

239 H. Amani, E. Mostafavi, H. Arzaghi, S. Davaran, A. Akbarzadeh and O. Akhavan, et al., Three-dimensional graphene foams: synthesis, properties, biocompatibility, biodegradability, and applications in tissue engineering, ACS Biomater. Sci. Eng., 2018, 5(1), 193-214.

240 M.-Y. Xia, Y. Xie, C.-H. Yu, G.-Y. Chen, Y.-H. Li and T. Zhang, et al., Graphene-based nanomaterials: the promising active agents for antibiotics-independent antibacterial applications, J. Controlled Release, 2019, 307, 16-31.

241 K. Lü, G. Zhao and X. Wang, A brief review of graphenebased material synthesis and its application in environmental pollution management, Chin. Sci. Bull., 2012, 57(11), 1223-1234.

242 A. M. Jastrzębska, P. Kurtycz and A. R. Olszyna, Recent advances in graphene family materials toxicity investigations, J. Nanopart. Res., 2012, 14(12), 1320.

243 S. Goenka, V. Sant and S. Sant, Graphene-based nanomaterials for drug delivery and tissue engineering, J. Controlled Release, 2014, 173, 75-88.

244 S. Darvishi, S. Ahadian and H. Savoji, Graphene-Based Nanomaterials in Tissue Engineering and Regenerative Medicine, Handb. Graphene Set, 2019, 1, 637-658.

245 D. Li, T. Liu, X. Yu, D. Wu and Z. Su, Fabrication of graphenebiomacromolecule hybrid materials for tissue engineering application, Polym. Chem., 2017, 8(30), 4309-4321.

246 T. P. D. Shareena, D. McShan, A. K. Dasmahapatra and P. B. Tchounwou, A review on graphene-based nanomaterials in biomedical applications and risks in environment and health, Nano-Micro Lett., 2018, 10(3), 53.
247 A. F. de Faria, D. S. T. Martinez, S. M. M. Meira, A. C. M. de Moraes, A. Brandelli and A. G. Souza Filho, et al., Antiadhesion and antibacterial activity of silver nanoparticles supported on graphene oxide sheets, Colloids Surf., B, 2014, 113, 115-124.

248 Z. Zhu, M. Su, L. Ma, L. Ma, D. Liu and Z. Wang, Preparation of graphene oxide-silver nanoparticle nanohybrids with highly antibacterial capability, Talanta, 2013, 117, 449-455.

249 O. Akhavan and E. Ghaderi, Photocatalytic reduction of graphene oxide nanosheets on TiO2 thin film for photoinactivation of bacteria in solar light irradiation. The, J. Phys. Chem. C, 2009, 113(47), 20214-20220.

250 C.-H. Deng, J.-L. Gong, G.-M. Zeng, C.-G. Niu, Q.-Y. Niu and W. Zhang, et al., Inactivation performance and mechanism of Escherichia coli in aqueous system exposed to iron oxide loaded graphene nanocomposites, J. Hazard. Mater., 2014, 276, 66-76.

251 T. R. Nayak, H. Andersen, V. S. Makam, C. Khaw, S. Bae and $\mathrm{X} . \mathrm{Xu}$, et al., Graphene for controlled and accelerated osteogenic differentiation of human mesenchymal stem cells, ACS Nano, 2011, 5(6), 4670-4678.

252 S. R. Shin, Y.-C. Li, H. L. Jang, P. Khoshakhlagh, M. Akbari and A. Nasajpour, et al., Graphene-based materials for tissue engineering, Adv. Drug Delivery Rev., 2016, 105, 255-274.

253 T.-J. Lee, S. Park, S. H. Bhang, J.-K. Yoon, I. Jo and G.-J. Jeong, et al., Graphene enhances the cardiomyogenic differentiation of human embryonic stem cells, Biochem. Biophys. Res. Commun., 2014, 452(1), 174-180.

254 S. Ahadian, Y. Zhou, S. Yamada, M. Estili, X. Liang and K. Nakajima, et al., Graphene induces spontaneous cardiac differentiation in embryoid bodies, Nanoscale, 2016, 8(13), 7075-7084.

255 J. Park, B. Kim, J. Han, J. Oh, S. Park and S. Ryu, et al., Graphene oxide flakes as a cellular adhesive: prevention of reactive oxygen species mediated death of implanted cells for cardiac repair, ACS Nano, 2015, 9(5), 4987-4999.

256 J. Park, Y. S. Kim, S. Ryu, W. S. Kang, S. Park and J. Han, et al., Graphene potentiates the myocardial repair efficacy of mesenchymal stem cells by stimulating the expression of angiogenic growth factors and gap junction protein, Adv. Funct. Mater., 2015, 25(17), 2590-2600.

257 M. H. Norahan, M. Pourmokhtari, M. R. Saeb, B. Bakhshi, M. Soufi Zomorrod and N. Baheiraei, Electroactive cardiac patch containing reduced graphene oxide with potential antibacterial properties, Mater. Sci. Eng., C, 2019, 104, 109921.

258 G. Choe, S.-W. Kim, J. Park, J. Park, S. Kim and Y. S. Kim, et al., Anti-oxidant activity reinforced reduced graphene oxide/alginate microgels: Mesenchymal stem cell encapsulation and regeneration of infarcted hearts, Biomaterials, 2019, 225, 119513.

259 J. Wang, C. Cui, H. Nan, Y. Yu, Y. Xiao and E. Poon, et al., Graphene sheet-induced global maturation of cardiomyocytes derived from human induced pluripotent stem cells, ACS Appl. Mater. Interfaces, 2017, 9(31), 25929-25940. 
260 M. H. Norahan, M. Amroon, R. Ghahremanzadeh, M. Mahmoodi and N. Baheiraei, Electroactive graphene oxide-incorporated collagen assisting vascularization for cardiac tissue engineering, J. Biomed. Mater. Res., Part A, 2019, 107(1), 204-219.

261 T. Kim, Y. H. Kahng, T. Lee and K. Lee, Graphene films show stable cell attachment and biocompatibility with electrogenic primary cardiac cells, Mol. Cells, 2013, 36(6), 577-582.

262 S. Ahadian, Y. Zhou, S. Yamada, M. Estili, X. Liang and K. Nakajima, et al., Graphene induces spontaneous cardiac differentiation in embryoid bodies, Nanoscale, 2016, 8(13), 7075-7084.

263 J. Park, S. Park, S. Ryu, S. H. Bhang, J. Kim and J. K. Yoon, et al., Graphene-regulated cardiomyogenic differentiation process of mesenchymal stem cells by enhancing the expression of extracellular matrix proteins and cell signaling molecules, Adv. Healthcare Mater., 2014, 3(2), 176-181.

264 S. R. Shin, B. Aghaei-Ghareh-Bolagh, X. Gao, M. Nikkhah, S. M. Jung and A. Dolatshahi-Pirouz, et al., Layer-by-layer assembly of 3D tissue constructs with functionalized graphene, Adv. Funct. Mater., 2014, 24(39), 6136-6144.

265 S. R. Shin, C. Zihlmann, M. Akbari, P. Assawes, L. Cheung and K. Zhang, et al., Reduced graphene oxide-gelMA hybrid hydrogels as scaffolds for cardiac tissue engineering, Small, 2016, 12(27), 3677-3689.

266 G. Zhao, H. Qing, G. Huang, G. M. Genin, T. J. Lu and Z. Luo, et al., Reduced graphene oxide functionalized nanofibrous silk fibroin matrices for engineering excitable tissues. NPG Asia, Materials, 2018, 10(10), 982-994.

267 H. Nazari, A. Heirani-Tabasi, M. Hajiabbas, M. Khalili, M. Shahsavari Alavijeh and S. Hatamie, et al., Incorporation of two-dimensional nanomaterials into silk fibroin nanofibers for cardiac tissue engineering, Polym. Adv. Technol., 2020, 31(2), 248-259.

268 S. M. Zargar, M. Mehdikhani and M. Rafienia, Reduced graphene oxide-reinforced gellan gum thermoresponsive hydrogels as a myocardial tissue engineering scaffold, J. Bioact. Compat. Polym., 2019, 34(4-5), 331-345.

269 A. Ghasemi, R. Imani, M. Yousefzadeh, S. Bonakdar, A. Solouk and H. Fakhrzadeh, Studying the Potential Application of Electrospun Polyethylene Terephthalate/ Graphene Oxide Nanofibers as Electroconductive Cardiac Patch, Macromol. Mater. Eng., 2019, 304(8), 1900187.

270 M. Sharma, Transdermal and Intravenous Nano Drug Delivery Systems: Present and Future. Applications of Targeted Nano Drugs and Delivery Systems, Elsevier, 2019, pp. 499-550.

271 H. K. Yadav, A. A. Almokdad, I. Sumia and M. S. Debe, Polymer-based nanomaterials for drug-delivery carriers. Nanocarriers for Drug Delivery, Elsevier, 2019, pp. 531-56.

272 A. Gelmi, A. Cieslar-Pobuda, E. de Muinck, M. Los, M. Rafat and E. W. Jager, Direct mechanical stimulation of stem cells: a beating electromechanically active scaffold for cardiac tissue engineering, Adv. Healthcare Mater., 2016, 5(12), 1471-1480.
273 H. Cui, J. Shao, Y. Wang, P. Zhang, X. Chen and Y. Wei, PLA-PEG-PLA and its electroactive tetraaniline copolymer as multi-interactive injectable hydrogels for tissue engineering, Biomacromolecules, 2013, 14(6), 1904-1912.

274 T. H. Qazi, R. Rai, D. Dippold, J. E. Roether, D. W. Schubert and E. Rosellini, et al., Development and characterization of novel electrically conductive PANI-PGS composites for cardiac tissue engineering applications, Acta Biomater., 2014, 10(6), 2434-2445.

275 R. Dong, X. Zhao, B. Guo and P. X. Ma, Self-healing conductive injectable hydrogels with antibacterial activity as cell delivery carrier for cardiac cell therapy, ACS Appl. Mater. Interfaces, 2016, 8(27), 17138-17150.

276 R. M. Moura and A. A. A. de Queiroz, Dendronized polyaniline nanotubes for cardiac tissue engineering, Artif. Organs, 2011, 35(5), 471-477.

277 K. Roshanbinfar, L. Vogt, F. Ruther, J. A. Roether, A. R. Boccaccini and F. B. Engel, Nanofibrous composite with tailorable electrical and mechanical properties for cardiac tissue engineering, Adv. Funct. Mater., 2020, 30(7), 1908612.

278 P. Hitscherich, S. wu, R. Gordan, L. H. Xie, T. Arinzeh and E. Lee, The effect of piezoelectric PVDF-TrFE scaffolds on stem cell derived cardiovascular cells, Biotechnol. Bioeng., 2015, 113(7), 1577-1585, DOI: 10.1002/bit.25918.

279 K. Roshanbinfar, L. Vogt, F. Ruther, J. A. Roether, A. R. Boccaccini and F. B. Engel, Nanofibrous Composite with Tailorable Electrical and Mechanical Properties for Cardiac Tissue Engineering, Adv. Funct. Mater., 2019, 1908612.

280 R. Yokoyama, M. Ii, Y. Tabata, M. Hoshiga, N. Ishizaka and M. Asahi, Cardiac regeneration by statin-polymer nanoparticle-loaded adipose-derived stem cell therapy in myocardial infarction, Stem Cells Transl. Med., 2019, 8(10), 1055-1067.

281 A. Borriello, V. Guarino, L. Schiavo, M. Alvarez-Perez and L. Ambrosio, Optimizing PANi doped electroactive substrates as patches for the regeneration of cardiac muscle, J. Mater. Sci.: Mater. Med., 2011, 22(4), 1053-1062.

282 T. Hu, Y. Wu, X. Zhao, L. Wang, L. Bi and P. X. Ma, et al., Micropatterned, electroactive, and biodegradable poly (glycerol sebacate)-aniline trimer elastomer for cardiac tissue engineering, Chem. Eng. J., 2019, 366, 208-222.

283 J. H. Tsui, N. A. Ostrovsky-Snider, D. M. Yama, J. D. Donohue, J. S. Choi and R. Chavanachat, et al., Conductive silk-polypyrrole composite scaffolds with bioinspired nanotopographic cues for cardiac tissue engineering, J. Mater. Chem. B, 2018, 6(44), 7185-7196.

284 N. Baheiraei, H. Yeganeh, J. Ai, R. Gharibi, S. EbrahimiBarough and M. Azami, et al., Preparation of a porous conductive scaffold from aniline pentamer-modified polyurethane/PCL blend for cardiac tissue engineering, J. Biomed. Mater. Res., Part A, 2015, 103(10), 3179-3187.

285 N. Ashammakhi, S. Ahadian, M. A. Darabi, M. El Tahchi, J. Lee and K. Suthiwanich, et al., Minimally invasive and regenerative therapeutics, Adv. Mater., 2019, 31(1), 1804041. 